\title{
WHOLE BUILDING LIFE CYCLE ASSESSMENT OF A LIVING BUILDING
}

$$
\text { by }
$$

\section{Haley M. Gardner}

Bachelor of Science, Civil and Environmental Engineering, Virginia Tech, 2017

\author{
Submitted to the Graduate Faculty of \\ Swanson School of Engineering in partial fulfillment \\ of the requirements for the degree of \\ Master of Science in Civil Engineering
}

University of Pittsburgh 


\section{UNIVERSITY OF PITTSBURGH \\ SWANSON SCHOOL OF ENGINEERING}

This thesis was presented

by

\section{Haley M. Gardner}

It was defended on

March 21 $1^{\text {st }}, 2019$

and approved by

Dr. Leanne Gilbertson, PhD, Assistant Professor Department of Civil and Environmental Engineering

Dr. Vikas Khanna, PhD, Associate Professor Department of Civil and Environmental Engineering

Thesis Advisor: Dr. Melissa M. Bilec, PhD, Associate Professor

Department of Civil and Environmental Engineering 
Copyright (C) by Haley M. Gardner 2019 


\title{
WHOLE BULIDING LIFE CYCLE ASSESSMENT OF A LIVING BUILDING
}

\author{
Haley Gardner, M.S. \\ University of Pittsburgh, 2019
}

Life cycle assessment (LCA) is a tool to quantify the environmental impacts of a product or system. This tool is used to assess environmental impacts of buildings over their lifespan. LCAs performed on standard buildings showed that the use phase dominated the impacts over the course of a building's lifespan. Consequently, building energy efficiency was the target of reduction measures and high-performing buildings began to emerge. The design of living buildings followed, which are buildings that are defined as being net-positive energy and water. In these energy efficient buildings the significance of the use phase diminishes, shifting the focus to other life cycle stages.

This research includes a whole-building LCA of a living building that focuses on the impacts from green building materials, a decentralized water system, a net-positive use phase, and the disposal of structural materials. The material processes used in this LCA were modified by removing the use of highly toxic chemicals per the product submittals; results showed carcinogenic impacts were decreased by up to $96 \%$. The septic system, which is not aerated, used for wastewater treatment contributes to $37 \%$ of the global warming potential (GWP, $\mathrm{kg} \mathrm{CO} 2 \mathrm{Cq}$ ) for the whole building's lifespan due to methane emissions. The solar panels on-site generate more electricity than the site demands, allowing for $44,000 \mathrm{kWh}$ of green energy to be returned to the grid. Lastly, a scenario analysis was performed on multiple waste streams for materials of two structural models (lumber or steel) with a concrete foundation. Results showed that based on the frame and waste stream selected, the end of life GWP impacts could vary from $+14,000 \mathrm{~kg} \mathrm{CO} \mathrm{CO}_{2}$ eq to $-10,500 \mathrm{~kg}$ 
$\mathrm{CO}_{2}$ eq for the as-built structure. This whole-building LCA aims to identify and mitigate hotspots of the case study building, and to reduce life cycle impacts of living buildings moving forward. 


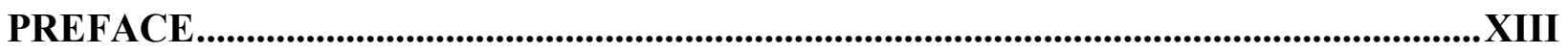

ACKNOWLEDGEMENTS _......................................................................................

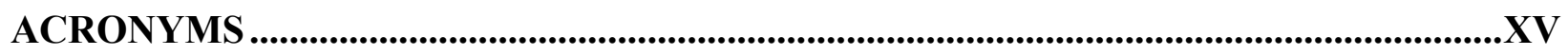

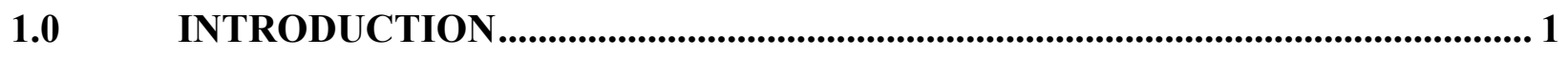

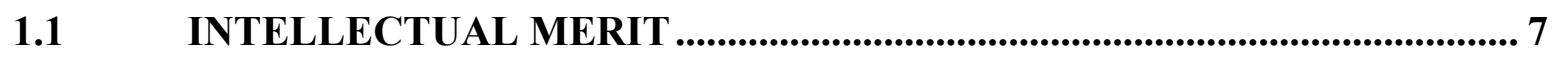

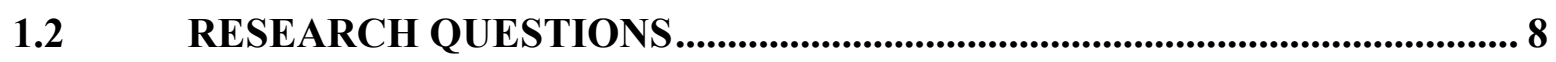

2.0 WHOLE BUILDING LIFE CYCLE ASSESSMENT ........................................9

2.1 BACKGROUND OF GREEN BUILDINGS AND THIS CASE STUDY ......9

2.1.1 High-Performance Buildings and Their Life Cycle Impact........................ 9

2.1.2 Living Building Challenge................................................................................... 10

2.1.3 Case Study Description......................................................................................... 11

2.2 LIFE CYCLE ASSESSMENT, DATA SOURCES, AND SCENARIOS ..... 12

2.2.1 Goal and Scope Definition ....................................................................... 12

2.2.2 Life Cycle Inventory …….................................................................................. 13

2.2.2.1 Material Data Sources................................................................................. 15

2.2.2.1.1 As-built Construction Drawings........................................................... 15

2.2.2.1.2 LEED Submittals .......................................................................... 15

2.2.2.1.3 Living Building Challenge Submittals................................................ 15

2.2.2.1.4 Environmental Product Declarations (EPDs) .................................... 16

2.2.3 Life Cycle Impact Assessment .......................................................................... 16

2.2.4 Quantity Take-Off ......................................................................................... 18 
2.2.5 Green Material Considerations .................................................................... 20

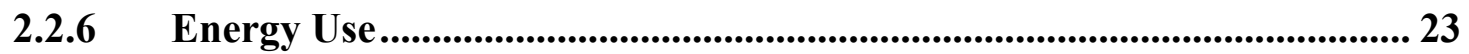

2.2.7 Recurring Embodied Impacts from Replacements .................................... 26

2.2.8 Water System Impacts of Green Buildings .................................................. 27

2.2.9 FEC Water System Impacts................................................................. 30

2.2.10 Water System Comparison: FEC to CSL ....................................................... 34

2.2.11 EOL Impacts within Building LCA .............................................................. 37

2.2.12 EOL Scenario Assessment.....................................................................37

3.0 RESULTS AND DISCUSSION ……......................................................................... 44

OVERALL LCA IMPACTS.................................................................................. 44

3.1.1 Material Pre-Use Impacts ................................................................................. 44

3.1.2 Material Replacement Impacts............................................................................ 46

3.1.3 Red List Free Impacts ......................................................................... 48

3.1.4 Water System Impacts and Comparison .......................................................5 53

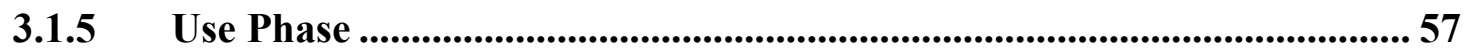

3.1.6 End-of-life ......................................................................................................... 60

3.1.7 Holistic LCA Impacts ......................................................................................... 64

BUILDING COMPARISONS ...................................................................................... 70

3.2

4.0 RECOMMENDATIONS \& CONCLUSION ............................................................... 72

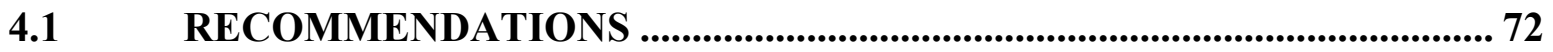

4.1.1 ILFI's Red List is Working, But More Can Be Done................................ 72

4.1.2 Septic Systems of Green Buildings Must Be Aerated ................................. 73 
4.1.3 FEC is Net-Zero Energy and Water, but Not Net-Zero Carbon............ 73

4.1.4 End of Life Impacts: It Depends.................................................. 74

4.1.5 Quantitative LCA Cannot Capture Critical Qualitative Aspects ......... 75

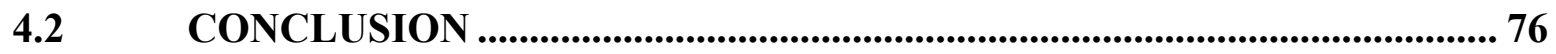

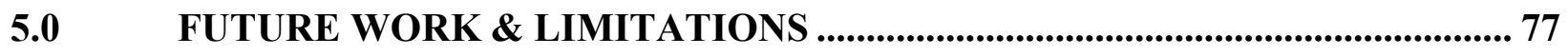

APPENDIX A

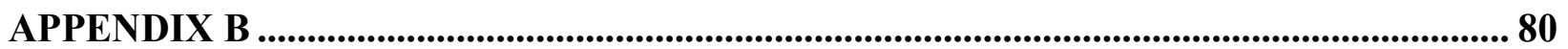

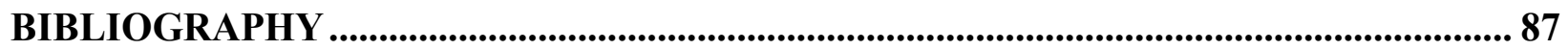




\section{LIST OF TABLES}

Table 1. TRACI impact categories, unit, and abbreviations. 16

Table 2. Material weight and sourcing distance from the manufacturer to project site for structural materials.

Table 3. Annual total energy for the FEC over one-year tracking from July 2017-June 2018... 24

Table 4. Water demand and collection for testing period, July 2017-June 2018_.................... 33

Table 5. Comparison of water system attributes and WUI for CSL and FEC ......................... 36

Table 6. EOL material quantities and emissions factors...................................................... 40

Table 7. Potential scenarios for each material, " $\mathrm{x}$ " denoting it is a possible disposal path. ....... 41

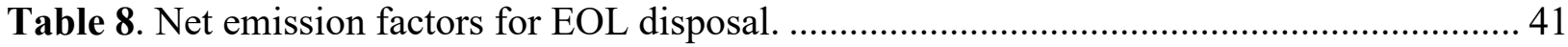

Table 9. Example Red List Free product assessment via ecoinvent 3.4 database..................... 51

Table 10. Tabulated Scenarios 1-8 and their frame type and waste stream per material........... 59

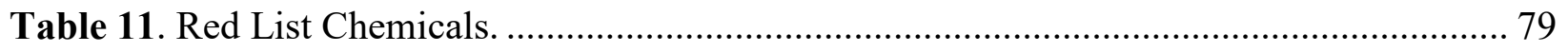

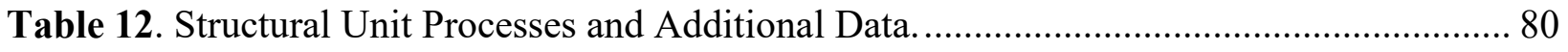

Table 13. MEP Unit Processes and Additional Data. .......................................................... 81

Table 14. PV Unit Processes and Additional Data.............................................................. 82

Table 15. Geothermal Unit Processes and Additional Data............................................... 82

Table 16. Architecture Unit Processes and Additional Data............................................... 83

Table 17. Architecture Unit Processes and Additional Data, cont'd...................................... 84

Table 18. Architecture Unit Processes and Additional Data, cont'd. ....................................... 85

Table 19. Use Phase Unit Processes and Additional Data.................................................... 86 


\section{LIST OF FIGURES}

Figure 1. Main components of the Frick Environmental Center's site ................................. 12

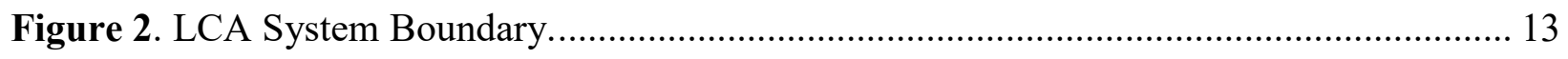

Figure 3. Screenshot from On-Screen takeoff software, ductwork assembly......................... 14

Figure 4. Tree breakdown of raw material assemblies. ................................................... 19

Figure 5. Material assemblies of quantity takeoff subassemblies...................................... 19

Figure 6. Annual energy profile for FEC from LBC energy data from tracking year of July 2017-

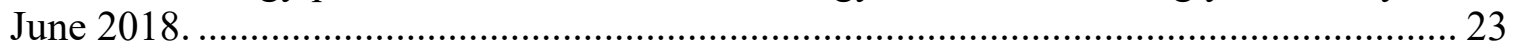

Figure 7. a) Pennsylvania's electricity generation by source from October 2018 (USEIA, 2018).

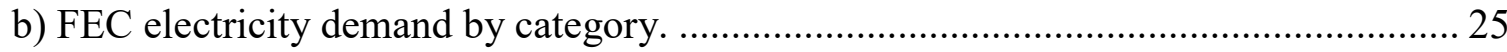

Figure 8. FEC water system schematic, including the wastewater and stormwater systems, plus the tie in to the municipal potable water system...................................................... 29

Figure 9. Map of Pittsburgh showing the FEC on the edge of Frick Park (Google)................. 30

Figure 10. Stormwater management features on the Frick Environmental Center's site. .......... 31

Figure 11. Net-zero water profile over 12-month testing period, July 2017-June. 2018............ 32

Figure 12. CSL wastewater system schematic (Hasik, Anderson et al., 2017)..................... 36

Figure 13. Revit models of (a) streel frame (as-built) and (b) lumber frame. ......................... 38

Figure 14. System boundary for EPA WARM tool for concrete waste scenarios (EPA, 2016a).42

Figure 15. System boundary for EPA WARM tool for wood waste scenarios (EPA, 2016a). ... 43

Figure 16. TRACI Impacts percentages from pre-use material impacts, per assembly............. 45

Figure 17. TRACI Impacts percentages from material replacements per assembly.................. 47

Figure 18. Overall percent change in material impacts per material assembly once Red List impacts were removed from standard material category indicator lists. 48 
Figure 19. Normalized percent change in total material impacts from Standard Material Adjustments to Red List Free adjustments, by TRACI impact category.

Figure 20. Comparison of percent changes in overall impacts from Standard to Red List Free materials for ductwork, flooring, and wallboards.

Figure 21. Pre-use phase material impacts for wastewater (top) and stormwater (bottom) systems.

Figure 22. Use phase impacts (emissions, energy, material replacement) for wastewater (top) and stormwater (bottom) systems.

Figure 23. Combined pre-use and use phase impacts for wastewater (top) and stormwater

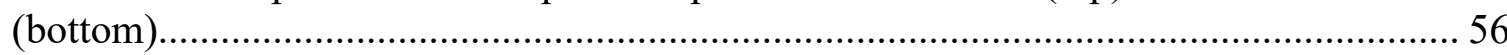

Figure 24. Life cycle impacts of wastewater systems of the CSL, FEC, a low flow, and average building.

Figure 25. Annual average GWP ( $\left.\mathrm{kg} \mathrm{CO}_{2} \mathrm{eq}\right)$ of the impacts for materials pre-use and use, water systems, and energy offsets. GWP was totaled for the 100-year lifespan then averaged per year.

Figure 26. Total $\mathrm{Mg} \mathrm{CO}_{2}$ eq for EOL impacts of increasing concrete recycle rate for steel and lumber model.

Figure 27. Total $\mathrm{kg} \mathrm{CO}_{2}$ eq for EOL impacts for waste scenario options for lumber frame. 62

Figure 28. Comparison of GWP life cycle (pre-use, use, and EOL) impacts for three primary disposal options for steel and wood framed model.

Figure 29. PV system GWP ( $\left.\mathrm{kg} \mathrm{CO}_{2} \mathrm{eq}\right)$ over the lifespan of the building, summing energy offsets and material impacts.

Figure 30. Cumulative GWP of material impacts (pre-use and use) and energy offsets over building lifespan with water system and transportation emissions.

Figure 31. Percent per TRACI category for lifecycle impacts (pre-use, transportation, and use) per assembly.

Figure 32. Total Global Warming Potential $\left(\mathrm{MT} \mathrm{CO}_{2} \mathrm{eq}\right)$ per assembly showing net GWP after energy offsets for the 100-year lifespan.

Figure 33. Total GWP impacts by life cycle stage for pre-use, transportation, use, and end of life. 
Figure 34. Comparison of material pre-use impacts (GWP, $\mathrm{kg} \mathrm{CO}_{2} \mathrm{eq}$ ) of three previous studies

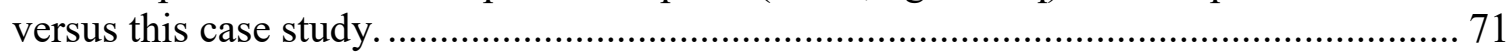




\section{PREFACE}

This research analyzes the changing significance of each life cycle stage of high-performance

buildings by assessing comprehensive life cycle impacts of a living building case study, delving into impacts from materials, on-site water treatment, and material end-of-life. 


\section{ACKNOWLEDGEMENTS}

I would like to acknowledge the following for their funding and support throughout my research:

- Dr. Melissa M. Bilec

- Thesis committee: Dr. Vikas Khanna and Dr. Leanne Gilbertson

- Mascaro Center for Sustainable Innovation

- NSF Grants 1038139 and 1323190

- My family and fellow graduate students 


\section{ACRONYMS}

ASTM - American Society for Testing and Materials

$\mathrm{CH}_{4}$ - Methane

$\mathrm{CO}_{2}$ eq - Carbon dioxide equivalent

C\&D- Construction and demolition

CMU - Concrete masonry unit

CLT - Cross-Laminated Timber

CSO - Combined sewer overflow

EOL - End-of-life

EPA - Environmental Protection Agency

EPD - Environmental Product Declaration

FEC - Frick Environmental Center

GBA - Green Building Alliance

GBRS - Green building rating system

GI - Green infrastructure

GHG - Greenhouse gas emissions

GHP - Geothermal heat pump

GWP - Global warming potential

HVAC - Heating, ventilation, and air conditioning

IEQ - Indoor environmental quality

ILFI - International Living Future Institute

ISO - International Organization for Standardization 
LFG - Landfill gas

LBC - Living Building Challenge

LCA - Life cycle assessment

LCE - Life cycle energy

LCI - Life cycle inventory

LCIA - Life cycle inventory assessment

LEED - Leadership in Energy and Environmental Design

MEP - Mechanical, electrical, plumbing

MSW- Municipal solid waste

PPC - Pittsburgh Parks Conservancy

PV - Photovoltaic

RLF - Red list free

USGBC - United States Green Building Council

WUI - Water use intensity

WWTP - Wastewater treatment plant 


\subsection{INTRODUCTION}

The impacts of the building sector have been steadily increasing in terms of energy and resource consumption, resulting in large environmental impacts. In the US, buildings account for $41 \%$ of primary energy consumption, $73 \%$ of electricity use, $39 \%$ of the greenhouse gas emissions, and $45 \%$ of the construction and demolition (C\&D) waste stream (USDOE, 2012; USEPA, 2018). It is clear that buildings contribute significantly to environmental impacts, thus presenting opportunities for mitigation and reduction.

Around the 1990s, the green building field more formally emerged. In 1993, the US Green Building Council (USGBC) formed and released the pilot program of Leadership in Energy and Environmental Design (LEED) in 1999 (USGBC, 2018). Since the new millennium, the green building design initiative has gained momentum. A plethora of other green building rating systems (GBRS) have emerged domestically, including Energy Star, the Living Building Challenge (LBC), and the WELL Building Standard, as well as internationally, including Canada's Green Globes, Germany's Passive House, UK's BREEAM (Building Research Establishment Assessment Method), and Japan's CASBEE (Comprehensive Assessment System for Building Environmental Efficiency) (US EPA, 2017; ILFI, 2017; WELL, 2018; GBI, 2014; PHI, 2018; BRE Group, 2018; JSBC, 2014). Although these are some of the more recognized GBRS, this is not an exhaustive list as more rating systems are continuously emerging and evolving. Each of these GBRS was developed in order to target the reduction of impacts from either specific building aspects, in the 
case of WELL which focuses on human health impacts, or a more holistic design approaches in the case of LBC. Although the GBRS have different foci, they all have the common overarching goal of reducing the impacts of the built environment.

In addition to an increase in GBRS over the last two decades, there has also been a rapid increase in local, national, and international initiatives to reduce buildings' impacts. One initiative is the 2030 Challenge, which has the overall goal for all new buildings to be carbon neutral by 2030. There are also 2030 Districts with the goals of reducing building energy use, water consumption, and transportation emissions by $50 \%$ by 2030 . These targets are being pursued in over 20 districts across the nation including Seattle, Los Angeles, San Francisco, Dallas, New York City, and Pittsburgh (2030, 2018). Pittsburgh's Green Building Alliance (GBA) is convening the Pittsburgh District.

Life cycle assessment (LCA) and life cycle thinking are implemented in various green building rating systems. LEED $\mathrm{v} 4$ has a credit involving the completion of a whole-building LCA to show a $10 \%$ reduction of life cycle impacts as compared to a baseline building (USGBC, 2018). The Living Building Challenge requires the use of life cycle assessment with respect to the assessing embodied carbon impacts from building materials used during the construction phase (ILFI, 2017). Additionally, Green Globes strongly encourages the use of various LCA tools to assess building performance (GBI, 2014). Although there are certain challenges associated with integrating LCA into GBRS, such as uncertainty and project variability, LCA can be used as a tool to identity and mitigate life cycle stages that see high environmental impacts (Al-Ghamdi \& Bilec, 2017).

In order to critically assess the impacts of the building sector and emerging green buildings, full life cycle assessments are often performed. LCA quantifies environmental impacts based on 
the input and output flows (e.g. materials, energy, emissions) of a given product, process, or system. LCAs are standardized by the International Organization for Standardization (ISO 14044) and have four primary steps: goal and scope definition, life cycle inventory analysis (LCI), and life cycle impact assessment (LCIA), and interpretation and analysis (ISO, 2006). The first step seeks to define the system boundary, scope, and overall objectives of the study. Next, the LCI involves the collection of input/output data (e.g. material quantities, energy required, emissions released) for the system; for this research, one component of the LCI was compiling total quantities for all material used in the building. Lastly, the LCIA is when the LCI data collected is assessed and impacts are analyzed. The life cycle inventory items are first assigned to selected impact categories via classification; the impact categories used in this research are those of EPA's TRACI v2.1, including global warming potential, carcinogens, and ecotoxicity (Bare v2.1, 2012). Characterization is the subsequent step of the LCIA where category indicator results are calculated using characterization factors which convert LCI data into numerical indicator results for each impact category (ISO, 2006); category indicator results are obtained for each material as a function of the total material quantity and the material's category indicator value. For example, for this research, the category indicator for steel in the global warming potential category may be $1 \mathrm{~kg}$ $\mathrm{CO}_{2} \mathrm{eq} / \mathrm{lb}$ steel; this is subsequently multiplied by the total weight of steel required resulting in a total category indicator result measured in $\mathrm{kg} \mathrm{CO}_{2}$ eq. Finally, the normalization of the results can be used to compare category indicator results to reference information, showing the relative impact significance of a given material. Lastly, interpretation and analysis, step 4, is conducted throughout the whole process.

While ISO 14044 standardizes the LCA process, buildings are complex structures and often have unique systems, components, and materials; therefore, ISO 21931 was developed which 
defines a framework for the assessment of the environmental performance of buildings (ISO, 2010). This standard share similar methodology to ISO 14044 but uses language specific to buildings and construction to help direct these assessments. Subsequently, the United States' standards organization, American Society for Testing and Materials (ASTM), adapted ISO 21931 into an American standard (E2921); ASTM addresses the standard practice for comparing whole building life cycle assessments to a reference building, with additional consideration of building codes, standards, and rating systems (ASTM, 2016). More so, ISO 14044 and ASTM E2921 are being incorporated into International Green Construction Codes, which dictate a comparative life cycle assessment of two building designs in order to select the less environmentally impactful option (IgCC, 2018). These standards have been developed as a way to better direct the assessment of buildings and their complex and unique systems.

LCA of buildings is continuously being improved upon. Full LCAs have been performed on various types of buildings, which are frequently used as 'reference LCA buildings.' For example, Junnila et al. (2006) performed a whole-building LCA of an office building; this study found that with respect to global warming potential (GWP in $\mathrm{CO}_{2} \mathrm{eq}$ ), the use phase impacts accounted for nearly $80 \%$ of the total impacts. Another study by Scheuer et al. (2003) conducted a whole-building LCA of a new university building; this study found that the use phase accounted for $94 \%$ of the primary energy consumption, with materials and end-of-life each contributing approximately $2 \%$. However, once the large use-phase impacts of buildings were understood, the energy efficiency of these buildings was targeted and improved; the use phase was found to be the highest contributor and therefore could result in the most significant reduction in environmental impacts if drastically decreased. As this progress was made and the energy efficiency of buildings 
increased, researchers such as Blengini et al. (2009) found that other life stages, specifically materials and disposal, considerably increased in relative significance as the use phase decreased.

In recent years, there has been an increase in studies that focus on life cycle stages beyond or in addition to the use phase. There is an expanding body of research regarding materials and end-of-life as potential targets for decreasing the environmental impacts (Berggren, Hall et al., 2013; Bribián, Capilla et al., 2011; Cellura, Guarino et al., 2014; Rashid, 2015). Embodied energy, defined in Sartori \& Hestnes (2007) as the sum of all energy needed to manufacture a good, is a significant component of a building's life cycle impacts and can be reduced in various ways, including choosing greener materials or considering the end-of-life of the products (Blengini, 2009; Sartori \& Hestnes, 2007). However, it is important to note that green buildings can sometimes see an increase in embodied energy from their complex systems, such as solar panels or geothermal wells (Thiel, Campion et al., 2013). Therefore, tradeoffs in design are prevalent in high-performance buildings.

Sustainable material selection includes choosing materials that are locally sourced, have fewer toxins, or have higher recycled content, all of which have the potential to result in lower life cycle impacts (Bribián et al., 2011). Additionally, as for end-of-life, recycling and repurposing lessen on overall life cycle impacts as they prevent material from being introduced into both manufacturing processes and waste streams (Blengini \& Di Carlo, 2010).

Many studies have performed whole-building life cycle assessments that incorporate an assessment of the end-of-life. For example, Junnila et al. (2006) found that the end-of-life accounted for $\sim 1 \%$ of the total building life cycle impacts; this LCA was performed on a standard office building and therefore has a use phase that accounts for nearly $80 \%$ of the total building impacts. Blengini (2009) found that the recycling potential for a standard apartment building was 
equivalent to $29 \%$ of its life cycle energy. While this recycling potential is an important factor of building materials, the actual end-of-life impacts are often different; recycling potential is defined by Thormark (2002) as "the potential for environmental benefits from recycling building materials after refurbishment or demolition." End-of-life (EOL) impacts, however, are a synthesis of these recycling benefits with disposal, transportation, and processing impacts. For example, with respect to the apartment building assessed in Blengini (2009), the net EOL impacts ranged from $-0.2 \%$ to $-2.6 \%$ while the recycling potential was equivalent to a third of the total building impacts; these net impacts are a more appropriate representation of building material impacts as the recycling potential incorporates energy needed to process materials through their EOL, thus illustrating optimal waste scenarios of materials after deconstruction.

As the large impacts of the building sector were realized, a shift to the assessment of lowenergy buildings started to take place. These are buildings with lower use phases relative to standard structures, and therefore the focus on the use phase shifts to other life cycle stages. Thormark (2002) found that since embodied energy accounts for a higher percentage in low-energy buildings $(40 \%)$, the recycling potential is fairly significant in terms of the building life cycle impacts as it could equate to up to $15 \%$ of the total building energy. One case study on a lowenergy house found that the end-of-life GWP impacts were $-8 \%$ relative to the impacts from all other life cycle stages (Blengini \& Di Carlo, 2010). Therefore, these impacts could be similarly negative (offsetting) for the case study living building.

The USGBC, ILFI, and other green building rating system organizations have recognized that life cycle stages beyond the use phase have a significant effect on building life cycle impacts and have therefore implemented strategies into their certifications (ILFI, 2017; IWBI, 2018; USGBC, 2018). Therefore, this LCA assesses the material impacts, use phase, and end-of-life of 
a living building in order to determine its holistic life cycle impacts. This is also the first wholebuilding LCA to be performed on a living building, and therefore aims to elucidate the life cycle impacts of these high-preforming buildings.

\subsection{INTELLECTUAL MERIT}

A whole-building life cycle assessment was performed on a case study living building, with a focused assessment on the material, use, and end-of-life stages of the building; an evaluation of water system impacts was also included in this research. The goal of this comprehensive LCA was to identify any aspects throughout the buildings lifespan that have significant negative environmental effects. Because living buildings are still emerging, there is a lack of assessment on their performance and environmental impacts.

Additionally, as more buildings are certified via green building rating systems, it is critical that all green designs that are encouraged by these rating systems and subsequently implemented are the most sustainable option for the project in question. This research intends to provide further recommendations while exploring if sustainable features implemented on-site result in lower life cycle impacts. Therefore, the material selection, use phase, and end of life disposal of a living building are assessed in depth to discern life cycle impacts; this will identify improvement areas to progress the design of living buildings. 


\subsection{RESEARCH QUESTIONS}

The main objective of this research was to perform a whole-building life cycle assessment of a living building in order quantify comprehensive building impacts; this LCA focuses on impacts

from materials, use, and end-of life. In order to perform this task, this research was guided by several research questions:

- What are the life cycle environmental impacts of a living building and what are the relative impacts from materials, use, and end-of-life?

- How are current building life cycle assessments evaluating material impacts, and are new green building materials being integrated into common LCA databases?

- What are the impacts and benefits of a decentralized water system?

- What is the environmental impact of the end-of-life of materials, and how does this affect the distribution of the impacts by LCA stage?

From these questions arose several objectives:

- Conduct a whole building life cycle assessment of a living building

- Provide guidance based on quantitative data on how to improve the integration of green building material information in LCA tools and databases via Environmental Product Declarations (EPDs), project submittals, and green building rating system documents

- Assess the impacts of the water systems in the living building, focusing on the stormwater and wastewater system impacts

- Perform scenario analyses of end-of-life for structural materials used within a living building 


\subsection{WHOLE BUILDING LIFE CYCLE ASSESSMENT}

\subsection{BACKGROUND OF GREEN BUILDINGS AND THIS CASE STUDY}

\subsubsection{High-Performance Buildings and Their Life Cycle Impact}

In the United States, buildings account for 39\% of energy consumption (USEIA, 2018). Therefore, any improvements to this sector can have significant impacts on the reduction of energy use and consequently greenhouse gas emissions. There has been a large effort in recent years to design high-performance buildings in order to reduce the energy demand of the building sector. Examining high-performance buildings from a life cycle perspective (raw material extraction, material production, use, and end-of-life) shows that as the impacts from the use phase decrease, all other life cycle stages will see a proportional increase in significance.

Because the use phase has been proven to account for $80-90 \%$ of overall life cycle impacts of conventional buildings, the focus on this stage is justified (Ramesh, Prakash et al., 2010). Although materials in conventional buildings account for on average $10 \%$ of life cycle impacts, one study found that materials can account for up to $46 \%$ of a low-energy building's life cycle impacts (Sartori \& Hestnes, 2007). With respect to end-of-life of materials, another study found that the recycling of building materials could results in a $30 \%$ decrease in the life cycle energy of a building; because this study was performed on a conventional building, it can be concluded that these savings would be greater for an energy-efficient building due to the higher significance of the end-of-life phase (Blengini, 2009). Therefore, this assessment focuses on the impacts of other life cycle stages that relatively increase as the use phase for high-performing buildings decrease. 


\subsubsection{Living Building Challenge}

In 2006, the Cascadia Green Building Council launched version 1 of the Living Building Challenge (LBC); due to growing interest in this program over its early years, the Living Building Institute was formed in order to manage the LBC and any additional future programs (ILFI, 2017). Today, Cascadia works alongside what is now the International Living Future Institute (ILFI), which encompasses the Living Building, Product, and Community Challenges. Each program has similar themes of enhancing quality of life with focuses on promoting social justice, celebrating culture, and ensuring ecological restoration. Because of its extensive and interdisciplinary requirements, this is one of the most challenging building certifications to obtain. To demonstrate how rigorous this rating system is, as of 2017 , there are about 6,600 buildings in the world that had received US Green Building Council's Leadership in Energy and Environmental Design (LEED) Platinum status, yet only 15 that had received ILFI's Full Living Certification (ILFI, 2017; USGBC, 2018). Although LEED has been around for a longer period of time, these values illustrate how challenging it is to receive Living Certification.

LBC requirements are organized into 7 petals: place, water, energy, health and happiness, materials, equity, and beauty. Each petal has a series of imperatives, for a total of 20, which all must be met to achieve Living Certification. These imperatives encompass a wide range of concepts, including net-positive energy and water, biophilic environment, and beauty and spirit (ILFI, 2017). Achieving this certification requires integrated design strategies, community involvement, and an unprecedented amount of communication between the designers, manufacturers, and contractors, making it a challenging certification process to experience. 


\subsubsection{Case Study Description}

The Frick Environmental Center (FEC) sits on the edge of Frick Park, the largest park in the greater Pittsburgh area, and serves as the case study building. It is a municipally-owned, public facility that is a joint venture between the City of Pittsburgh and the Pittsburgh Parks Conservancy (PPC); it is meant to serve as a resource for visitors to the park by welcoming them into the center and subsequently ushering them out into the nearby landscape (PPC). The building is comprised primarily of office space for staff as well as classrooms, which are used for the numerous educational events (i.e. summer camps, nature classes) hosted by the PPC at this facility.

The FEC is a 3 -story, 15,000sf building that has steel framing and a concrete foundation. Because it is net-positive energy and water, the site contains many sustainable systems and strategies including solar panels, geothermal wells, a rainwater collection and purification system, permeable pavement, passive ventilation, and daylighting. There are four structures on site: the main building, a service barn, and two gatehouses that date back 70 years. The construction began in 2014 and the facility opened in 2016.

Due to the extensive sustainable features present in this facility, it is both LEED Platinum and Certified Living by the ILFI. Additionally, the previous structure on-site was destroyed due to arson, providing the community with the unique opportunity of reimagining the facility; the decision to construct a new building with such sustainable features reflects Pittsburgh's commitment to creating a greener future.

This four-acre site encompasses the main building, two historic gatehouses, a historic fountain, a service barn, an outdoor amphitheater, and a parking lot covered by a photovoltaic (PV) structure (see Figure 1). 

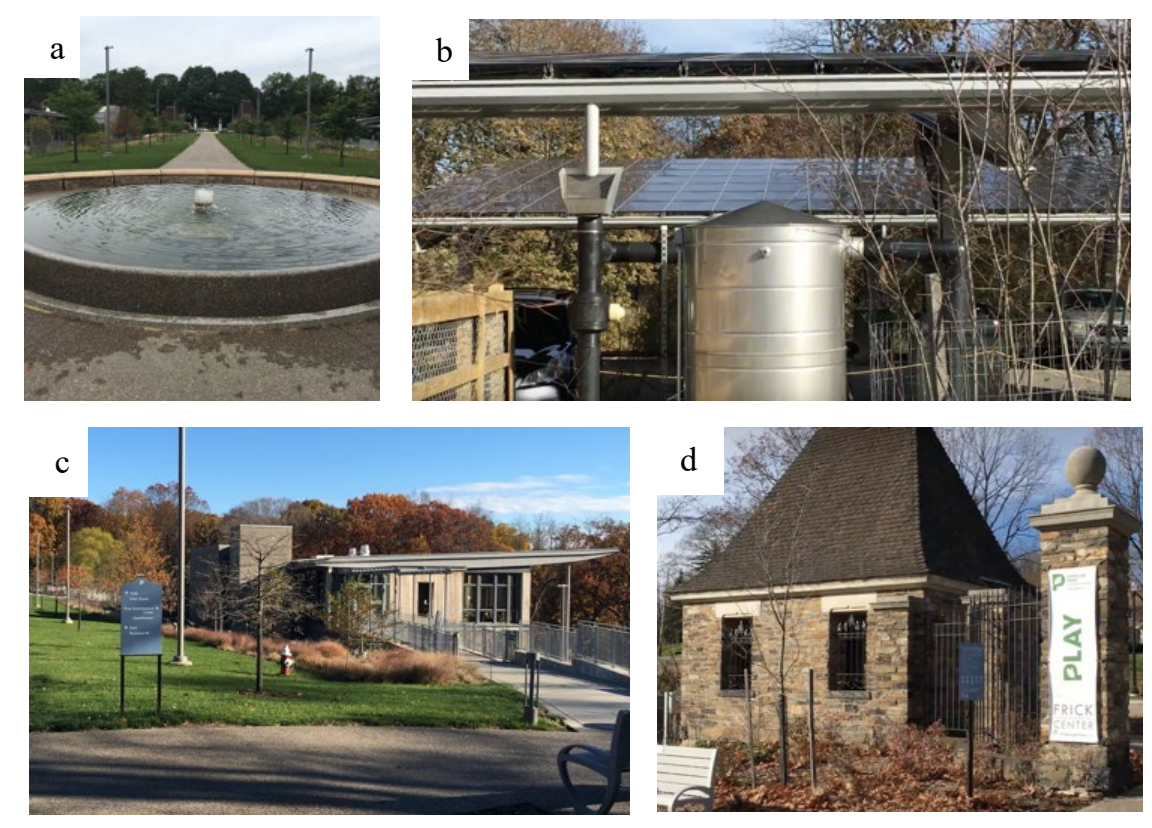

Figure 1. Main components of the Frick Environmental Center's site

(a) Historic fountain; (b) PV parking lot structure; (c) Main building; (d) Historic gatehouse.

\subsection{LIFE CYCLE ASSESSMENT, DATA SOURCES, AND SCENARIOS}

\subsubsection{Goal and Scope Definition}

The goal of this study was to assess the life cycle environmental impacts of a living building in order to identify areas for mitigation of the case study building as well as help improve the design of future living buildings. The intended audience was building designers and operators, as well as researchers in this field who are seeking to reduce the impacts of buildings.

The primary life cycle stages of a building are raw material extraction, material manufacturing and processing, construction, use, and end-of-life. The scope of this whole-building LCA includes the stages shown in the system boundary presented in Figure 2. Construction was not included in this assessment as there was a lack of available data from this stage, such as 
emissions from construction equipment and transportation distances driven by trucks during construction. The functional unit for this study is the living building with an assumed lifetime of the building at 100 years. The results are also reviewed on an annualized basis as well for comparative purposes. Any assumptions made will be addressed throughout the assessment.

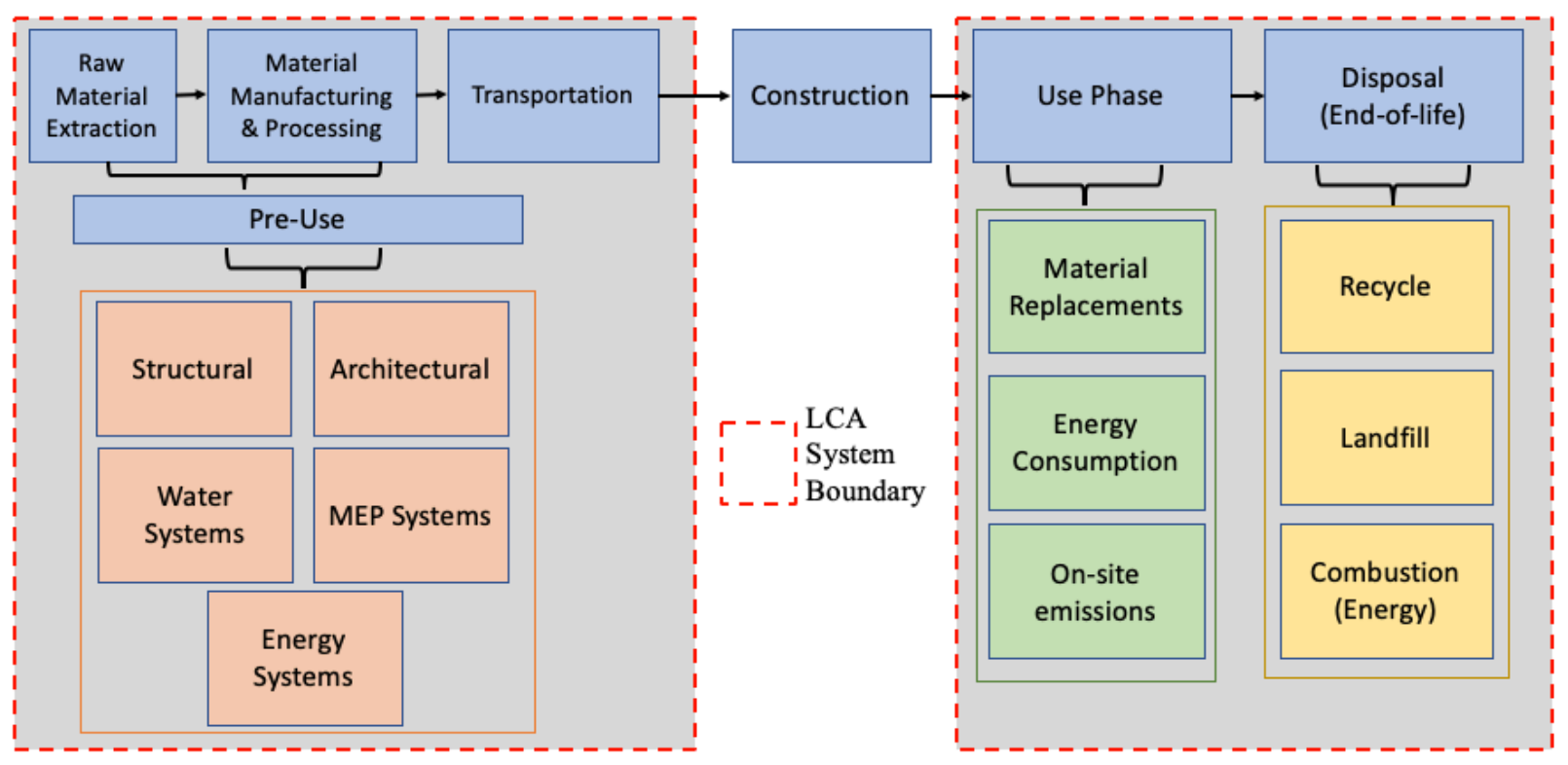

Figure 2. LCA System Boundary.

\subsubsection{Life Cycle Inventory}

A unit process is the most fundamental element of the LCI and is a critical component of the LCIA; it contains information regarding all inputs and outputs of a given material or process. These inputs/outputs include energy, water, material resources, and emissions (to air, water, soil) (ISO, 2006). The unit processes can be chosen from LCA databases (i.e. ecoinvent, US LCI), built within an LCA software if sufficient data (collected and/or experimental) is available (ecoinvent, 2018; Frischknecht, Jungbluth et al., 2005; NREL, 2012b). For this assessment, the vast majority of the 
unit processes were primarily from the ecoinvent database (see Appendix A), and any that were constructed for this work will be explained in greater detail (ecoinvent, 2018). Because the unit processes dictate the impacts of each material, it is critical that these unit processes are as accurate as possible for the material in question; a substantial amount of work was put into ensuring the unit process selected would provide the most accurate results.

Within whole building LCAs, data collection to develop the LCI is critical, and includes detailed considerations and modeling for materials, energy use, water systems, and end-of-life, which are described in the subsequent sections.

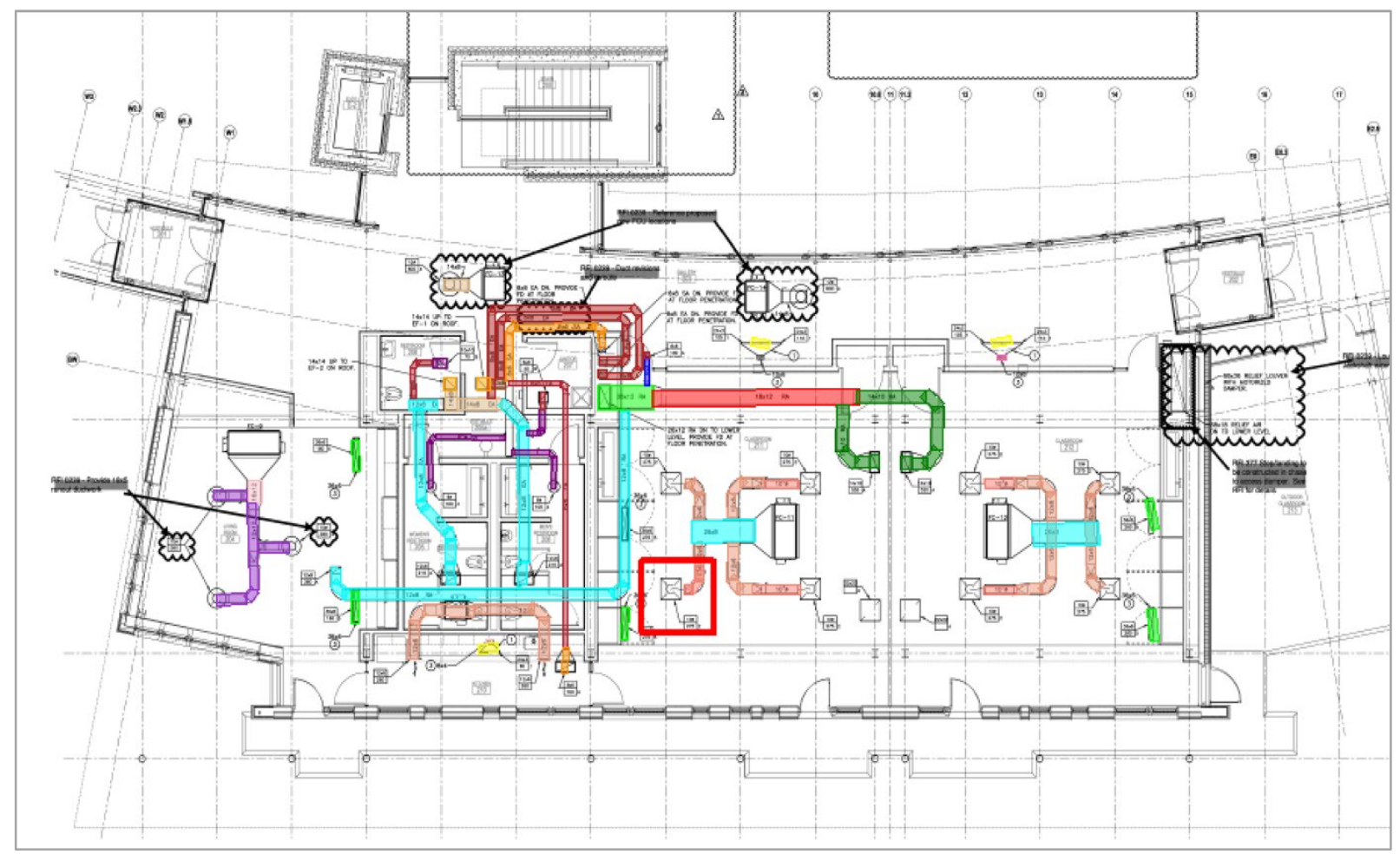

Figure 3. Screenshot from On-Screen takeoff software, ductwork assembly.

Each color represents a different sized duct throughout this one floor of the as-built construction drawings. 


\subsubsection{Material Data Sources}

The following are all documents/sources that were used and will be referred to throughout this work.

\subsection{As-built Construction Drawings}

The as-built construction documents were vital in obtaining material quantities. These documents were uploaded into the software On-Screen Takeoff and a takeoff was performed on the entire building and each system (OST, 2018). An example of this process is shown in Figure 3, which shows one floor of the ductwork takeoff. This full process is explained in Section 2.2.4 Quantity Take-Off.

\subsection{LEED Submittals}

Various submittals are required during the LEED certification process, and one of the primary aspects when it comes to materials is their tracking distances and recycled content. Both of these attributes were extracted for all materials from LEED documentation.

\subsection{Living Building Challenge Submittals}

Similar to LEED, LBC has specific requirements for material sourcing, so each material's transportation distances are tracked in detail. These distances and percent recycled content were cross-references with those of LEED submittals. Additional information from LBC documentation is whether or not materials have Declare labels or contain any chemicals on the Red List; these

ILFI initiatives will be discussed in detail in subsequent sections. Finally, net-zero monitoring information was also included in these submittals for both energy generation/use and water collection/use. 


\subsection{Environmental Product Declarations (EPDs)}

Lastly, information was extracted from EPDs. Because only some materials have detailed EPDs with specific impact information, the only information that was analyzed from EPDs was if they contained any toxic chemicals or other hazardous elements.

Table 1. TRACI impact categories, unit, and abbreviations.

\begin{tabular}{lll}
\hline \multicolumn{1}{c}{ Impact category } & \multicolumn{1}{c}{ Unit Equivalency } & Abbreviation \\
\hline Ozone Depletion & $\mathrm{kg} \mathrm{CFC}-11 \mathrm{eq}$ & $\mathrm{OD}$ \\
\hline Global Warming Potential & $\mathrm{kg} \mathrm{CO}_{2} \mathrm{eq}$ & $\mathrm{GWP}$ \\
\hline Smog Formation Potential & $\mathrm{kg} \mathrm{O}_{3}$ eq & $\mathrm{SFP}$ \\
\hline Acidification Potential & $\mathrm{kg} \mathrm{SO}_{2} \mathrm{eq}$ & $\mathrm{AP}$ \\
\hline Eutrophication Potential & $\mathrm{kg} \mathrm{N} \mathrm{eq}$ & $\mathrm{EP}$ \\
\hline Carcinogens & $\mathrm{CTUh}$ & $\mathrm{CAR}$ \\
\hline Non-Carcinogens & $\mathrm{CTUh}$ & $\mathrm{NCAR}$ \\
\hline Respiratory Effects & $\mathrm{kg} \mathrm{PM}_{2.5}$ eq & $\mathrm{RE}$ \\
\hline Ecotoxicity & $\mathrm{CTUe}$ & $\mathrm{ETX}$ \\
\hline Fossil Fuel Depletion & $\mathrm{MJ} \mathrm{surplus}$ & $\mathrm{FFD}$ \\
\hline
\end{tabular}

\subsubsection{Life Cycle Impact Assessment}

ISO 14044 provides three mandatory elements of an LCIA:

1. "Selection of impact categories, category indicators, and characterization models

2. Assignment of LCI results to the selected impact categories (classification)

3. Calculation of category indicator results (characterization)" (ISO, 2006)

The first step of LCIA defines the setup of the assessment. The impact categories chosen for this study were those of TRACI (Tools for Reduction and Assessment of Chemicals and Other 
Environmental Impacts) categories as created by the US Environmental Protection Agency; this tool was developed to improve the sustainability of products, processes, and communities (Bare v2.1, 2012). TRACI evaluates impacts based on 10 primary impact categories, see Table 1, providing midpoint indicators for each. These factors are all contributors to environmental degradation and should be evaluated, however this is not an exhaustive list and research is ongoing to continuously improve each category and their impacts; these factors are evaluated along with information from the ecoinvent database in the software SimaPro v8.5.2 (PRé, 2017).

TRACI has an inventory of chemicals and their stressors, based on collaborative efforts between various departments within the EPA, that assess impacts from greenhouse gases, energy types, and hazardous air pollutants to name a few (Bare v2.1, 2012). These stressors are factors that evaluate the impact of a given chemical for each TRACI category; they are based on chemical composition and specific potency of a given chemical. Subsequently, based on these stressors, an inventory of category indicators is created based on the amount present of a given chemical within a specific material assembly. For example, for the impact category of Global Warming Potential (measured in $\mathrm{kg} \mathrm{CO}_{2} \mathrm{eq}$ ), methane $\left(\mathrm{CH}_{4}\right)$ has a characterization factor of $25 \mathrm{~kg} \mathrm{CO}_{2} \mathrm{eq}$ as $\mathrm{CH}_{4}$ is 25 times more potent that $\mathrm{CO}_{2}$ (USEPA, 2014). For the production of $11 \mathrm{~b}$ of steel, it may hypothetically result in the release of $10 \mathrm{~kg}$ of methane, which, using the characterization factor of 25 , would be converted into $250 \mathrm{~kg} \mathrm{CO}$ eq. Then, $250 \mathrm{~kg} \mathrm{CO} 2 \mathrm{eq} / \mathrm{lb}$ steel is the category indicator value for steel and would be multiplied by the total material quantity to obtain a total impact for the GWP category for steel. The characterization factor for methane $\left(25 \mathrm{~kg} \mathrm{CO}_{2} \mathrm{eq}\right)$ is a defined property of the compound based on the current knowledge of the species and its associated radiative forcing; the category indicator, however, is based on how much methane is released during the manufacturing/processing of a given product and is therefore not necessarily a static, 
defined value. It also should be noted that for this assessment, each unit process was constructed based on the base unit of the product (i.e. lb, cuft), which is why the final step is multiplying the total material quantities by the category indicator value.

The second and third steps take place at this time and the results from the category indicator values are totaled for each impact category. These are category indicator results and can be presented by impact category for a specific building element or by total building impacts. After this process is complete, each impact category will have a comprehensive total of all building impacts.

\subsubsection{Quantity Take-Off}

In order to perform a comprehensive whole-building LCA of the case study building, a full quantity take-off was completed for the structure. This take-off was fragmented into the five main assemblies of raw materials (see Figure 4): architectural, structural, and mechanical assemblies along with the water and energy systems. As-built construction documents were provided by the design team and were uploaded into the take-off software On-Screen Takeoff (OST, 2018). Materials were organized by assembly and type with totals were exported accordingly into Excel. Additional information was input directly into the software to allow for the exportation of desired information. For example, the height and width of a duct could be input so the surface area was exported, rather than simply the linear footage. Totals were acquired for all building materials shown in Figure 5. 


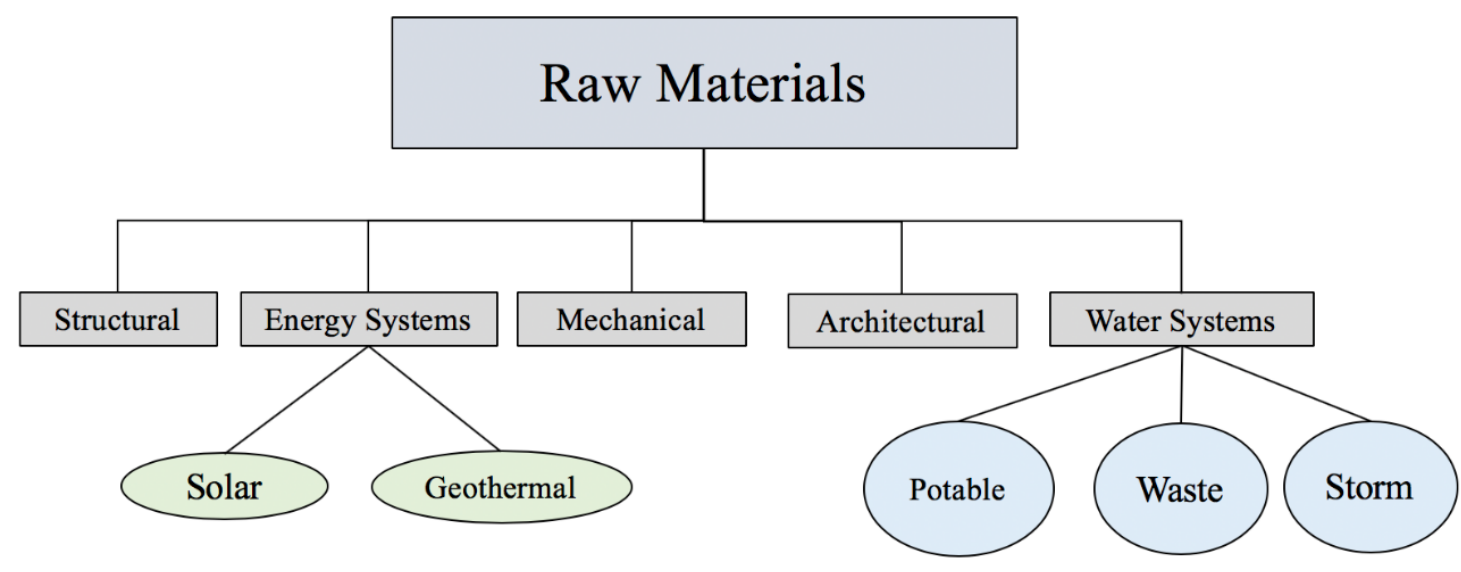

Figure 4. Tree breakdown of raw material assemblies.

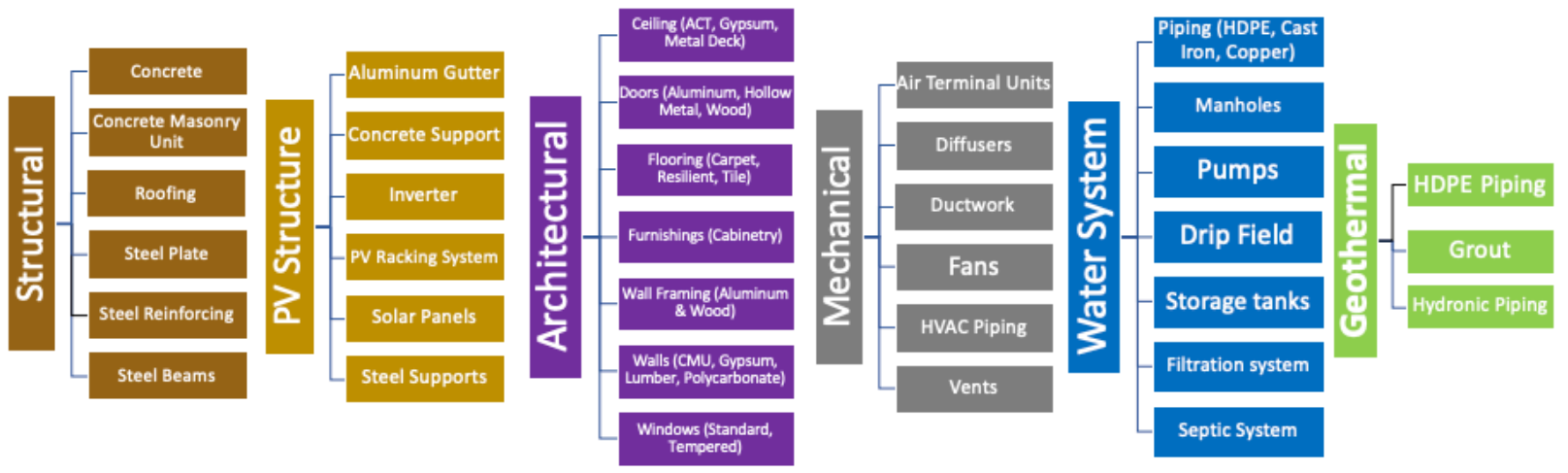

Figure 5. Material assemblies of quantity takeoff subassemblies.

Another quantity assessed for select building materials was their transportation distances. LBC 3.1 has detailed imperatives regarding transportation distances and material sourcing, requiring $25 \%$ material sourcing from $<500 \mathrm{~km}, 30 \%$ from $<1000 \mathrm{~km}, 25 \%$ from $<5000 \mathrm{~km}$, and the remaining $20 \%$ sourced from anywhere (ILFI, 2017). Therefore, all materials used in the project were tracked with their sourcing distances documented; transportation impacts were therefore included in the Holistic LCA Impacts section. The chosen unit process for this assessment is a diesel truck. Because transportation impacts are measured in a unit process based on tonkilometers, the materials with the largest weights were the focus of calculating overall 
transportation impacts. Structural materials (steel and concrete) account for $98 \%$ of the building's total material weight and are therefore the only materials included in the transportation impact assessment, see Table 2; the steel used for the photovoltaic assembly was acquired from a different location than that of the structural steel, resulting in two sourcing distances. Future transportation analysis will incorporate impacts from other material assemblies in order to calculate more holistic impacts from transit.

Table 2. Material weight and sourcing distance from the manufacturer to project site for structural materials.

\begin{tabular}{ccc}
\hline Material & $\begin{array}{c}\text { Sourcing Distance } \\
\text { (miles, manufacturer to site) }\end{array}$ & $\begin{array}{c}\text { Material } \\
\text { Weight (lb) }\end{array}$ \\
\hline Structural Steel & 165 & 171,334 \\
\hline Concrete & 115 & $5,031,499$ \\
\hline PV Structural Steel & 325 & 85,635 \\
\hline
\end{tabular}

\subsubsection{Green Material Considerations}

One issue with respect to the life cycle assessment of high-performance buildings is that unit processes present in commercial or publicly available life cycle databases may not be truly reflective of novel or "green" materials. A common example of one material that has been improved over the years is the use of asbestos in building insulation. Once the US EPA and US Department of Health and Human Services declared asbestos a carcinogen, all new forms of it were banned (USDHHS, 2001). Now, safer types of insulation are used. Because these new alternatives are a common practice, unit processes for these materials exist in LCA databases and can be selected when appropriate. This concept of updated unit processes needs to now be extended to a multitude of other materials as 'greener,' healthier options emerge. 
Recently, there has been an increase in material transparency, which will streamline the integration of material attributes into LCA databases. ILFI created the material transparency label Declare wherein manufactures share various features about a product, including a precise list of ingredients, life expectancy, management at end-of-life, and if it contains any materials on the Red List. Also created by ILFI, this list includes chemicals common in building materials that have impacts with respect to environmental pollution, bio-accumulation, and/or negative human health impacts on construction/factory workers (ILFI, 2017). As these transparency efforts continue, general databases containing this material information are beginning to emerge; however, there is a disconnect between the information itself and the integration of this updated information into databases use during LCA. In order to accurately determine the impacts of buildings that use greener materials, it is imperative that the information used to assess material impacts reflect the lower impacts of these materials.

Therefore, an additional analysis of this whole building LCA was performed on material adjustments to demonstrate how to improve the accuracy of green building LCAs. Adjustments were made to each material assembly; this way, the impact significance could be compared for each category. Because living building materials cannot contain any Red List chemicals, all of these toxins' impacts were removed. In order to effectively remove these impacts, each toxin's contributions were subtracted from each material's chemical inventory.

The Red List contains 20 general chemicals but is disaggregated into 815 specific chemicals. For example, the single item "Chlorofluorocarbons (CFCs) and Hydrochlorofluorocarbons (HCFCs)" encompasses 90 individual chemicals (ILFI, 2017). These 815 chemicals were queried and subsequently removed from each material inventory of 2,000 
chemicals; since all 10 impact categories were assessed for all material assemblies, 60 inventories were evaluated and adjusted in order to obtain more reflective life cycle assessment results.

The inventories contain all chemicals that contribute to each material's unit process flow, whether that is upstream or downstream. These values are the category indicators based on the characterization factors of each chemical, Equation (2). The inventory of indicators was exported into Excel so that the totals for each selected LCIA category could be evaluated. Additionally, when the indicator inventories were exported, the values sum to the category indicator for each LCIA category. This indicator is a multiplier for each LCIA category that is ultimately multiplied by the total material quantities, shown in Equation (1). Once exported, the contributions to the category indicator of each Red List toxin for each material assembly were removed, resulting in a new category indicator value. Note that because the category indicator value is a composition of the specific material/unit process in question, it can be altered in this way to better reflect the given material, unlike the characterization factor which is a defined for a chemical. An example is provided for three specific building materials in Results, subsection Red List Free Impacts.

$$
\begin{array}{r}
\text { Total Material Impacts, per TRACI category } \\
\text { Category Indicator Result } \\
=\sum(\text { Category Indicator Value }) * \sum(\text { Material Quantity })
\end{array}
$$

where

Category Indicator Value

$=\sum$ (Chemical Inventory $*$ Chemical Characterization Factor $)$ 
A material tracking sheet was provided by the building designers that designates whether or not a material was Red List free (RLF) or if an exception was made; therefore, a product was only adjusted if it is noted as RLF. These adjustments consequently resulted in a more representative category indicator value for the greener materials and overall more accurate whole building LCA results. All 10 LCIA categories were assessed for each material assembly in order to identify where the largest impact reductions were made as a result of being RLF.

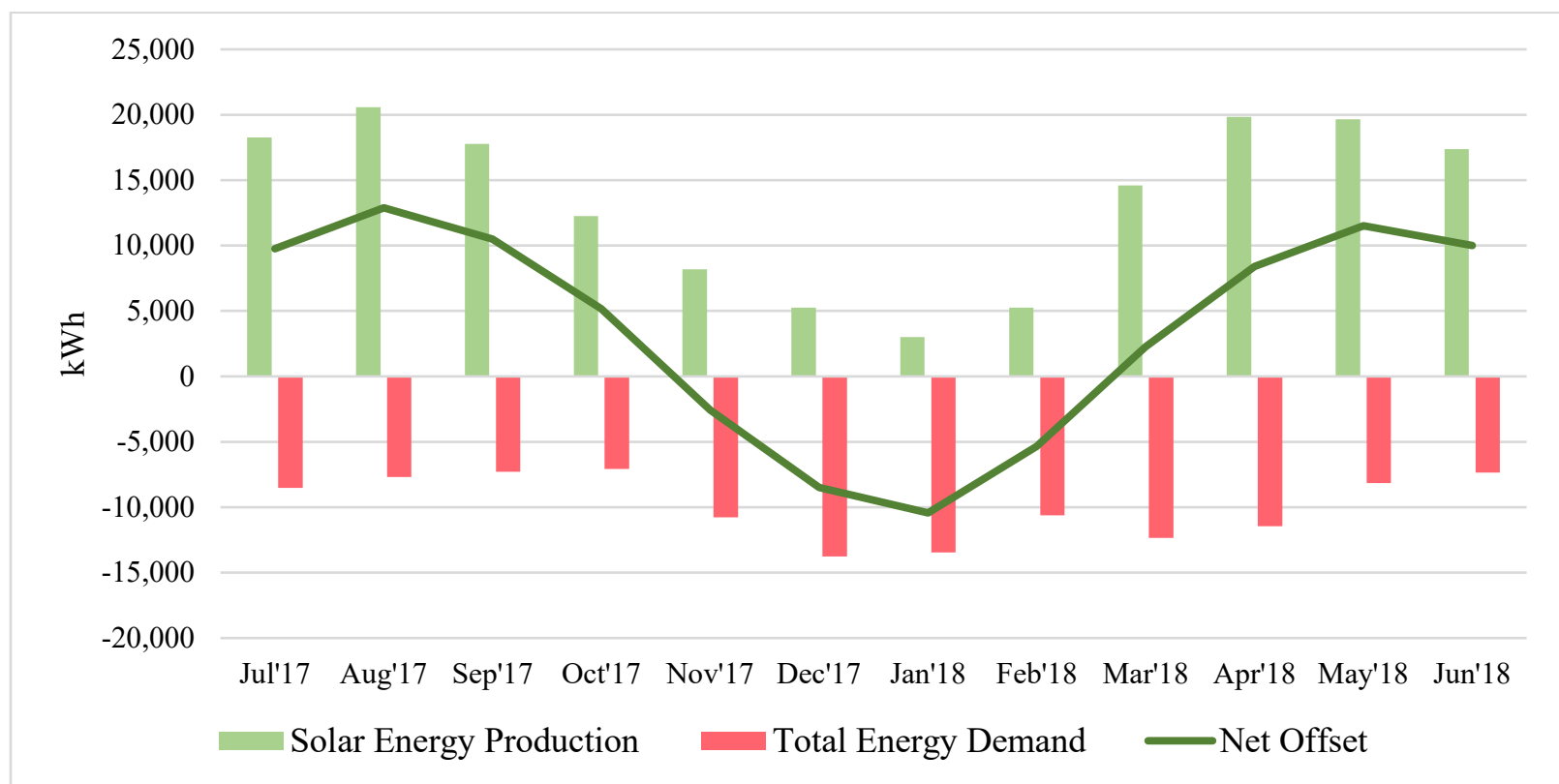

Figure 6. Annual energy profile for FEC from LBC energy data from tracking year of July 2017-June 2018.

\subsubsection{Energy Use}

As expected, the use phase of living buildings is distinctive to that of a traditional building. With respect to energy consumption, the facility is required to generate more energy than it uses on an annual basis with the excess electricity transmitted back into the grid. FEC achieved net-positive energy via solar panels for electricity and a geothermal well system for heating and cooling loads. 
In order to calculate life cycle impacts from the use phase, the building energy demand and generation were evaluated. For LBC, a building's energy generation and use must be tracked over the course of a year to ensure it is achieving a net-positive energy profile; a testing period was chosen and all data from this year was reported to ILFI. These 12 months of data need to be consecutive but do not need to begin immediately after the building's construction is completed. The reported year for the FEC was July 2017-June 2018, even though the building opened to the public in September 2016, seen in Figure 6, with annual totals shown in Table 3.

Table 3. Annual total energy for the FEC over one-year tracking from July 2017-June 2018.

\begin{tabular}{|l|c|}
\hline Energy Type & Annual Total (kWh) \\
\hline Solar Production & 162,054 \\
\hline Total Energy Demand & $-118,396$ \\
\hline Net Offset & 43,658 \\
\hline
\end{tabular}

Because the FEC is connected to the electrical grid, surplus electricity generated by the PV panels is sent directly into the grid. Since the energy source of the Pittsburgh area is dominated by fossil fuels, providing renewable energy into the grid offsets greenhouse gas (GHG) emissions originating from electricity generation. This offset energy was modeled based on the grid energy sources of this region (see Figure 7). The expected lifespan of this building is 100 years, which means that $44,000 \mathrm{kWh}$ of primarily fossil fuel-based electricity are projected to be offset by renewable energy each year, based on Figure 6. Based on the GHG emissions factors from the local grid mix, this results in $8,000 \mathrm{~kg} \mathrm{CO}$ eq offset annually; equivalent to 19,000 passenger miles driven (USEPA, 2016b). 
One aspect about the panels is their overall life cycle impacts compared to traditional sources of electricity, such as coal. The most environmentally damaging life cycle stage for fossil fuels occurs during the operational/use phase when the coal is combusted. Conversely, most of the impacts from solar panels originate from the material extraction and processing required to manufacture the panels; the operational/use phase is much less significant and is dominated by the material replacements over the lifespan of the panels (NREL, 2012a). There are no direct emissions associated with the use phase of solar panels, nor are there transmission losses in this case as they are located on-site. This makes the energy profile of the FEC's use phase notably different than a conventional building and explains the substantial offsets from this life cycle stage, discussed further in the results section.

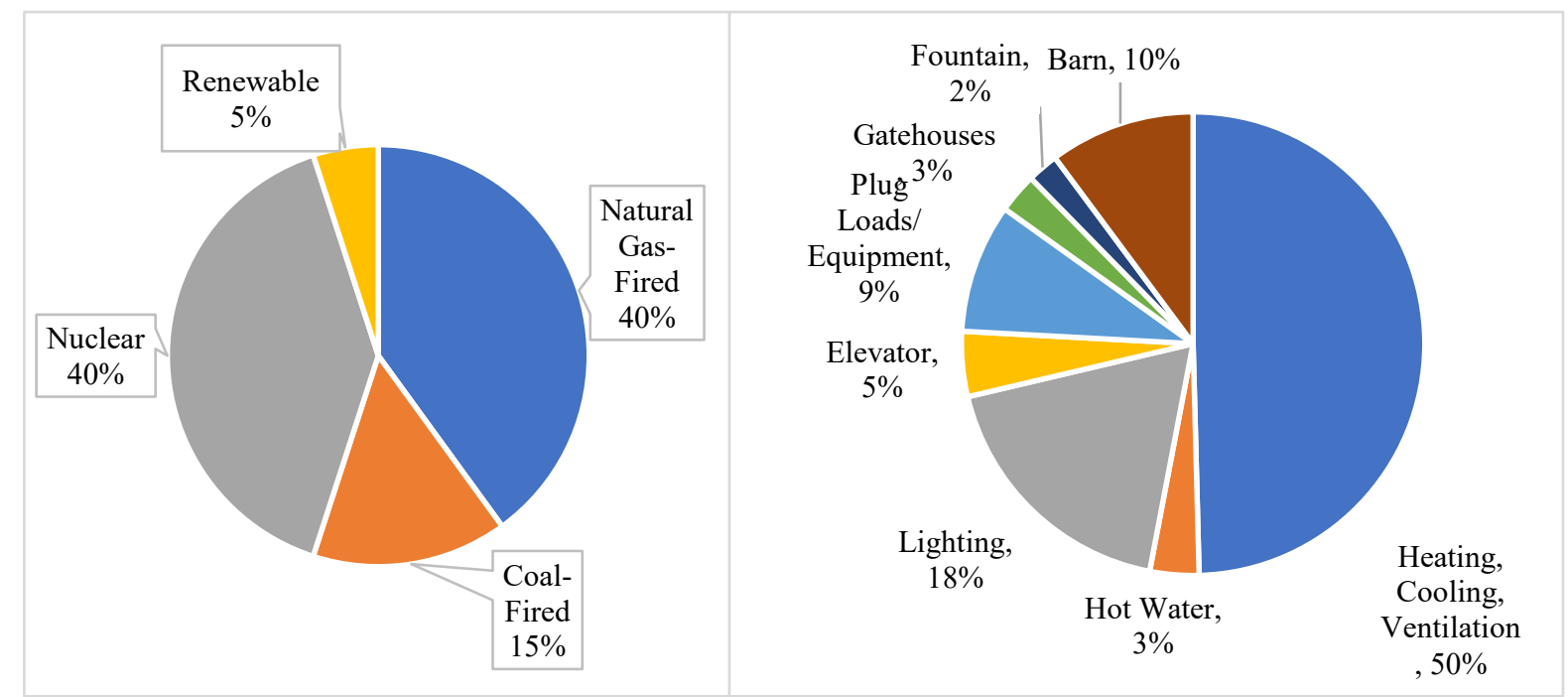

Figure 7. a) Pennsylvania's electricity generation by source from October 2018 (USEIA, 2018). b) FEC electricity demand by category.

Additionally, there is a geothermal heat pump (GHP) system on-site for heating and cooling loads. There are 18 vertical wells that are 520' deep; this $6 \times 3$ grid of wells is located in the center of the site underneath the main walkway. The energy offset by the GHPs is not directly 
measured by the building operators, but such systems are known to reduce energy consumption by 25-50\% (USEIA, 2011). Because this is a newer building that implements passive design strategies and therefore has decreased ventilation demands, the lower value can be applied to the FEC. Based on $25 \%$ savings, the heat pumps prevent $40 \mathrm{MWh}$ in energy demand on an annual basis, equivalent to the annual electricity used in 5 homes (USEPA, 2016b).

In order to identify the largest contribution to the electricity demand, Figure 7(b) shows the distribution of FEC's electricity demand. As with most buildings, heating, cooling, and ventilation dominate these demands. Although the use phase has minor impacts from a life cycle perspective, this should be considered moving forward should any energy reduction strategies need to be implemented as it is clear that HVAC loads should be the focus of any reduction measures.

\subsubsection{Recurring Embodied Impacts from Replacements}

In order to obtain comprehensive results for the entire life cycle of the building, it was imperative to factor in material replacements into this LCA. Because all product submittals were provided, the warranties for all products assessed could be acquired and thus generate the number of replacements required over the course of the 100-year lifespan of the building. These impacts are critical to include because there is potential for the building to have relatively high embodied impacts from material replacements, especially when the energy use impacts are so low. These impacts are considered during the use phase because they occur periodically over the course of the building's 100-year lifespan. Comprehensive impacts from material replacements will be explored further in the Results and Discussion section. 


\subsubsection{Water System Impacts of Green Buildings}

Since many GBRS such as LEED and LBC have many requirements or offer strategies for on-site water systems, it is critical to ensure that these systems result in lower life cycle impacts. LEED v4 has many water-centric requirements, including the water efficiency of all fixtures installed onsite, the thorough metering of building water use, and encourages efforts to reduce indoor/outdoor water use (USGBC, 2018). Similarly, the Living Building Challenge requires a net-positive water profile, meaning all water needs must be met by water collected and treated on-site; this creates a synthesis between the stormwater, wastewater, and potable systems (ILFI, 2017). Therefore, the water systems at the FEC are designed with great intent in order to meet the requirements of both of these rating systems. However, there is continuous research into discovering which systems are the most sustainable options, namely for the storm and wastewater systems. Additionally, although the FEC is not connected to the sewer nor stormwater systems, Pittsburgh faces a significant problem with combined sewer overflow (CSO) so it is important to examine the ways FEC provides relief to this system by being independent from it.

With respect to stormwater, green infrastructure (GI) is generally agreed upon as having lower impacts. This could be with respect to GI used for combined-sewer overflow mitigation (De Sousa, Montalto et al., 2012) or embodied material and use impacts (O'Sullivan, Wicke et al., 2015). One study assessed three stormwater systems as mitigation strategies for the combinedsewer overflow problem that New York City faces, similar to Pittsburgh. This study found that one scenario with a GI stormwater system, which included pervious pavement, infiltration planters, and rain gardens had $85 \%$ lower emissions (measured in $\mathrm{CO}_{2} \mathrm{eq}$ ) compared to a second scenario with a standard detention basin with no GI; this is a result of the trees planted offsetting any installation impacts by year 25 as a result of their carbon uptake, combined with high material 
impacts from constructing a concrete detention basin (De Sousa et al., 2012). Similarly, another study focusing on combined sewer systems assessed GWP of three GI options (biorention basin, green roof, and permeable pavement), a centralized municipal sewer system, and combinations of one GI with the municipal system; the biorention had the lowest associated GWP due to its low installation impacts (Wang, 2013). Lastly, one study focused on the impacts from the materials used in the system and concluded that on-site infiltrative rain gardens had the lowest GWP compared to a concrete storage unit and a sand filter detention basin. Therefore, GI components can result in lower impacts as a result of their potentially offsetting carbon impacts via trees or plants, combined with their lower material embodied impacts. The FEC therefore implements green infrastructure components for the stormwater system throughout the site.

Converse to GI stormwater management systems, the use of building-scale water treatment systems is under continuous debate within the green building research community. Although all grey and blackwater must be treated on-site per LBC requirements, studies are emerging that assess the scalability of decentralized water systems. Cornejo et al. (2016) focused on the economies of scale for water treatment systems, assessing them on a household, community, and city scale. They found that both the embodied energy $\left(\mathrm{MJ} / \mathrm{m}^{3}\right)$ and carbon footprint $\left(\mathrm{kg} \mathrm{CO}_{2} \mathrm{eq} / \mathrm{m}^{3}\right)$ of the systems decreased from household to city scale; however, community scale did have the lowest eutrophication potential $\left(\mathrm{g} \mathrm{PO}_{4} \mathrm{eq} / \mathrm{m}^{3}\right)$ compared to household and city. A similar study compared a living machine (LM), which is a building-scale decentralized system, to a standard centralized wastewater treatment plant (WWTP) (Hendrickson, Nguyen et al., 2015); the LM system had larger GHG emissions ( $98 \%$ greater, $\sim 17,500 \mathrm{~kg} \mathrm{CO} 2$ eq/ML) but lower energy consumption ( $8 \%$ lower). These large emissions occur when the septic systems emissions were not captured; when a scenario with capture was performed, the $\mathrm{LM}$ emissions were only $1,500 \mathrm{CO}_{2} \mathrm{eq} / \mathrm{ML}$ greater than 
the WWTP. Another study assessed various multi-occupant buildings and found that the buildings that used highly efficient water fixtures saw lower life cycle impacts (Arpke \& Hutzler, 2005). Lastly, a comparable study of the water system of another living building in Pittsburgh found that a standard building modeled with low-flow water fixtures had the potential to have lower life cycle impacts than a building with a complete wastewater treatment system on-site (Hasik et al., 2017). It is therefore critical to understand the impacts and scalability of these systems in order to design and construct the most sustainable buildings feasible. Consequently, the wastewater treatment systems of the FEC are assessed in detail in order to acquire life cycle impacts, while potentially identifying any hotspots in the systems.

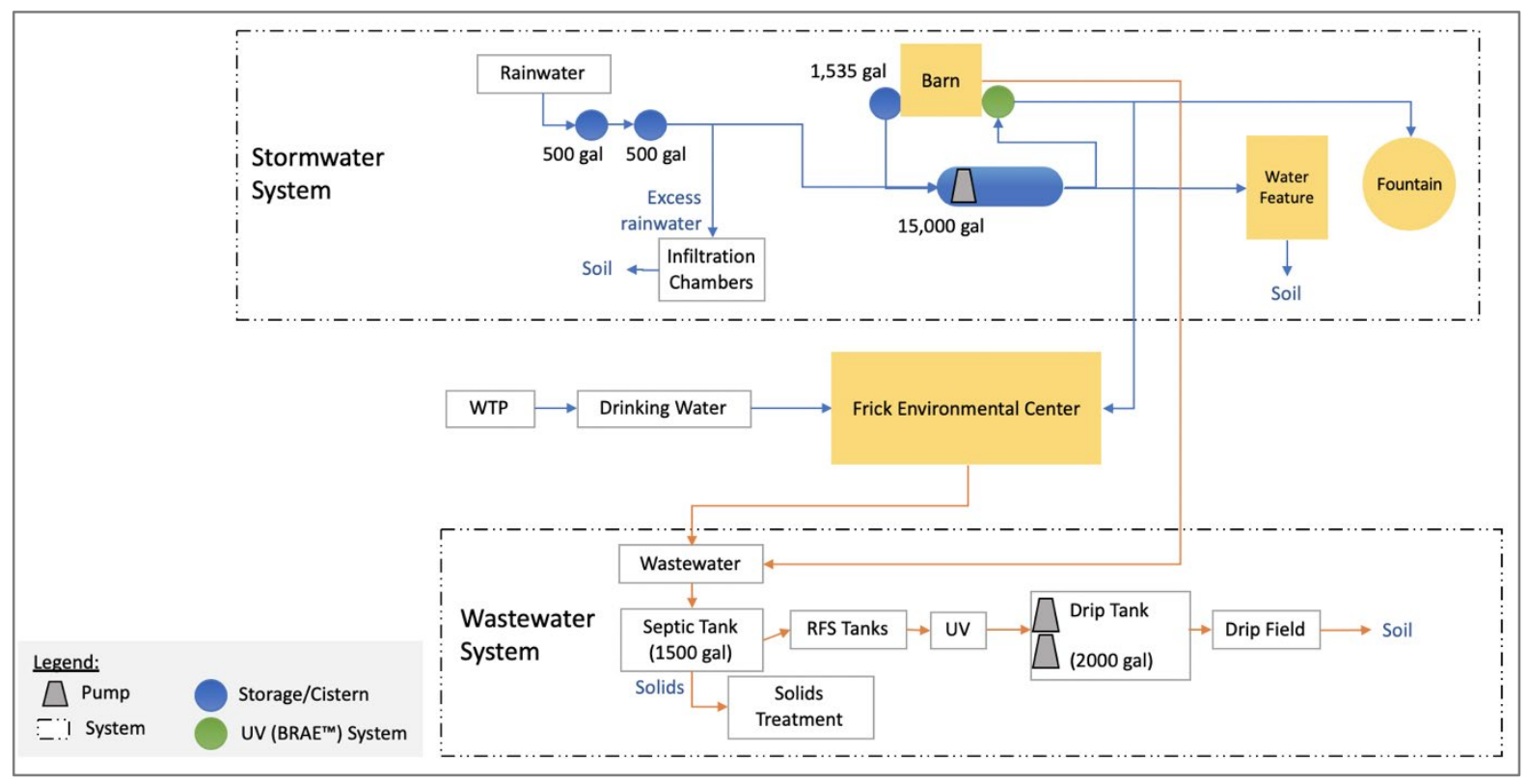

Figure 8. FEC water system schematic, including the wastewater and stormwater systems, plus the tie in to the municipal potable water system. 


\subsubsection{FEC Water System Impacts}

The FEC has three primary water systems on site: potable, stormwater, and wastewater (see Figure 8). These water systems are extensive and deliberate in order to meet net-positive criteria from the Living Building Challenge, which demands all water used on-site needs to be collected from precipitation (ILFI, 2017). Therefore, rainwater and snowfall are collected via three rain barrels placed throughout the site: two at the foot of the solar panel parking coverage and one adjacent to the barn. This water is collected and stored in one large 15,000-gallon cistern located underground in the middle of the site. Two UV purification systems are present on-site to treat this collected water.

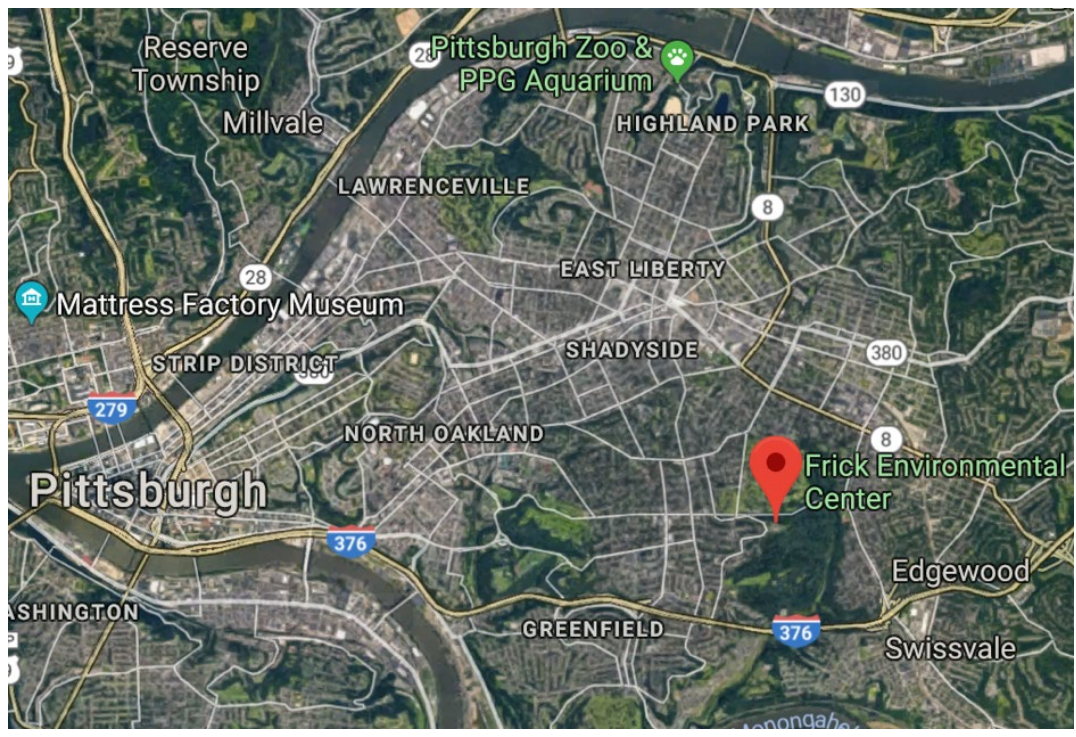

Figure 9. Map of Pittsburgh showing the FEC on the edge of Frick Park (Google).

Due to Pennsylvania water regulations, water reclaimed and treated on-site can only be used for non-potable purposes (ICC, 2015). However, the FEC treats its reclaimed water to potable standards with the expectation that state regulations progress over the life of the building. A portion of the stormwater collected is treated to potable standards but used for non-potable uses in the 
building, such as flushing and irrigation; this semi-closed loop system with storage allows achieving the net-positive target attainable and reasonable. Because there are roughly 20 occupants regularly in the space, Pittsburgh receives ample precipitation to meet daily demands, with the cistern assisting on peak days when summer camps or community events are held.

A large problem that the city of Pittsburgh faces is the issue of combined sewer overflow (CSO). Because Pittsburgh has older city infrastructure, most parts of the city have combined sewers where both stormwater and sewage are transported in the same pipe. Therefore, during average or large rain events, these systems exceed capacities, leading to CSO events; these have significant environmental impacts, including ecosystem damage and negative human health impacts. The City's public infrastructure entities are working to reduce the frequency of these CSO events by improving the city's infrastructure and reducing the peak volumes these systems face.
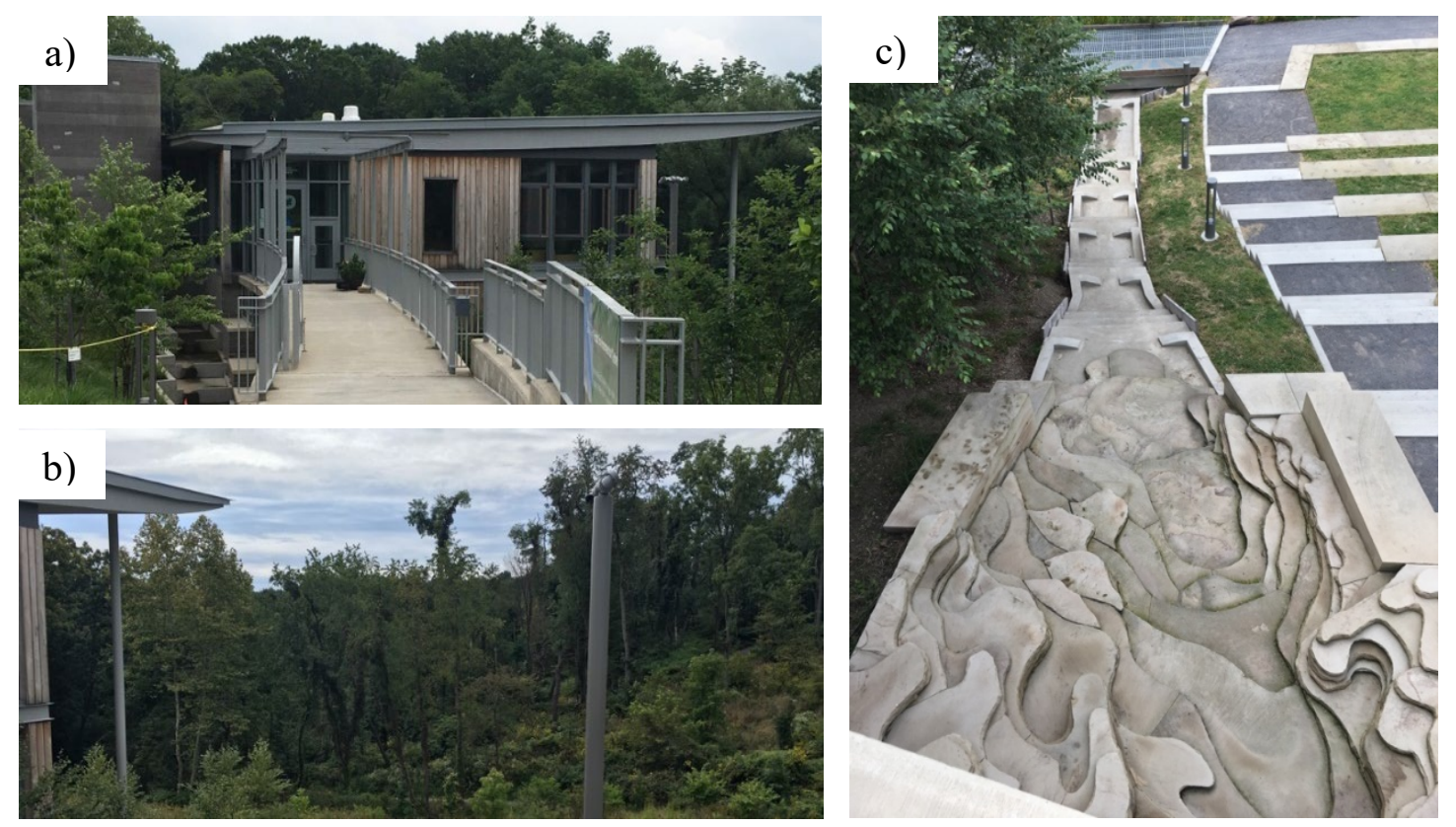

Figure 10. Stormwater management features on the Frick Environmental Center's site.

a) View of the sloped roof. b) South-facing view from the FEC into Frick Park. c) Rain ravine that directs water into Frick Park. 
The FEC project helps reduce this load because it is not directly connected to the Pittsburgh stormwater or sewer system; all rainwater is either collected as previously explained or redirected into the nearby park. The FEC sits in the northwest corner of Frick Park, which is the largest park within Pittsburgh (see Figure 9). The project team worked to make the stormwater management of the site a sustainable, interactive, and educational experience. The roof of the structure is slightly sloped to direct all of the water to cascade off the north façade of the building in what is termed a "Rain Veil," which is designed to allow visitors of the building to experience the rain by seeing, hearing, and smelling it in the main walkway of the building. It falls in sheets into a drainage basin which redirects it into an art piece entitled the "Rain Ravine," as seen in Figure 10. It then drains into the nearby forest and ultimately Four Mile Run, a local stream. Being completely disconnected from the stormwater system has positive impacts on both the civil infrastructure and the ecosystems of the park as there is minimal disruption to the natural water cycle by the building.

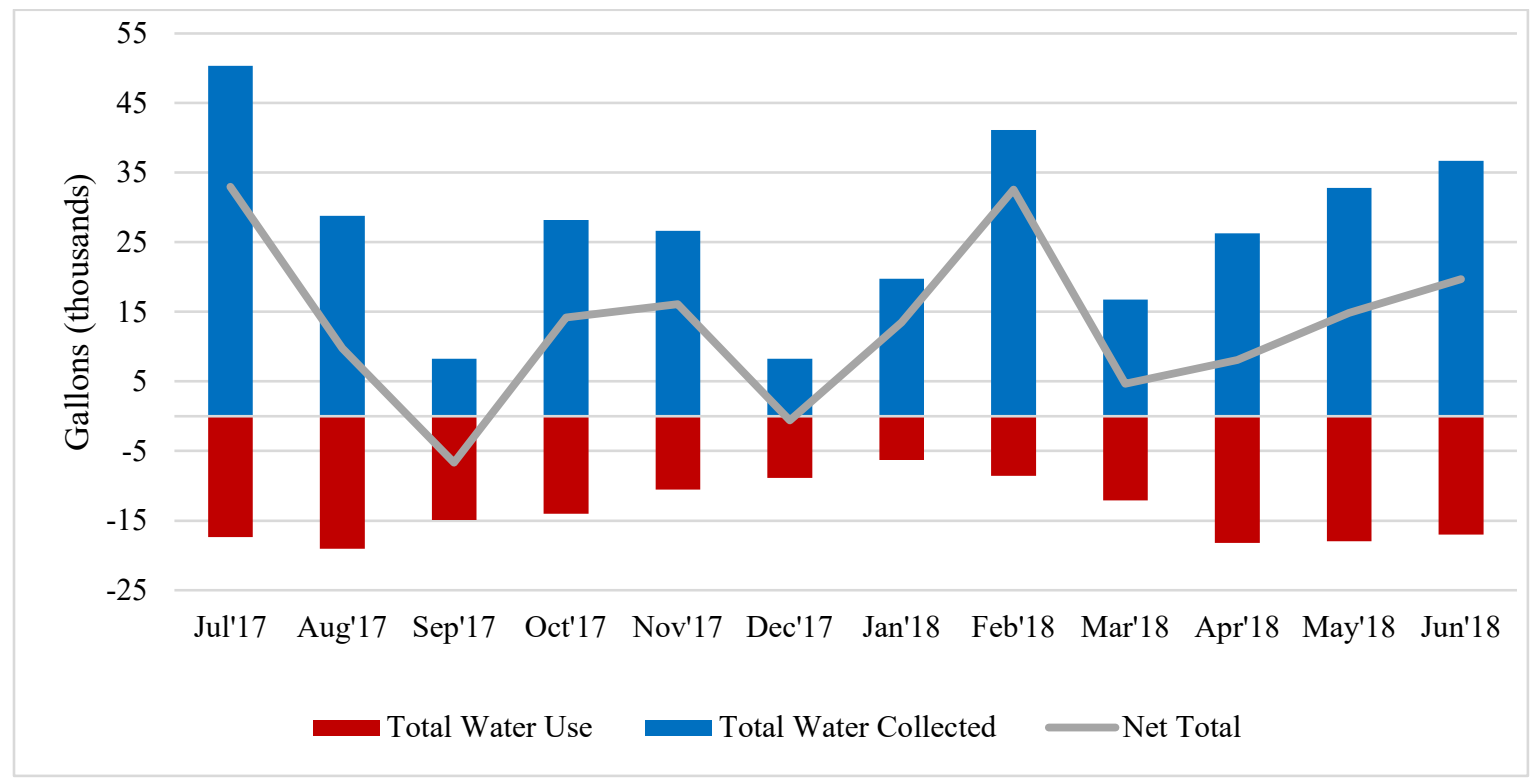

Figure 11. Net-zero water profile over 12-month testing period, July 2017-June 2018. 
Although the FEC is not connected to the sewer system either, the impacts of the wastewater system are more significant than those of the stormwater system. As seen in Figure 8, the wastewater from the building is stored in a septic tank, treated, and ultimately distributed into a drip field adjacent to the site and infiltrates into the soil. The impacts of this system are discussed in greater detail in the Water System Impacts section.

When the water profile of the FEC was assessed, it is clear to see that it has a net-positive water use, shown in Figure 11. The annual totals for the testing period, July 2017-June 2018, are shown in Table 4. The water use intensity (WUI) for the FEC is 10.1 gallons per square foot (sf). According to the US Energy Information Administration (US EIA), average office buildings tend to have WUI's around $14 \mathrm{gal} / \mathrm{sf}$, placing the FEC in the range of a building that uses low-flow fixtures (USEIA, 2017). This in itself is satisfactory with regards to water use, but of course this value is not a comprehensive representation of the FEC's net-positive water impacts and is a conservative value. On an annual basis, the FEC collects nearly 324,000 gallons of water; this exclusively comes from precipitation on site, whether that is rain or snow, that is then stored in an underground cistern. Therefore, from solely a water consumption perspective, the FEC largely exceeds all of ILFI's net-positive water requirements. The comprehensive impacts of the potable, waste, and stormwater systems will be assessed in Water System Impacts and Comparison.

Table 4. Water demand and collection for testing period, July 2017-June 2018.

\begin{tabular}{ll}
\multicolumn{1}{c}{ Type } & $\begin{array}{c}\text { Annual Total } \\
(1000 \text { gal })\end{array}$ \\
\hline Water Demand & 165.0 \\
\hline Water Collected On-Site & -323.9 \\
\hline Net Water Use & -159.0 \\
\hline
\end{tabular}




\subsubsection{Water System Comparison: FEC to CSL}

An LCA was performed on the water system of another living building in Pittsburgh, the Center for Sustainable Landscapes (CSL) located at Phipps Conservatory and Botanical Garden (Hasik et al., 2017). The CSL's main purpose is to provide office space for employees of Phipps; it therefore has less foot traffic and fewer visitors in general than the FEC. The assessment of the CSL was adjusted for the FEC and incorporated within the whole-building LCA results. The primary discovery from this assessment, which is discussed in the Water System Impacts section, is the amount of emissions from the septic system. The CSL has a closed loop system, incorporating sand filters, constructed wetlands, and solar distillation to purify all aspects of wastewater (see Figure 12). However, the FEC does not have a closed-loop system as the treated wastewater ultimately infiltrates into the soil via a septic system that feeds into a drip field. Although this is allowed by the ILFI and is a natural way of treating wastewater, the FEC does not use an aerator thus resulting in anaerobic digestion; this leads to high associated methane emissions. Because methane is a greenhouse gas that is 25 times more potent than carbon dioxide, it is critical to minimize its emissions especially when they could be mitigated via aeration of the septic system (USEPA, 2014). Note that septic system emissions for both the CSL and FEC were based off of published values and were adjusted to the volume rate that passes through each system (Leverenz, 2010).

Because the FEC is a living building, it must have a net-positive water profile; consumption is therefore tracked throughout the system. All potable consumption is tracked in order to ensure they account for and offset via rainwater collection all water drawn from the municipal system. The volume of water in the 15,000 gal capacity underground cistern is tracked in order to ensure this supply is never depleted. A shortcoming, however, is there is a lack of extensive submetering 
throughout the site. For example, the amount of water used by the toilets is not directly tracked; it is accounted for in various subtotals but is not available independently for assessment. This is a very important value, however, because it determines the volume of treated water that goes through the system to ultimately be anaerobically digested, producing methane. Therefore, values that were calculated for the CSL were adapted to acquire specific use values for the FEC. Volumetric rates that go into the water treatment system were calculated based on number of occupants, days per year of building operation, along with various average low-flow rates for water fixtures such as toilets and sinks.

Although the buildings have different functions, occupancies, and square footages, the water use intensity (WUI) can be used to compare the overall consumption of each building's water system (see Figure 12). Because no real time water tracking of the CSL was available, the WUI's presented are based on modeled water use numbers; this quantity was modeled using the same methodology for both buildings, thus allowing for the comparison of the two WUI's. Due to the greater square footage of the CSL and the larger modeled water use of the FEC, the modeled WUI for the CSL is significantly lower than that of Frick. Even when daily occupants are factored in to the water use intensity, the FEC's is double that of the CSL as seen in Table 5. Due to the large surplus of water collected annually, this larger water use of the FEC does not place any strain on its system with respect to demand; however, it does increase the volume of water that needs to be treated on-site. This leads to larger volumes that pass through the purification process, the septic tank, and drip field. The assessment of these impacts can be seen in Water System Impacts and Comparison. 


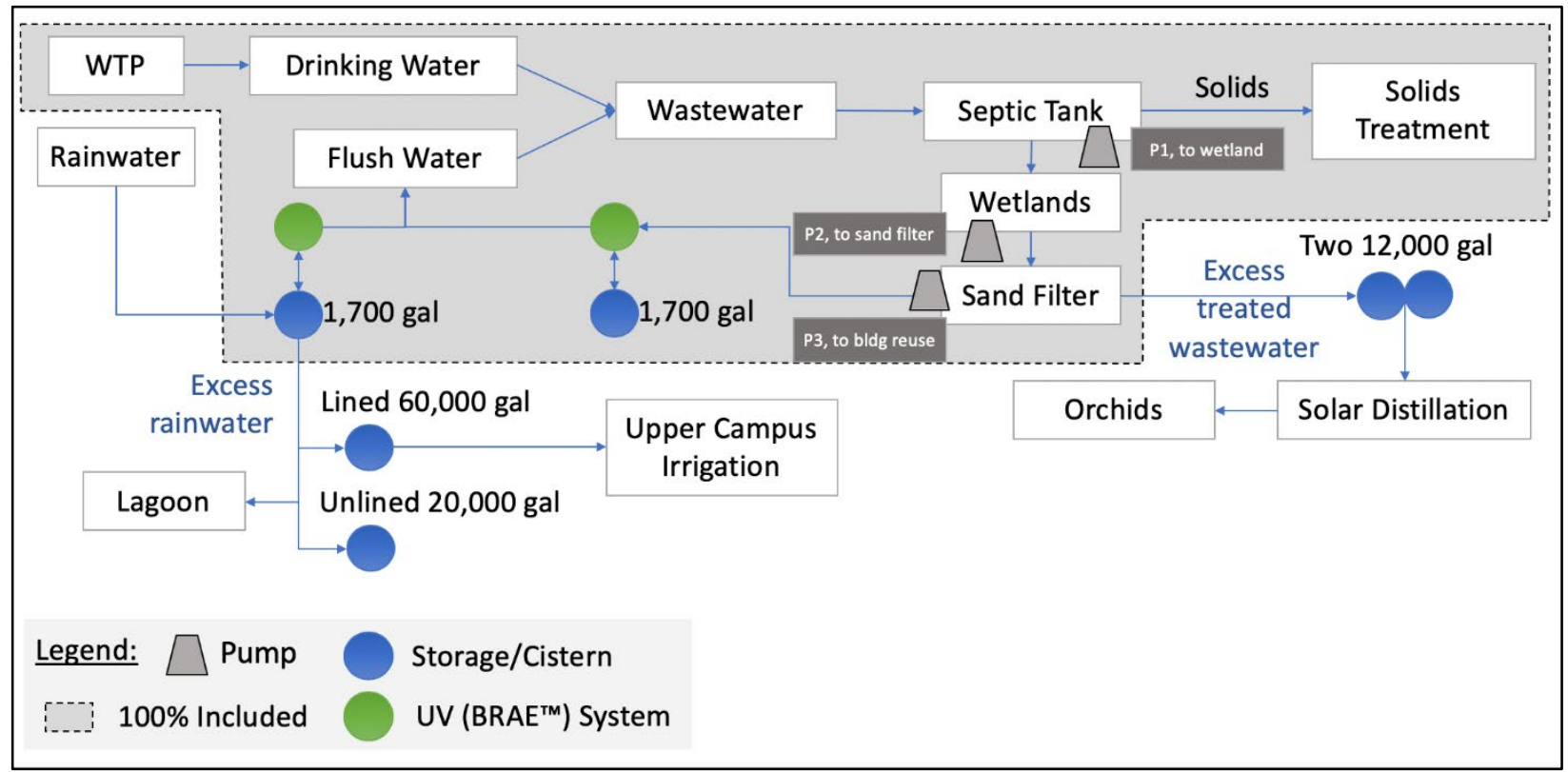

Figure 12. CSL wastewater system schematic (Hasik, Anderson, et al. 2017).

Despite the fact that the CSL and FEC have slightly different functions, they are both living buildings within the city of Pittsburgh. There is therefore a unique opportunity to compare buildings with two different water systems in order to determine which water system is optimal; this evaluation will be addressed in detail in the Water System Impacts and Comparison section.

Table 5. Comparison of water system attributes and WUI for CSL and FEC.

\begin{tabular}{lll}
\hline Building Attribute & CSL & FEC \\
\hline Daily Occupants (Staff + Visitors) & 50 & 70 \\
\hline Square Footage (ft ${ }^{2}$ ) & 24,000 & 15,000 \\
\hline Water Use (gal/day), modeled & 207 & 379 \\
\hline Modeled WUI (annual gal/sf) & 3.1 & 9.2 \\
\hline Modeled WUI per person (annual gal/sf/person) & 0.062 & 0.13
\end{tabular}




\subsubsection{EOL Impacts within Building LCA}

As more low energy and high-performing buildings emerge, there is a shift in the impact distribution for each life cycle stage. As the use phase impacts decline, research is now focusing on both materials and their end-of-life impacts. Depending on how significant the EOL environmental effects are, factoring these impacts in earlier in the life of a building could affect the overall life cycle impacts; specifically, due to their large embodied impacts, choosing a structural material with a lower end of life impact could result in a significant reduction in the total environmental impacts. For example, although recycled steel has a significantly higher embodied energy than concrete $(13 \mathrm{MJ} / \mathrm{kg}$ compared to $1 \mathrm{MJ} / \mathrm{kg})$, greater volumes of concrete are required thus allowing their total impacts to quickly surpass those from steel (Hammond \& Jones, 2008).

\subsubsection{EOL Scenario Assessment}

There is an important conversation occurring regarding sustainable building material selection, specifically as it applies to wood as a structural material. While steel and concrete have significant environmental impacts due to extensive energy and resources required for extraction, processing, manufacturing, and distribution, it is unclear how these impacts compare to wood. The use of wood as a structural material is complicated. Researchers are starting to detail the importance of factoring in the impacts of biogenic carbon into the life cycle assessment of wood as structural materials (Fouquet, Levasseur et al., 2015; Levasseur, Lesage et al., 2013). When a timber house was assessed, the carbon stored via landfilling offset nearly one third of the building life cycle impacts; when the wood was incinerated with energy recovery, greater offsets were seen but the release of carbon when burned resulted in an overall greater net GWP (Fouquet et al., 2015). This illustrates 
the complicated balance when using wood as a structural material and the significance of factoring in biogenic carbon impacts, which is something this EOL assessment sought to analyze within the context of a living building.

Another significant aspect of this discussion is the impacts on deforestation and forest management. Although land use impacts were outside of the scope of this LCA, it is an important consideration for the design of living buildings in general. Recently, the Sierra Club published an open letter calling for a need to focus on reducing the embodied carbon of building materials, while warning that a drastic shift to timber products could be damaging if not executed in a thoughtful, sustainable manner (SierraClub, 2018). They specifically called out Cross-Laminated Timber (CLT) as this material is a common wood product used in larger wood construction projects, referred to in this letter as "Tall Timber."

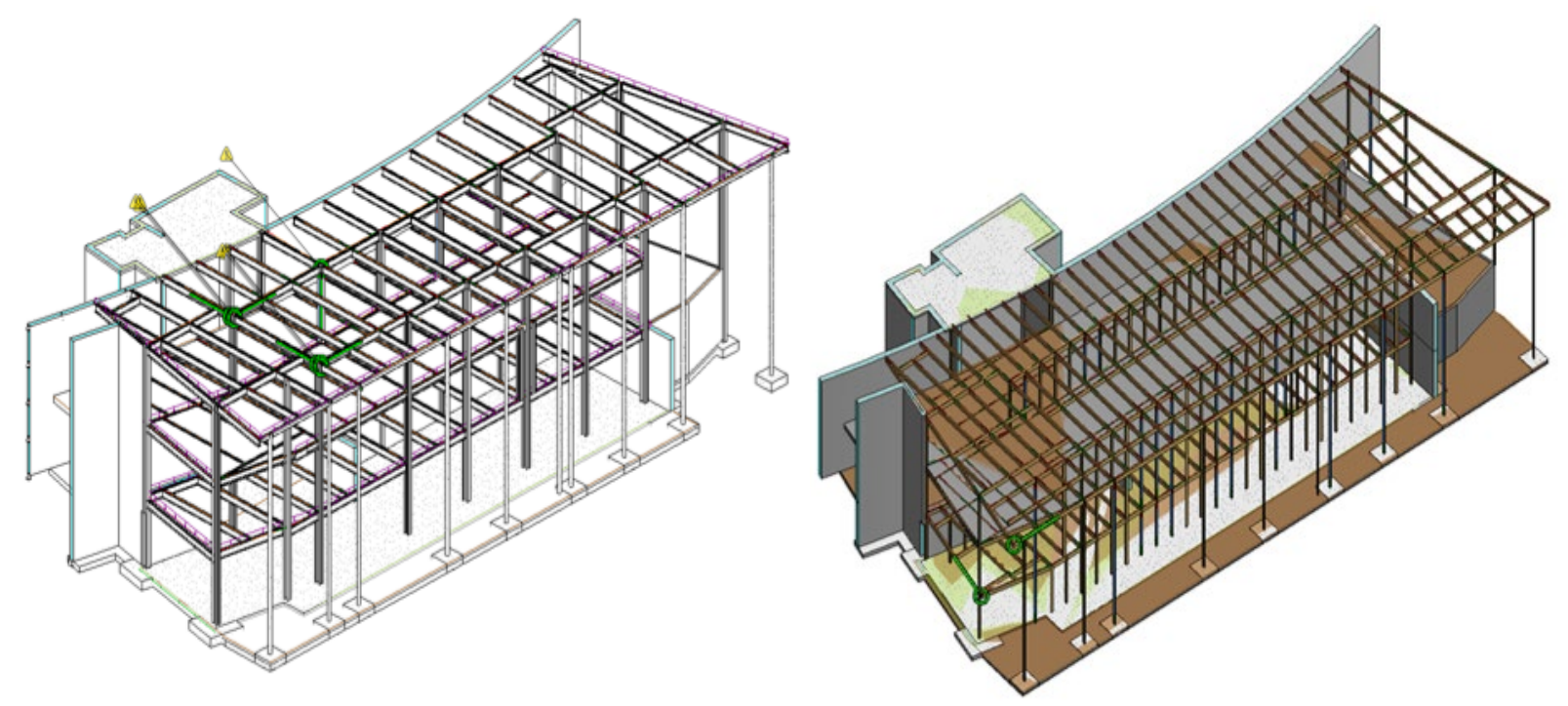

Figure 13. Revit models of (a) streel frame (as-built) and (b) lumber frame. 
As with most sustainability issues, this debate illustrates how the best option has to be optimal for the specific project in question and evaluated with tools such as life cycle assessment. A scenario analysis performed on FEC structural elements is discussed in the following section.

In order to determine which disposal option had the lowest environmental impacts, scenario analyses for the EOL impacts of steel, lumber, and concrete were assessed. Some general assumptions were made to perform this assessment:

- Only structural elements were considered (beams, foundations, columns)

- When lumber is replaced for steel in the assessment, the lumber connections are assumed to be designed for disassembly

- The concrete foundation is unchanged from the steel model to the lumber model

- Steel is always modeled being $100 \%$ recycled at its end of life.

In order to simplify the analysis, only the structure of the building was analyzed. To be able to isolate the impacts of different building materials, two models were constructed in Revit by Dr. Aziz Banawi, one with a steel structure (as-built) and one with a wooden structure (Figure 13). The details of those models are as follows:

(1) Steel (as-built): steel beams, concrete columns, concrete foundation

(2) Lumber: lumber beams, lumber columns, concrete foundation

Linear quantities from the Revit models were exported for each material and converted into mass quantities. These quantities and the global warming potentials of each material are shown in Table 6. 
Table 6. EOL material quantities and emissions factors.

a) Steel model (as-built) material quantities. b) Lumber model material quantities. c) GWP factor for each structural material, sourced from ecoinvent 3.4 (ecoinvent, 2018).

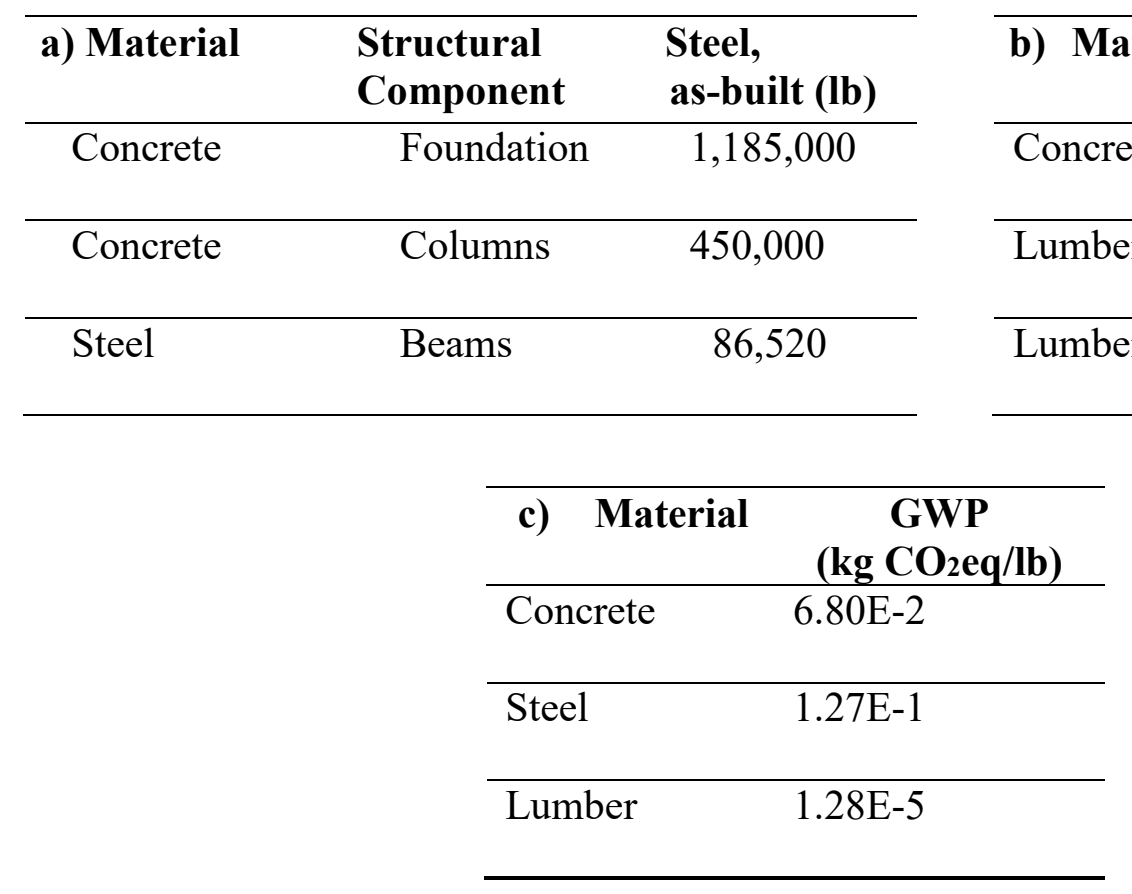

After the quantities for the models were obtained, the waste scenarios for each material were established. These various scenarios assessed are shown in Table 7. Because steel has a high recycling rate in construction of nearly $90 \%$, no alternative waste scenarios were considered (SRI, 2017). Concrete, on the other hand, is either landfilled or recycled to be used for aggregate. Lastly, wood products can either be landfilled (with or without landfill gas capture), recycled, or combusted for energy. For each scenario for concrete and lumber, a sensitivity analysis was performed using four $25 \%$ increments, with the other percentage being filled in by default with the "landfill" option. Assessments of the waste stream options presented in Table 7 were performed. In the scenarios where wood is landfilled, it was assumed no landfill gas (LFG) recovery for energy was implemented; this way, the number of scenarios is simplified and the effect that recovery has on lumber landfilling can be isolated in other scenarios. 
Table 7. Potential scenarios for each material, " $x$ " denoting it is a possible disposal path.

\begin{tabular}{lcccc}
\hline & $\begin{array}{l}\text { Landfill, } \\
\text { no recovery }\end{array}$ & $\begin{array}{l}\text { Landfill, } \\
\text { LFG } \\
\text { recovery }\end{array}$ & Recycling & $\begin{array}{c}\text { Combustion, } \\
\text { energy } \\
\text { recovery }\end{array}$ \\
\hline Concrete & $\mathrm{X}$ & -- & $\mathrm{X}$ & -- \\
\hline Steel & -- & -- & $\mathrm{X}$ & -- \\
\hline Lumber & $\mathrm{X}$ & $\mathrm{X}$ & $\mathrm{X}$ & $\mathrm{X}$ \\
\hline
\end{tabular}

Factors presented in Table 8 were extracted from the EPA's report regarding documentation for emissions factors for disposal used in the Waste Reduction Model (WARM); this specific report focuses on construction and demolition materials. Factors from this model were used for concrete and lumber, whereas the factor for steel was extracted from ecoinvent 3.4 (ecoinvent, 2018). Two waste pathways for concrete were considered: recycling and landfilling. The concrete emissions factor takes into consideration offsets associated with the prevention of virgin material for aggregate production (transport of raw materials, virgin aggregate mining and processing) as well as emissions (collection to and processing at recycling facility, transport to and processing at landfill) as seen in Figure 14.

Table 8. Net emission factors for EOL disposal.

Measured in $\mathrm{MT} \mathrm{CO}_{2} \mathrm{eq} /$ short ton of construction material for concrete, lumber, and steel, where ${ }^{\dagger}$ denotes sourced from the EPA WARM tool, and * sourced from ecoinvent3.4 (ecoinvent, 2018; PRé, 2017; USEPA, 2016a).

\begin{tabular}{cccccc}
\hline Material & $\begin{array}{c}\text { Net } \\
\text { Recycling } \\
\text { Emissions }\end{array}$ & $\begin{array}{c}\text { Net } \\
\text { Composting } \\
\text { Emissions }\end{array}$ & $\begin{array}{c}\text { Net } \\
\text { Combustion } \\
\text { Emissions }\end{array}$ & $\begin{array}{c}\text { Net } \\
\text { Landfilling } \\
\text { Emissions, } \\
\text { no recovery }\end{array}$ & $\begin{array}{c}\text { Net } \\
\text { Landfill } \\
\text { Emissions, } \\
\text { recovery for } \\
\text { electricity }\end{array}$ \\
\hline Concrete & $-0.01^{\dagger}$ & $\mathrm{n} / \mathrm{a}$ & $\mathrm{n} / \mathrm{a}$ & 0.02 & $\mathrm{n} / \mathrm{a}$ \\
\hline Lumber & $-2.46^{\dagger}$ & $\mathrm{n} / \mathrm{a}$ & -0.61 & -0.92 & -1.02 \\
\hline Steel & $-0.0322^{*}$ & $\mathrm{n} / \mathrm{a}$ & $\mathrm{n} / \mathrm{a}$ & $\mathrm{n} / \mathrm{a}$ & $\mathrm{n} / \mathrm{a}$ \\
\hline
\end{tabular}




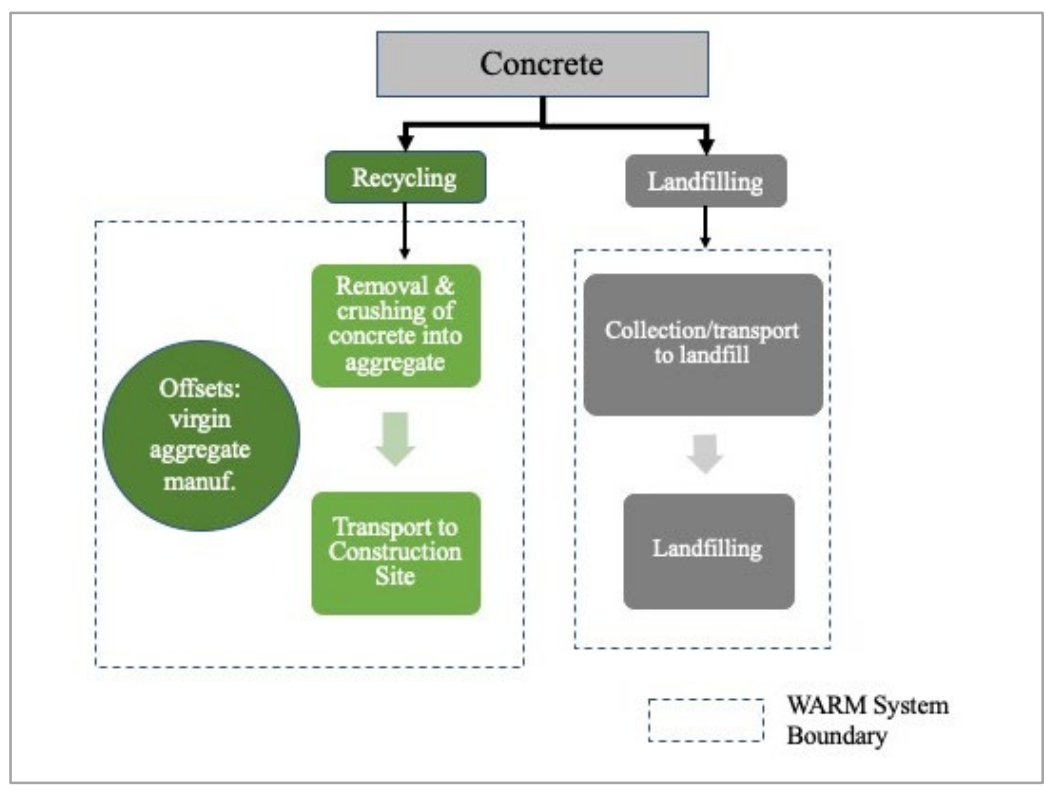

Figure 14. System boundary for EPA WARM tool for concrete waste scenarios (EPA, 2016a).

The lumber modeling, however, is more involved because there are four potential waste streams: recycling, combustion, and landfilling without landfill gas (LFG) recovery, landfilling with LFG for electricity generation. The recycling is assumed to be close-loop, meaning the lumber is processed back into lumber; this allows for the modeling of the avoided impacts by not requiring virgin material. Additionally, all processing energy required is factored in as well as forest carbon credits obtained from recycling. As for the combustion route, WARM does not consider $\mathrm{CO}_{2}$ emissions from the combustion of lumber as all carbon released is considered biogenic; however, $\mathrm{N}_{2} \mathrm{O}$ emissions were factored in, along with the transportation impacts and offset impacts from electricity generated by combustion. The WARM system boundary for wood products can be seen in Figure 15.

Similar to combustion, landfilling does not factor in $\mathrm{CO}_{2}$ emissions as they do not include biogenic carbon. However, the $\mathrm{CH}_{4}$ that forms during anaerobic digestion is accounted for; not all carbon is broken down, so landfilling is considered to be a carbon sink as it is being stored in the 
landfill. Transportation emissions plus all combustion of landfill vehicles is also considered when obtaining the final emission factor. Because methane is a potent GHG, there are varying impacts depending on what is done at the landfill. The landfill gas (LFG) can be not recovered, recovered and flared, or recovered for electricity generation. For the sake of this assessment, only "no recovery" and "recovery for electricity" will be analyzed; the emissions factors for "recovery for electricity" and "flaring and recovery for electricity" are within $1 \%$ of each other so only assessing electricity recovery is sufficient in this case (USEPA, 2016a). It should be noted that there are few C\&D landfills that are capable of landfill gas capturing, therefore the scenarios that model LFG capture from landfilling lumber are optimistic scenarios (USEPA, 2016a). Results of these scenario assessments are presented in the subsequent section.

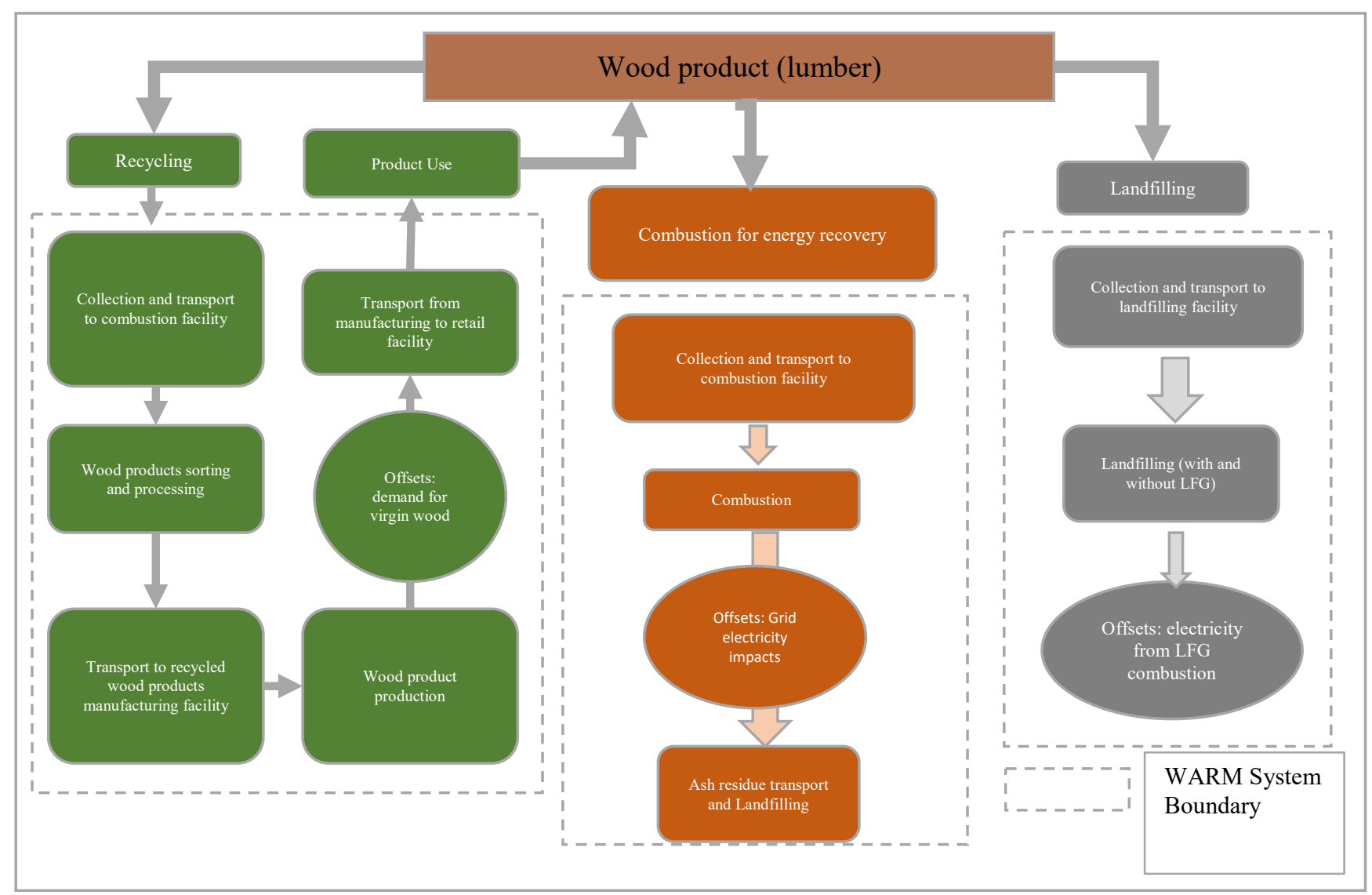

Figure 15. System boundary for EPA WARM tool for wood waste scenarios (USEPA, 2016a). 


\subsection{RESULTS AND DISCUSSION}

The results for the whole building LCA are presented. Material impacts are analyzed in detail, including those of the pre-use and use-phases, which were defined in Figure 2. Additionally, the effects of removing Red List chemicals are isolated and assessed. The water system use impacts are shown and subsequently compared to those of the Center for Sustainable Landscapes (CSL); a hotspot was identified during the use phase of the septic system. The electricity profile of the FEC is presented and annual life cycle offsets were calculated. Next, results from the EOL scenario analyses are shown with the significant offsets of lumber as a structural material. Lastly, electricity offsets are combined with impacts from recurring material replacement, transportation, on-site emissions, and end of life to generate a comprehensive profile for the lifespan of the building.

\subsection{OVERALL LCA IMPACTS}

\subsubsection{Material Pre-Use Impacts}

A significant component of this whole-building LCA was the material assessment. Each material assembly (see Figure 5) was assessed in detail, from acquiring precise material quantities through the evaluation of each material's negative environmental effects. Impacts from both the material pre-use and replacements that occur over the 100-year lifespan of the building were assessed. Replacement values were based on warranties that are documented within the material submittals 
required for both LEED and LBC certification; these values were included in the LCI to ensure that all assemblies had associated life expectancies for the 100-year lifespan of the building.

Material impacts are disaggregated per assembly in Figure 16 and reflect the Red List adjustments previously discussed. Structural impacts dominate the pre-use stage, contributing 21$57 \%$ of each TRACI category. Although these materials have comparable category indicator values to those of the other assemblies, the immense quantities required result in dominating impacts. The main materials in the structural assembly are CMU blocks, steel (reinforcing, beams, plates), and concrete, with weights around 270,90 , and 2200 tons, respectively; the substantial volume of concrete results in the structural assembly contributing to the majority of the GWP category. The choice of the structural materials of a building significantly affects the overall impacts.

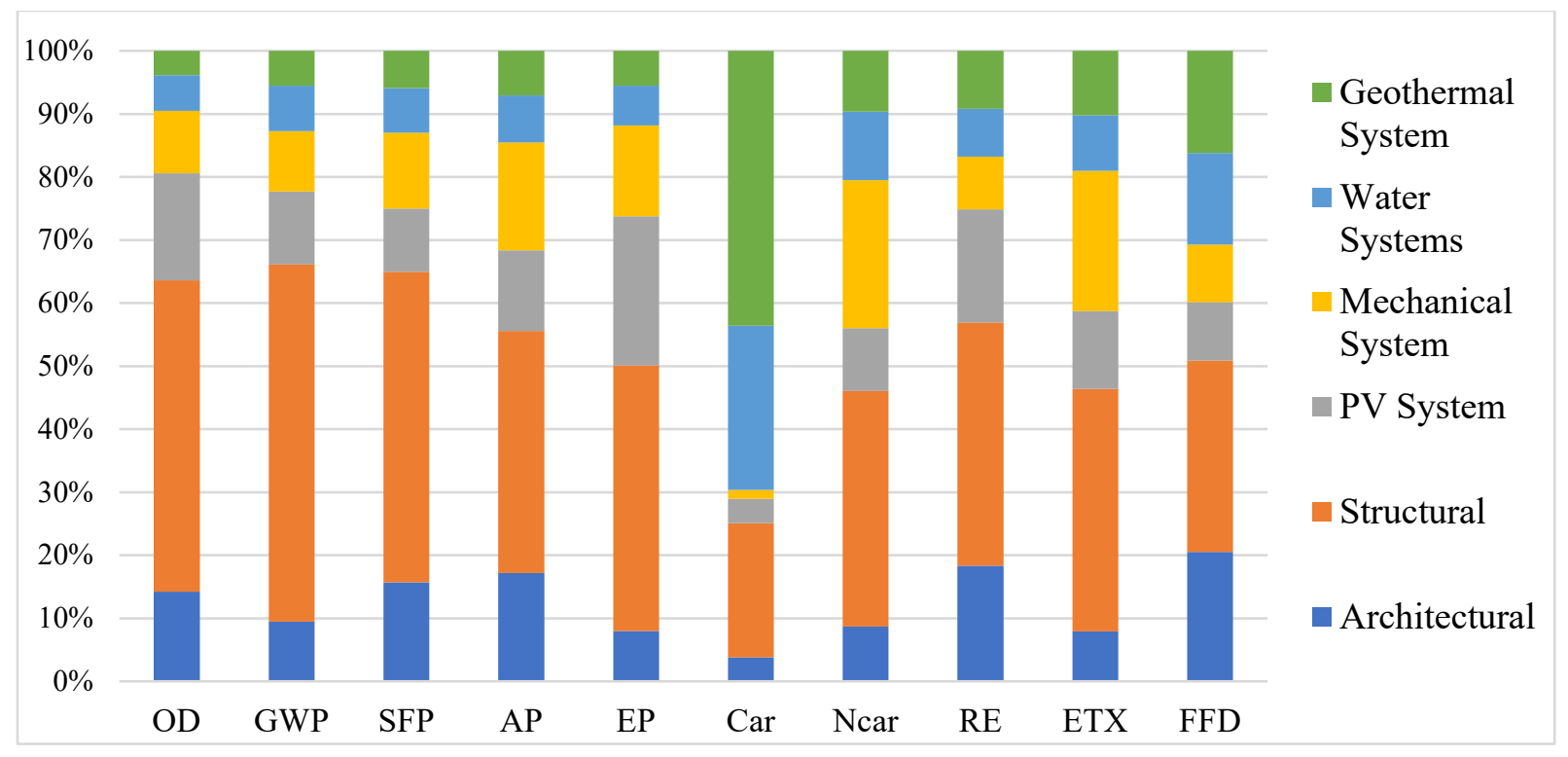

Figure 16. TRACI Impacts percentages from pre-use material impacts, per assembly.

Categories left to right are: Ozone Depletion (OD), Global Warming Potential (GWP), Smog Formation Potential (SFP), Acidification Potential (AP), Eutrophication Potential (EP), Carcinogens (Car), Non-Carcinogens (Ncar), Respiratory Effects (RE), Ecotoxicty (ETX), Fossil Fuel Depletion (FFD). 
The rest of the assemblies composed small to moderate percentages of each impact category. The MEP system sees higher contributions to non-carcinogens (23\%) and ecotoxicity $(22 \%)$ as a result of the sourcing and production impacts from the metals used in this assembly. Geothermal components contribute significantly to carcinogens (44\%), which is a result of the metals used in the hydronic piping network, namely chromium steel which has a higher contribution to carcinogens but is not on the Red List and therefore those impacts are not removed, creating a hotspot in the results. Although the architectural assembly has the most materials, it has smaller contributions to fossil fuel depletion (21\%), respiratory impacts (18\%), and acidification (17\%). The PV system only consists of the solar panels and their supporting structure, yet still contributes to eutrophication potential (24\%), respiratory impacts (18\%), and ozone depletion (17\%); the high EP impacts are due to the large volume of water required to manufacture the silicon for the photovoltaic panels. The only significant impact category for the water systems' materials is carcinogens (26\%) which is attributed to some complex filtration and pumping systems that contain a substantial amount of metal components.

\subsubsection{Material Replacement Impacts}

The distribution of replacement impacts is slightly different (see Figure 17); these results also include the Red List adjustments previously described. Because structural components do not require substantial replacements but only minimal maintenance of outdoor materials, other assemblies see an increase in significance. First, the architectural components are in general higher than in the material pre-use phase; this is because there are many components within this assembly (e.g., carpeting, windows, interior walls) and most of these elements have lifespans much shorter than 100 years, per their documentation, and therefore need to be replaced up to five times over 
the course of the building's life. Similarly, because the PV assembly also already has substantial pre-use impacts, it follows that its impact would be significant during the replacement phase as well; the lifespan of this assembly is 25 years, therefore over 100 years it would see three full replacements, assuming there are no additional replacements needed due to malfunctions or other reasons for panel degradation. The mechanical system contributes significantly to non-carcinogens $(56 \%)$ and ecotoxicity (55\%) as most of these elements require three replacements; these metal materials have high contributions to these specific TRACI categories because chemicals used to manufacture MEP products, especially chromium steel, have high carcinogenic impacts but are not on the Red List. Therefore, they remain in the inventory, resulting in this assembly dominating nearly each category that is otherwise diminished by Red List chemical removal. Lastly, the geothermal systems will only be replaced once, resulting in no increase in its impacts.

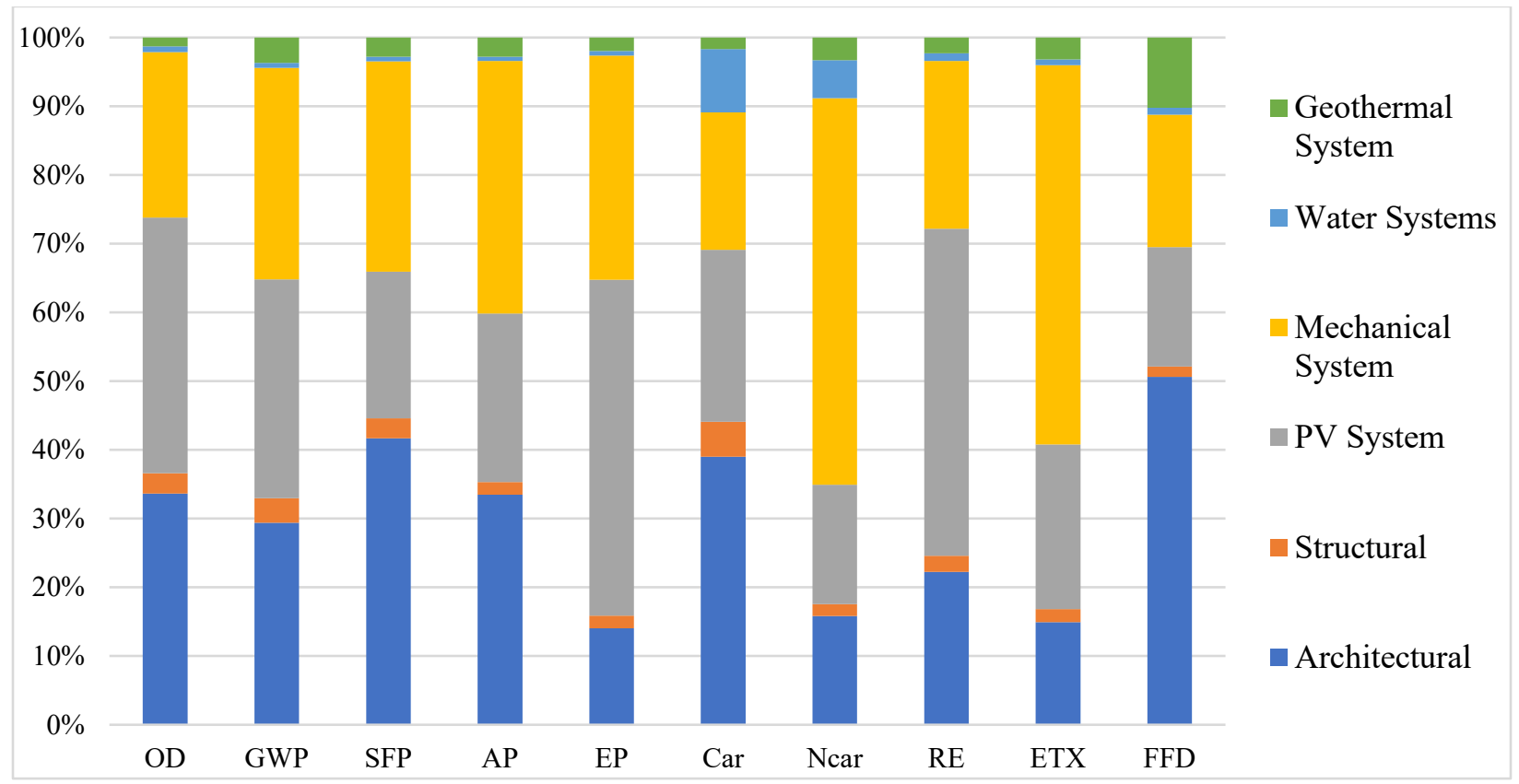

Figure 17. TRACI Impacts percentages from material replacements per assembly.

Categories left to right are: Ozone Depletion (OD), Global Warming Potential (GWP), Smog Formation Potential (SFP), Acidification Potential (AP), Eutrophication Potential (EP), Carcinogens (Car), Non-Carcinogens (Ncar), Respiratory Effects (RE), Ecotoxicty (ETX), Fossil Fuel Depletion (FFD). 


\subsubsection{Red List Free Impacts}

In order to demonstrate the potential impact that material selection has on overall environmental impacts, an in-depth materials LCA was performed; this evaluation focused on the material preuse stage and does not include replacement or use phase impacts. This assessment compares total material impacts for each assembly of two categories: Standard Material Adjustments and Red List Free. The former includes general information, such as recycled content and weight breakdown of each material, whereas the latter incorporates the extensive Red List adjustments discussed in Section 2.2.5 Green Material Considerations. These adjustments are reflected in all results, unless otherwise specified.

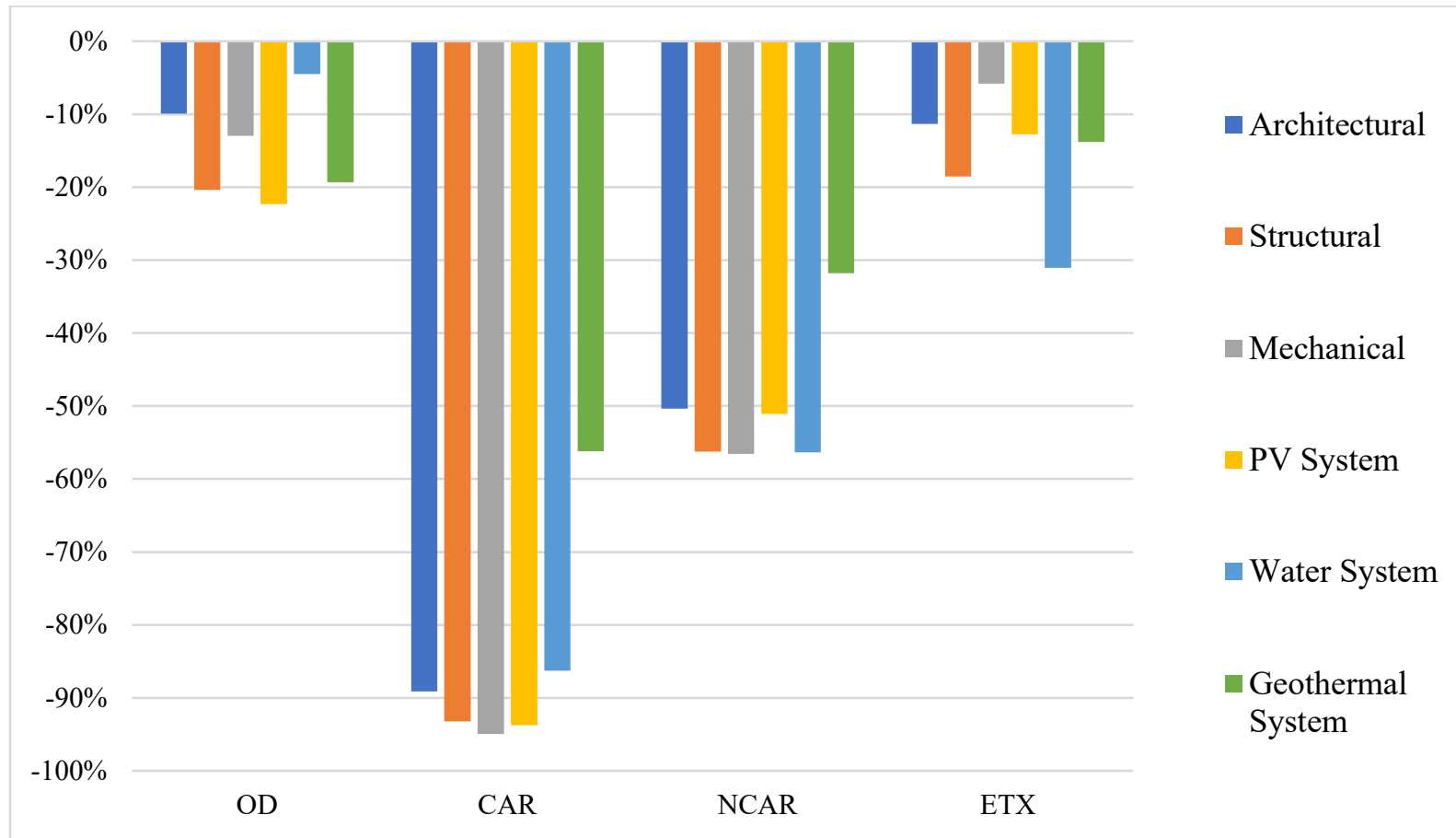

Figure 18. Overall percent change in material impacts per material assembly once Red List impacts were removed from standard material category indicator lists.

Categories left to right are: Ozone Depletion (OOD), Carcinogens (CAR), Non-Carcinogen (NCAR), and Ecotoxicty (ETX). Categories with $<1 \%$ change are not shown. 
As seen in Figure 18 there were substantial reductions in the overall impacts for each assembly in the life cycle impact categories: carcinogens, non-carcinogens, ecotoxicity, and ozone depletion. These reductions shown for each assembly were calculated by assessing the percent change in total impacts from Standard Material Adjustments to Red List Free. The overall average for all assemblies saw reductions in the life cycle impact categories carcinogens $(86 \%)$, noncarcinogens (47\%), ozone depletion $(16 \%)$, and ecotoxicity $(15 \%)$. These reductions primarily reflect the removal of upstream impacts of these building materials rather than the material use phase. The environmental impacts of extracting, processing, and manufacturing these materials (i.e. metals) are likely where the large carcinogenic impacts arise.

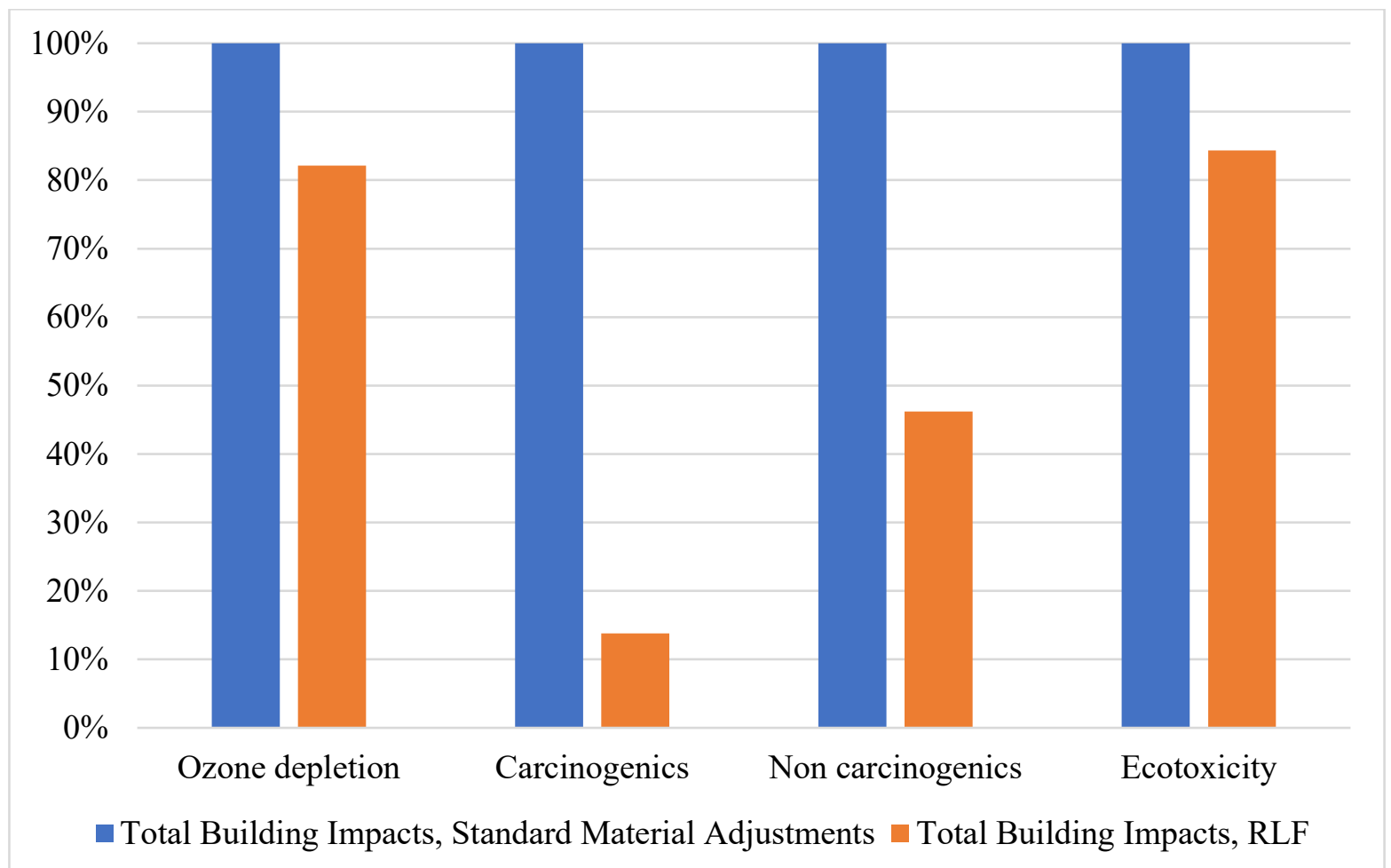

Figure 19. Normalized percent change in total material impacts from Standard Material Adjustments to Red List Free adjustments, by TRACI impact category.

Categories with $<1 \%$ change are not shown 


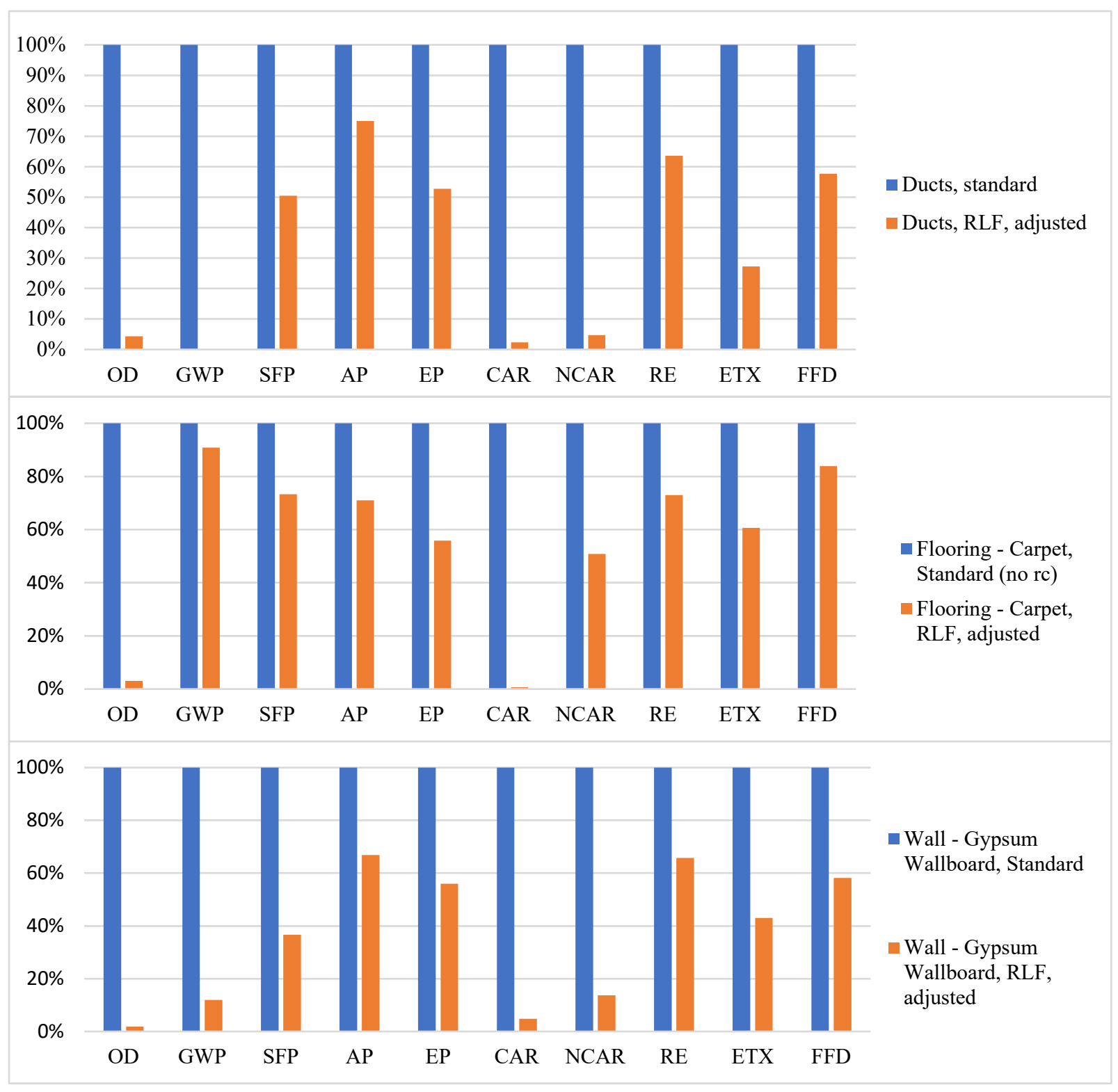

Figure 20. Comparison of percent changes in overall impacts from Standard to Red List Free materials for ductwork, flooring, and wallboards.

Categories left to right are: Ozone Depletion (OD), Global Warming Potential (GWP), Smog Formation Potential (SFP), Acidification Potential (AP), Eutrophication Potential (EP), Carcinogens (Car), Non-Carcinogens (NCAR), Respiratory Effects (RE), Ecotoxicty (ETX), Fossil Fuel Depletion (FFD).

Because the category indicators are subsequently multiplied by material quantities, they correspond to overall reductions in material impacts. Figure 18 shows this comprehensive change for each assembly by TRACI category; note that categories that saw less than a $1 \%$ change were 
not shown. Additionally, Figure 19 shows these total impacts normalized to the maximum for each TRACI category; the largest reduction overall was seen to the carcinogenic category, with the total impacts of the RLF materials totaling to only $14 \%$ of the standard material impacts.

There is not one material assembly that saw significantly greater reductions across the board for each life cycle impact category. Overall, however, the structural, PV, and water assemblies were affected the most by the removal of Red List chemicals. Structural components see large reductions because of the large quantity of these materials; any small decreases in the category indicators are therefore amplified.

Table 9. Example Red List Free product assessment via ecoinvent 3.4 database (ecoinvent, 2018).

\begin{tabular}{|c|c|c|c|}
\hline Material & Unit Process & $\begin{array}{l}\text { Unit } \\
\text { weight }\end{array}$ & $\begin{array}{l}\text { Recycled } \\
\text { content }\end{array}$ \\
\hline \multirow[t]{2}{*}{ Ducts, RLF } & Galvanized steel sheet, at plant/RNA & $1 \mathrm{lb}$ & -- \\
\hline & Rock wool $\{$ GLO $\} \mid$ market for $\mid$ Alloc Def, U & $1 \mathrm{lb}$ & -- \\
\hline \multirow[t]{2}{*}{ Ducts, standard } & Galvanized steel sheet, at plant/RNA & $1 \mathrm{lb}$ & -- \\
\hline & Glass fibre $\{\mathrm{GLO}\} \mid$ market for $\mid$ Alloc Def, $U$ & $1 \mathrm{lb}$ & -- \\
\hline \multirow[t]{2}{*}{ Carpet, RLF } & Nylon 6-6 \{GLO $\} \mid$ market for $\mid$ Alloc Def, $U$ & $0.2 \mathrm{lb}$ & $45 \%$ \\
\hline & Polypropylene, granulate $\{\mathrm{GLO}\} \mid$ market for $\mid$ Alloc Def, $U$ & $0.8 \mathrm{lb}$ & $99 \%$ \\
\hline \multirow[t]{2}{*}{ Carpet, standard } & Nylon 6-6 | market for $\mid$ Alloc Def, U & $0.2 \mathrm{lb}$ & -- \\
\hline & Polypropylene, granulate $\{\mathrm{GLO}\} \mid$ market for $\mid$ Alloc Def, U & $0.8 \mathrm{lb}$ & -- \\
\hline \multirow{2}{*}{ Wallboard, RLF } & $\begin{array}{l}\text { Gypsum wallboard product, regular, } 0.5 \text { inch } \\
(12.7 \mathrm{~mm}) / \mathrm{m} 2 / \mathrm{RNA}\end{array}$ & $0.41 \mathrm{~b}$ & -- \\
\hline & Rock wool $\{$ GLO $\} \mid$ market for $\mid$ Alloc Def, $U$ & $0.61 \mathrm{~b}$ & -- \\
\hline \multirow{3}{*}{ Wallboard, standard } & Gypsum wallboard product, regular, 0.5 inch & & \\
\hline & $(12.7 \mathrm{~mm}) / \mathrm{m} 2 / \mathrm{RNA}$ & $0.4 \mathrm{lb}$ & -- \\
\hline & Glass fibre $\{\mathrm{GLO}\} \mid$ market for $\mid$ Alloc Def, $U$ & $0.61 \mathrm{~b}$ & -- \\
\hline
\end{tabular}

To assess the impact of the removal of Red List chemicals with more detail, three specific building materials were evaluated: ducts, carpet, and wallboard. The information used for this assessment is in Table 9. First, there is no fiberglass used in any insulation applications in the FEC due to its high toxicity; instead, a biosoluble wool material is used in wall and duct insulation. Secondly, the carpet used has a Declare label and a high recycled content (ILFI, 2018). 
All Red List chemicals were then subtracted for materials labeled "RLF" and no adjustments were made to the "standard" products. As with the previous Red List assessment, carcinogens and non-carcinogens saw a decrease by $94 \%$ and $51 \%$ respectively on average for all assemblies. All categories saw a reduction (Figure 20). Displaying the results in this way shows how significant choosing the correct unit processes is, combined with how impactful removing all Red List chemicals is.

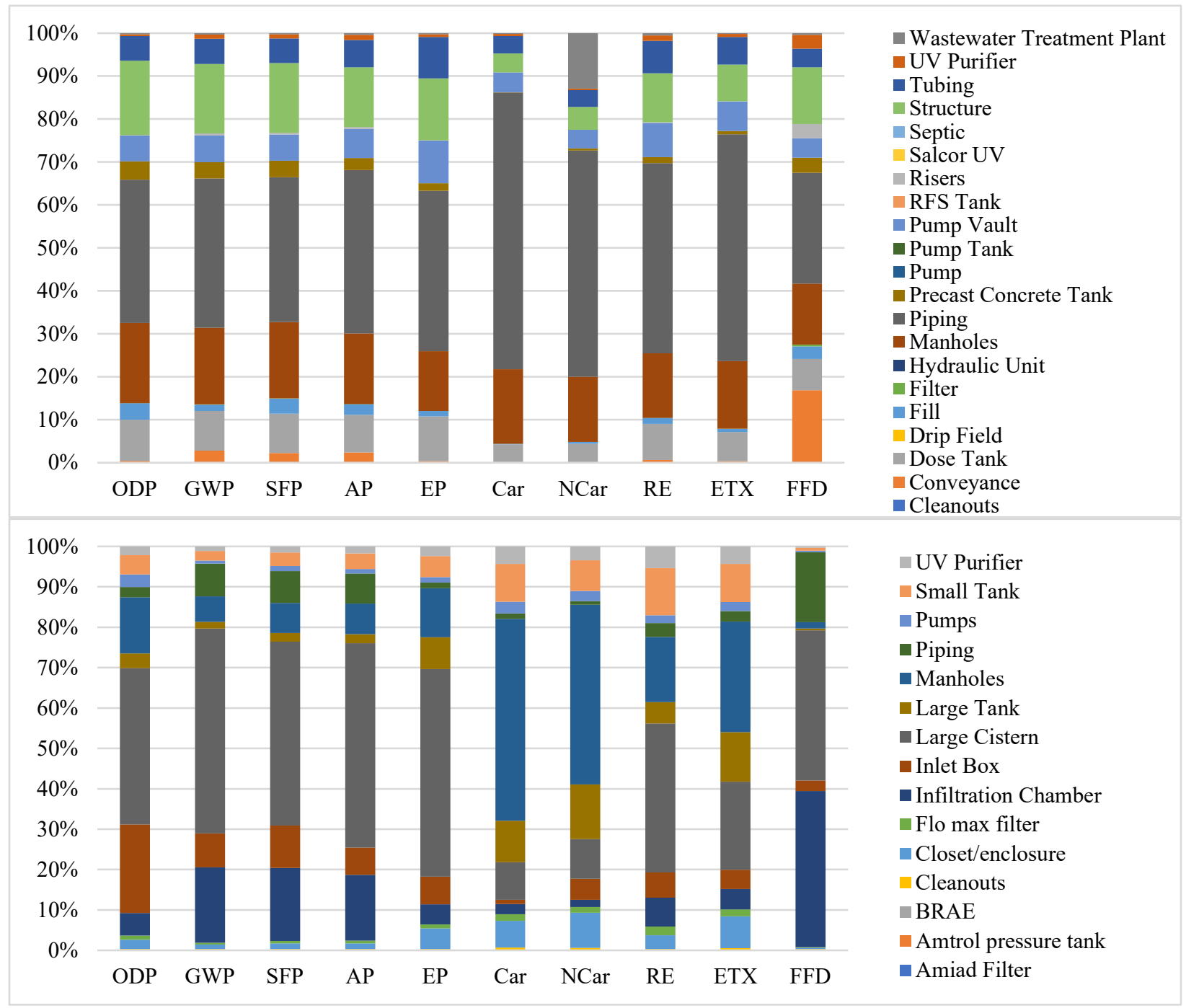

Figure 21. Pre-use phase material impacts for wastewater (top) and stormwater (bottom) systems.

Categories left to right are: Ozone Depletion (OD), Global Warming Potential (GWP), Smog Formation Potential (SFP), Acidification Potential (AP), Eutrophication Potential (EP), Carcinogens (Car), Non-Carcinogens (Ncar), Respiratory Effects (RE), Ecotoxicty (ETX), Fossil Fuel Depletion (FFD). 


\subsubsection{Water System Impacts and Comparison}

First, the pre-use and use phase impacts (see Figure 21) of the water systems are discussed. Then, a comparison between the water systems of the FEC and another living building in Pittsburgh, the Center for Sustainable Landscapes (CSL) is presented. Because a comprehensive LCA of the CSL's water system was previously performed, values from that assessment were adjusted when applicable to match the subsystems with the FEC's water system (Hasik et al., 2017).

Because minimal infrastructure is required for the potable system as the FEC ties into the municipal system per state and local requirements, there are minor material impacts for this system. Impacts related to the energy required to treat the water to potable standards are shown in the following charts as "Wastewater Treatment Plant;" the water is modeled in this way to account for off-site impacts of water treatment since water that is treated on-site to potable standards were not permitted to be used for potable purposes. These values are based on the volume of potable water demand for the FEC. The storm and wastewater systems, however, have nearly opposite dominating impacts for each life cycle impact category for the pre-use material stage. Stormwater has significant impacts to many categories as a result of the 15,000 gal cistern that is a part of this assembly; this cistern is constructed with reinforced plastic which contributes significantly to global warming, smog, acidification, ecotoxicity, and fossil fuel depletion due to the large

processing impacts of plastic. The larger impacts from the wastewater system materials are attributed to the fill required for the filtration tanks (sand and gravel), the concrete dose tank, and the HDPE piping network. For perspective, the stormwater and wastewater material impacts together account for $3 \%$ of total building material impacts. The detailed distribution of pre-use stage material impacts for storm and wastewater can be seen in Figure 21. 


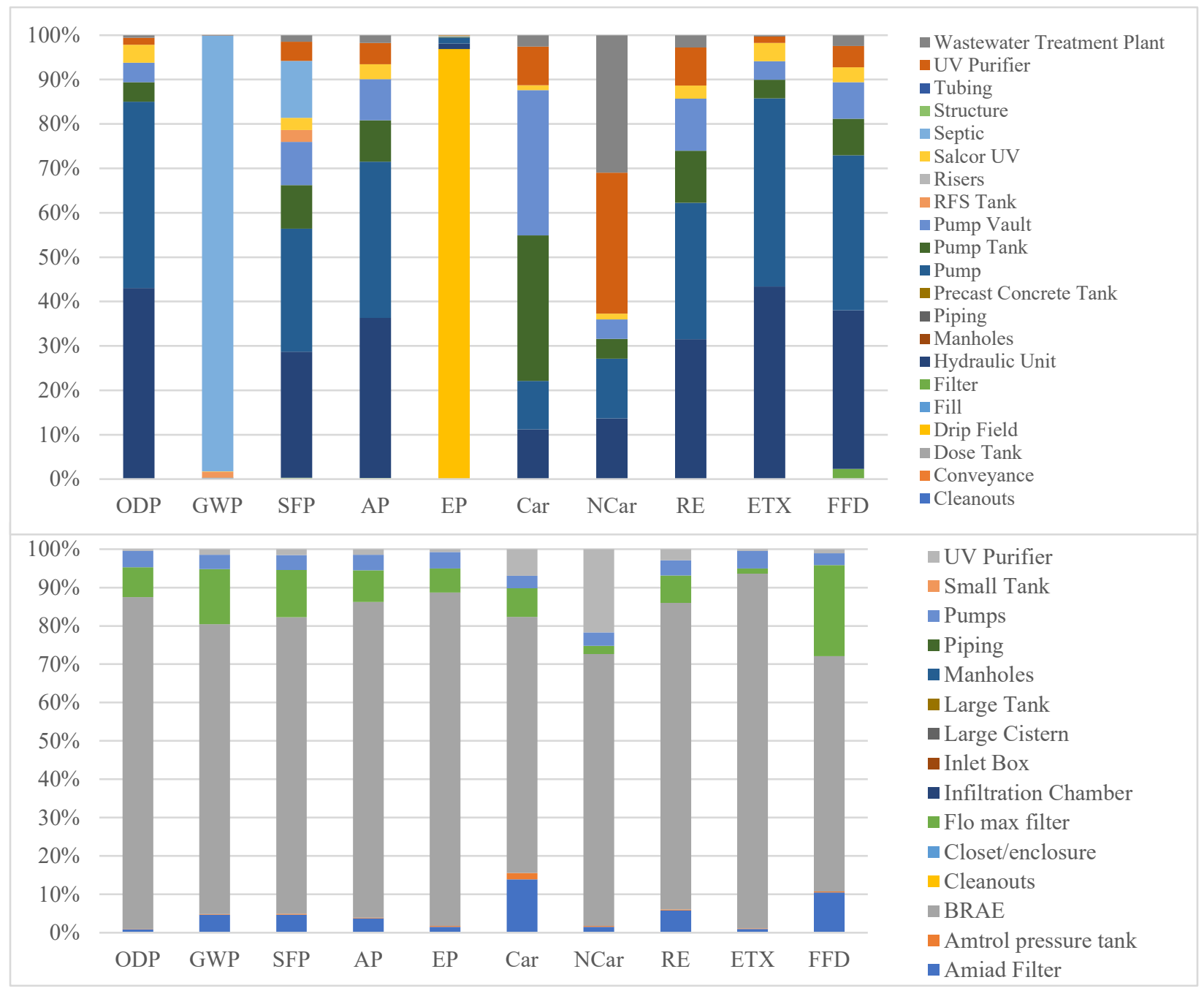

Figure 22. Use phase impacts (emissions, energy, material replacement) for wastewater (top) and stormwater (bottom) systems.

Categories left to right are: Ozone Depletion (OD), Global Warming Potential (GWP), Smog Formation Potential (SFP), Acidification Potential (AP), Eutrophication Potential (EP), Carcinogens (Car), Non-Carcinogens (Ncar), Respiratory Effects (RE), Ecotoxicty (ETX), Fossil Fuel Depletion (FFD).

The use phase for the water systems has a larger contribution to the overall building life cycle impacts. There are three primary hotspots within the use phase of the water systems that should be highlighted (see Figure 22). First, the emissions from the septic system account for 98\% of the wastewater GWP and a calculated $37 \%$ of the entire building life cycle's global warming potential. This is a significant contribution from a life cycle perspective and should be mitigated moving forward. Addressing this problem is explored later in this section. Second, the drip field 
contributes to $97 \%$ of the eutrophication potential (EP) for the entire wastewater system, and a calculated $14 \%$ of the whole building's life cycle EP. Because this drip field is located on the edge of a park, eutrophication is not a large concern since it is likely replenishing nutrients into a nearby ecosystem. Lastly, the BRAE water system dominates each category for the stormwater system's use phase; because this system runs continuously, it sees high use phase impacts compared to those from material replacements or pumps that require much less energy per day.

When the impacts from materials and their replacements are merged with energy and emissions impacts, the hotspot elements remain prevalent, namely the septic, drip field, and BRAE system impacts seen in Figure 23. The eutrophication impacts appear significant when only assessing the impacts of the water system because other components in this assembly do not have high eutrophication potential impacts; more so, the drip field does release nitrogen and phosphorous that is either taken up by soil or runs off into the local flora. These eutrophication impacts do not, however, show up on a life-cycle scale. However, the GWP of the septic system is a hotspot both in this system and from a life cycle perspective. Over the 100 -year life of the building, the emissions from the septic system were $725,000 \mathrm{~kg} \mathrm{CO} 2 \mathrm{eq}$, which is equivalent to the GHG emissions from 1.8 million passenger miles driven (USEPA, 2016b). These emissions are from methane as the septic system is not aerated, leading to anaerobic digestion and high methane emissions; these emissions are not captured in any way and therefore are released directly into the atmosphere. These results elucidate a simple intervention that the FEC could implement to dramatically reduce the building's life cycle impacts; if they aerate their system, as the CSL does, they could minimize these methane emissions. 


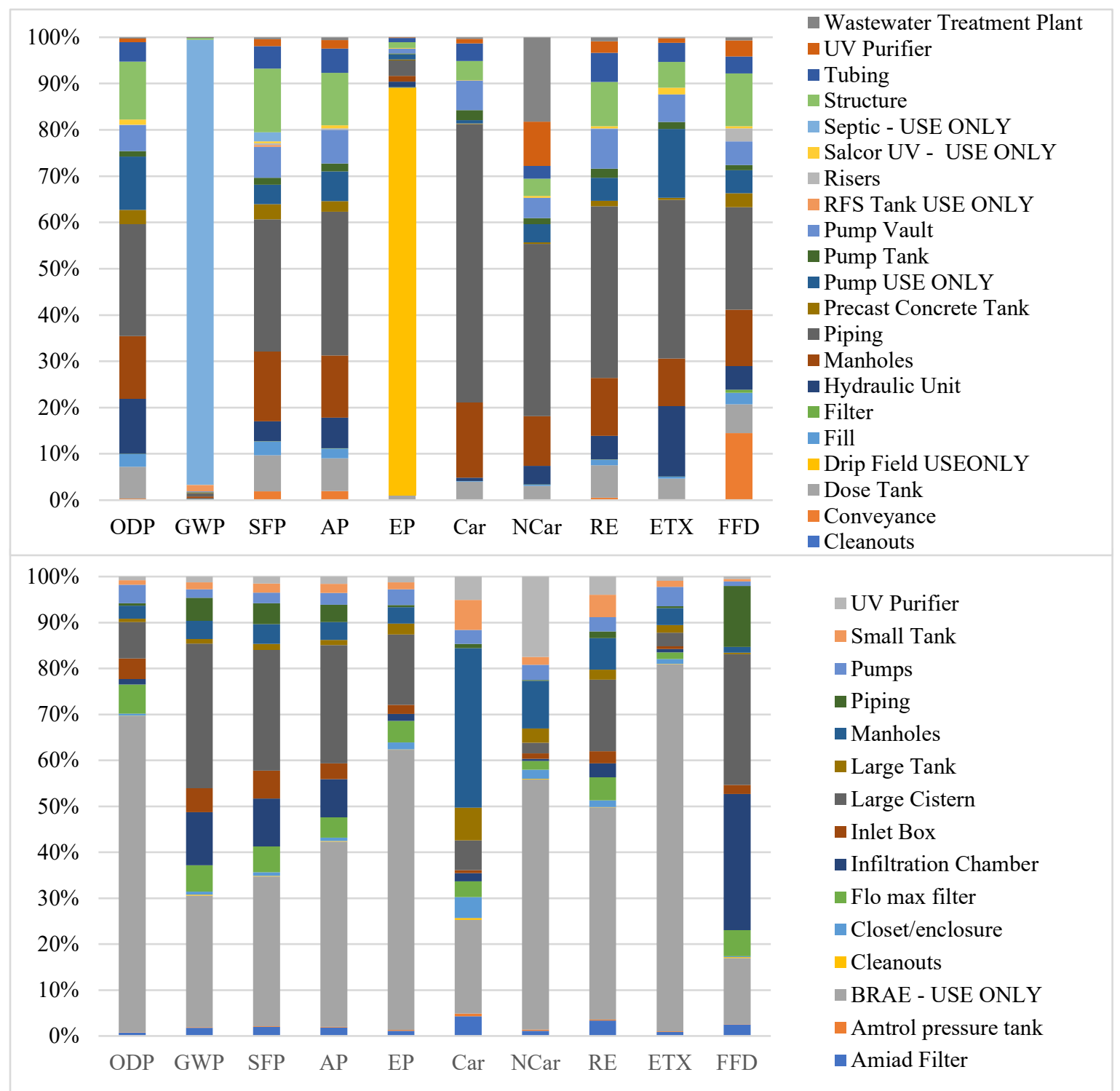

Figure 23. Combined pre-use and use phase impacts for wastewater (top) and stormwater (bottom).

Categories left to right are: Ozone Depletion (OD), Global Warming Potential (GWP), Smog Formation Potential (SFP), Acidification Potential (AP), Eutrophication Potential (EP), Carcinogens (Car), Non-Carcinogens (Ncar), Respiratory Effects (RE), Ecotoxicty (ETX), Fossil Fuel Depletion (FFD).

The comparison of each water system's overall impacts can be seen in Figure 24. The GWP impacts for the water system of the FEC is nearly five times that of the CSL. Normally with aerators there is debate regarding finding the balance between energy input into the aerator versus emissions out of the system; however, in this case, since the electricity that would be used to power the system is local PV electricity, as it is for the CSL as well, it would be an environmentally sound 
decision to invest in an aerator in order to reduce these methane emissions. In most other TRACI impact categories, FEC is either less than or on par with CSL impacts, besides the glaring impacts from these methane emissions. Additionally, the energy demand for the CSL is in fact higher than that of the FEC due to the aeration but powering this system with slightly more renewable electricity has large payoff when it comes to overall life cycle emissions.

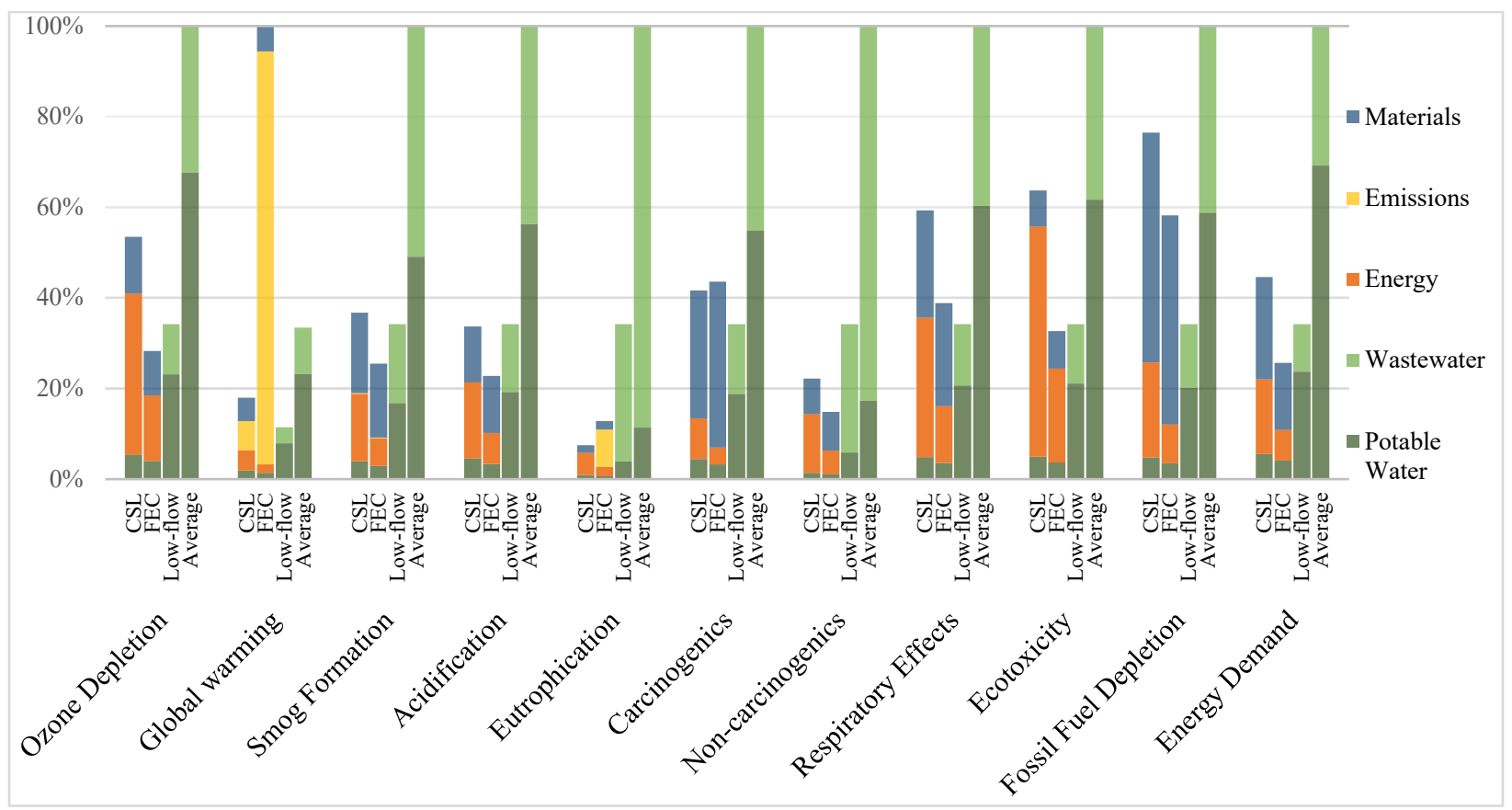

Figure 24. Life cycle impacts of wastewater systems of the CSL, FEC, a low flow, and average building.

Materials, emissions, energy, and water treatment included over 100 years per TRACI impact category (Hasik et al., 2017).

\subsubsection{Use Phase}

The use phase results of the building synthesize impacts from initial materials, building energy consumption, water system use, and material replacements. As a net-zero water and energy building, it has minimal impacts associated with the energy of the use phase. Therefore, as seen in 
Figure 25 shows that the impacts from the water system and material replacements are the only positive contributors to use phase impacts after year 1, whereas the building use energy is negative and therefore has offsetting impacts; specifically, an estimated 43,600 kWh are input to the grid by the FEC on an annual basis. Based off the grid mix of the Pittsburgh region, the electricity is equivalent to $7,700 \mathrm{~kg} \mathrm{CO}_{2}$ eq offset annually.

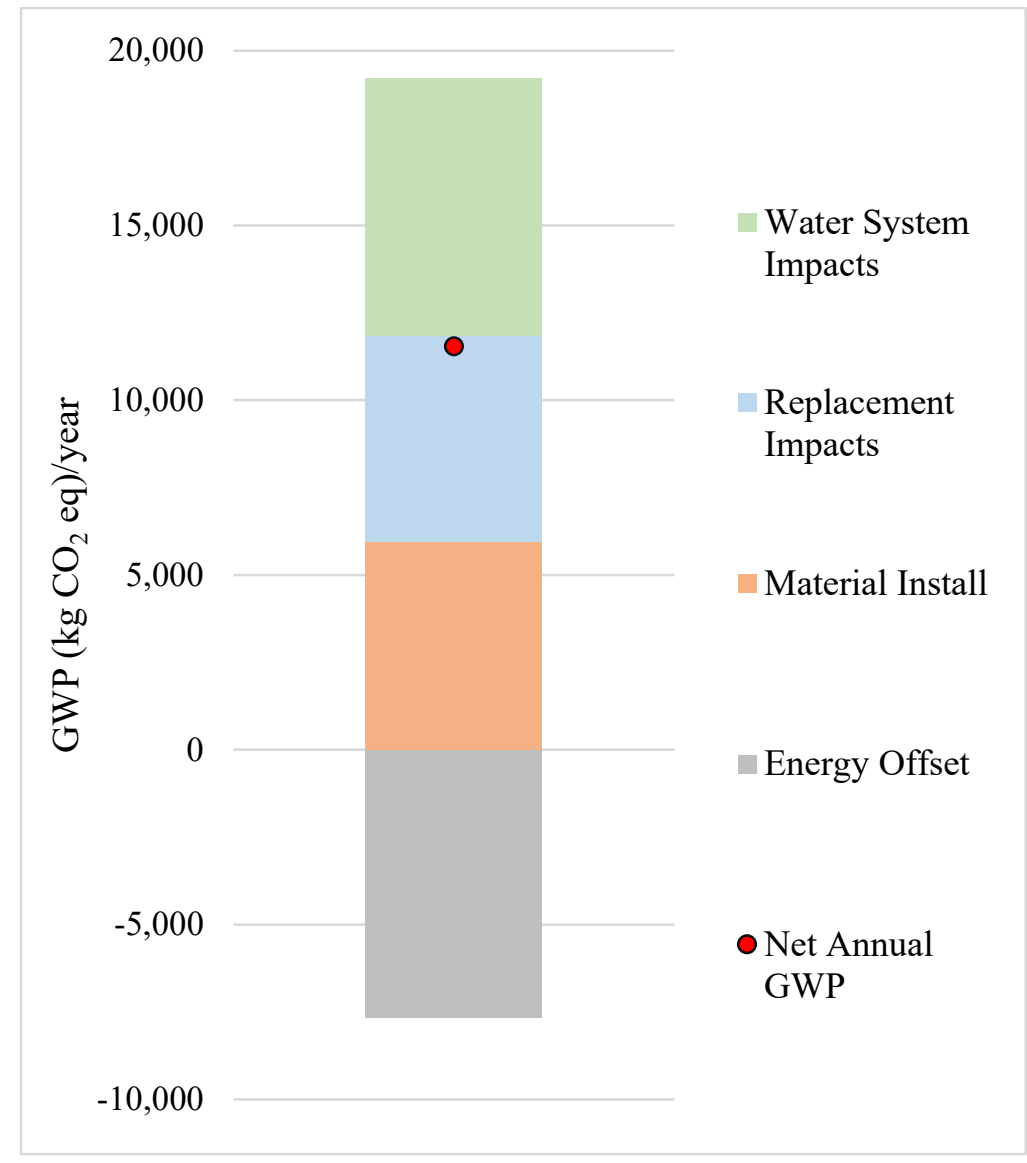

Figure 25. Annual average GWP ( $\left.\mathrm{kg} \mathrm{CO}_{2} \mathrm{eq}\right)$ of the impacts for materials pre-use and use, water systems, and energy offsets. GWP was totaled for the 100-year lifespan then averaged per year.

Figure 25 also highlights, however, that the average annual net GWP is positive $(11,500 \mathrm{~kg}$ $\left.\mathrm{CO}_{2} \mathrm{eq}\right)$; this average was calculated by totaling the life-cycle impacts for each category and dividing by the assumed lifespan of 100 years. It is evident that the life-cycle impacts will never 
reach zero but rather increases every year, meaning the building can never attain net-zero carbon over its life unless more offsets are implemented. The septic system emits $7,400 \mathrm{~kg} \mathrm{CO}$ eq per year which is almost equally offset by the electricity $(-7,700 \mathrm{~kg} \mathrm{CO}$ eq per year); therefore, if the septic emissions were significantly reduced, a net-zero carbon profile would to be attainable as the electricity sent back into the grid would be reallocated to offsetting material replacement impacts. These impacts are disaggregated annually over the building's 100-year life in Figure 30.

Table 10. Tabulated Scenarios 1-8 and their frame type and waste stream per material.

\begin{tabular}{|c|c|c|c|c|}
\hline Scenario No. & $\begin{array}{c}\text { Frame } \\
\text { Type }\end{array}$ & $\begin{array}{l}\text { Steel Waste } \\
\text { Stream }\end{array}$ & Concrete Waste Stream & Lumber Waste Stream \\
\hline Scenario 1 & Steel & $\begin{array}{l}100 \% \\
\text { Recycled }\end{array}$ & $\begin{array}{l}\text { Increasing recycling with } \\
\text { decreasing landfilling }\end{array}$ & $\mathrm{N} / \mathrm{A}$ \\
\hline Scenario 2 & Lumber & $\mathrm{N} / \mathrm{A}$ & $\begin{array}{l}\text { Increased recycling with } \\
\text { decreased landfilling }\end{array}$ & $\begin{array}{l}100 \% \text { Landfilled (no LFG } \\
\text { capture) }\end{array}$ \\
\hline Scenario 3 & Lumber & $\mathrm{N} / \mathrm{A}$ & $100 \%$ Landfilled & \\
\hline Scenario 4 & Lumber & N/A & $100 \%$ Recycled & $\begin{array}{l}\text { Increased reuse with decreasing } \\
\text { landfilling (no LFG capture) }\end{array}$ \\
\hline Scenario 5 & Lumber & $\mathrm{N} / \mathrm{A}$ & $100 \%$ Landfilled & \\
\hline Scenario 6 & Lumber & $\mathrm{N} / \mathrm{A}$ & $100 \%$ Recycled & $\begin{array}{l}\text { Increased combustion for } \\
\text { energy recovery with } \\
\text { decreasing landfilling (no LFG } \\
\text { capture) }\end{array}$ \\
\hline Scenario 7 & Lumber & $\mathrm{N} / \mathrm{A}$ & $100 \%$ Landfilled & $\begin{array}{l}\text { Increased LFG capture with } \\
\text { decreasing combustion for } \\
\text { energy recovery }\end{array}$ \\
\hline Scenario 8 & Lumber & $\mathrm{N} / \mathrm{A}$ & $100 \%$ Recycled & $\begin{array}{l}\text { Increased LFG capture with } \\
\text { decreasing landfilling }\end{array}$ \\
\hline
\end{tabular}




\subsubsection{End-of-life}

Using emissions factors from EPA's WARM for each disposal scenario, overall EOL impacts could be calculated for each material for the two types of model scenarios, steel and lumber, using these emissions factors for each disposal scenario presented previously in Table 6; all scenarios analyzed are tabulated in Table 10. The system boundaries for concrete and lumber can be seen in Figure 14 and Figure 15, respectively. For steel, only one scenario assessment was needed to analyze the EOL impacts, namely the amount of concrete recycled from the foundations. Steel has high recycling rates (around 90\%) so modeling the impacts of this material was straightforward. The waste stream options for concrete are recycling or landfilling as discussed previously; therefore, the independent variable for Scenario 1 was the percent concrete recycled, as seen in Figure 26. In Scenario 1, the percent of concrete recycled has a significant effect on the overall EOL impacts. An increase from $0 \%$ to $100 \%$ concrete recycled results in a shift from 13,000 to $-11,400 \mathrm{~kg} \mathrm{CO}_{2}$ eq, or a $-24,500 \mathrm{~kg} \mathrm{CO}_{2}$ eq shift in GWP. Therefore, it is critical that concrete debris enters the recycle stream instead of the waste stream. Similarly, Scenario 2 shows the large negative impacts of lumber landfilling and demonstrates how an increase in concrete recycling can further increase these offsets for the lumber framed model, which are the potential scenarios for concrete for both the steel and lumber framed models. 

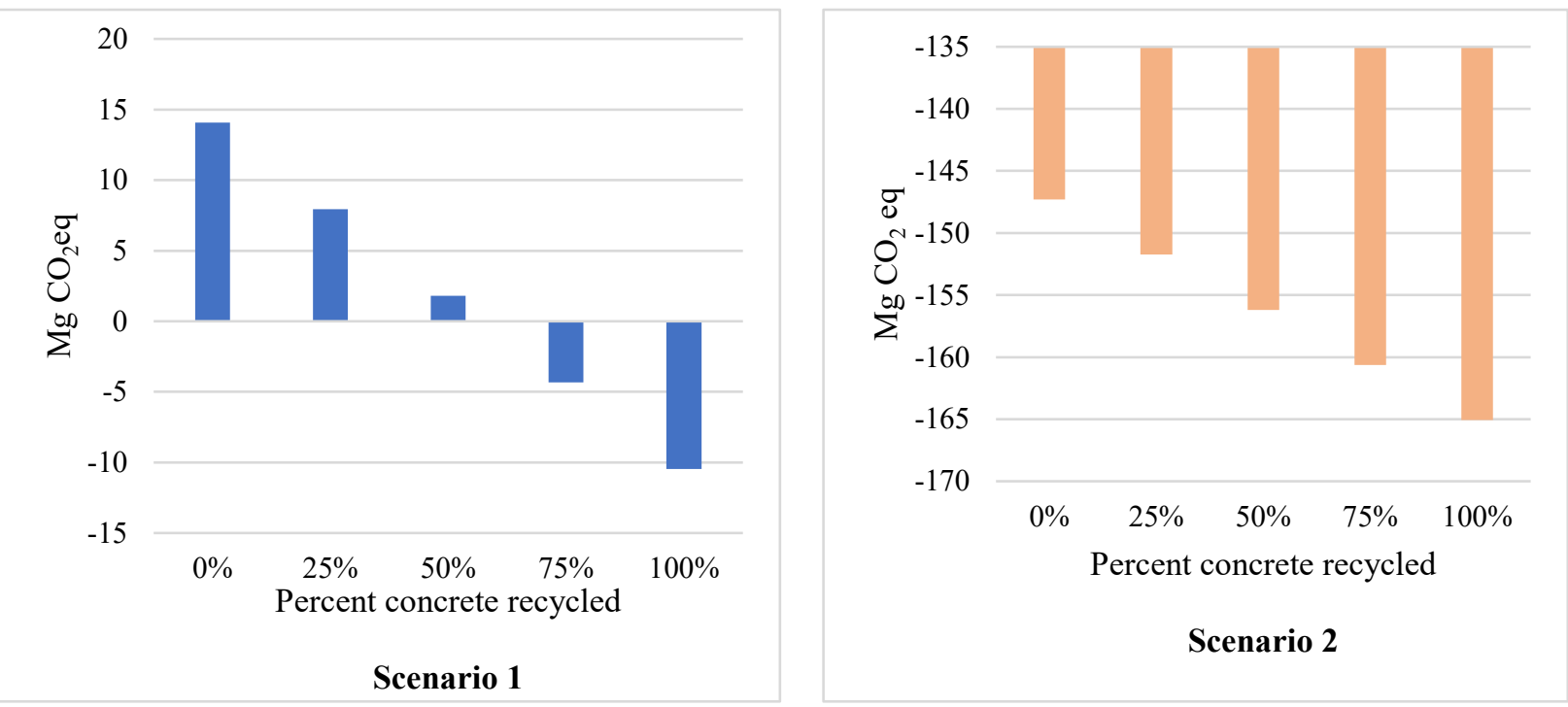

Figure 26. Total $\mathrm{Mg} \mathrm{CO}_{2} \mathrm{eq}$ for EOL impacts of increasing concrete recycle rate for steel and lumber model.

Scenario 1: Steel framed, increasing concrete recycling with decreasing concrete landfilling. Steel has constant recycling rate of $100 \%$.

Scenario 2: Lumber framed, increasing concrete recycling with decreasing concrete landfilling. Lumber constant landfill rate of $100 \%$ (no LFG capture).

With results shown in Figure 27, it can be seen that lumber has a multitude of waste stream pathways shown in Scenarios 3 - 8. Because these scenarios assess the lumber model, only lumber and concrete waste pathways were addressed as no structural steel is present in this simplified assessment. The four waste options for lumber (recycling, landfilling with LFG capture, landfill with no LFG capture, and combustion for energy recovery) are shown with concrete being either recycled or landfilled for each lumber EOL pathway.

Scenarios 3 and 4 assess an incremental increase in lumber recycling as landfilling decreases; because the EPA WARM offset factor for lumber recycling is nearly four times that of landfilling, it follows that the total offset from these two scenarios would be the largest, as seen in Figure 27. Recycling lumber avoids the introduction of virgin wood which prevents a plethora of negative environmental impacts, including deforestation along with all the energy, water, and other 
resources that is required to manufacture the lumber. Although slight, it should be noted that the total impacts for Scenario 4 are greater than Scenario 3 because the concrete is not being recycled.

Conversely, Scenarios 5 and 6 actually saw an increase in impacts as more lumber was combusted versus landfilled. Because all carbon released during both landfilling and combustion is considered biogenic in WARM, these differences are not a result of life cycle carbon accounting; however, carbon stored in landfills is accounted for as negative. The primary offsets from combustion are a function of the avoided utility emissions; the offset from landfilling, however, is a result of carbon uptake by the wood product itself. Due to the high carbon content of lumber, this uptake is larger than the avoided utility emissions. Therefore, an increase in combusted lumber while decreasing landfilled lumber results in lower EOL offsets.

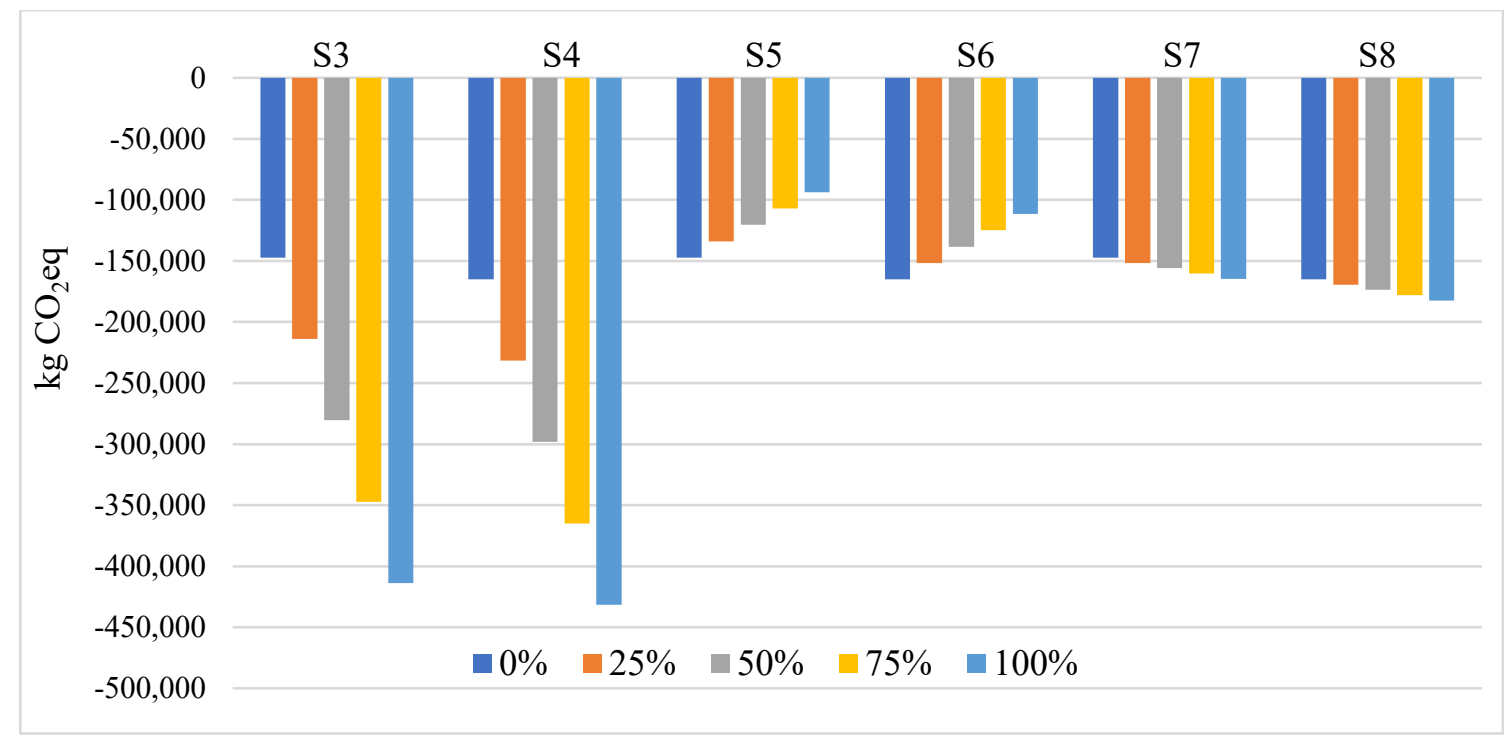

Figure 27. Total $\mathrm{kg} \mathrm{CO}_{2} \mathrm{eq}$ for EOL impacts for waste scenario options for lumber frame.

Scenario 3: Concrete fully landfilled, increasing percentage lumber recycled with decreasing landfilling Scenario 4: Concrete fully landfilled, increasing percentage lumber recycled with decreasing landfilling Scenario 5: Concrete fully landfilled, increasing percentage lumber combusted for energy recovery with decreasing landfilling

Scenario 6: Concrete fully landfilled, increasing percentage lumber combusted for energy recovery with decreasing landfilling

Scenario 7: Concrete fully landfilled, lumber landfilled, increasing LFG capture

Scenario 8: Concrete fully recycled, lumber landfilled, increasing LFG capture 
Lastly, Scenarios 7 and 8 compare landfills that capture LFG to use for electricity to those that do not, as seen in Figure 27. Because the WARM factors for these two types of landfills are not drastically different, seen in Table 8, the results in only slightly increasing offsets for no LFG capture. As expected, as the percentage of lumber that goes to a landfill that captures LFG increases, there is an increase in offset emissions; this is due to the avoided electricity emissions from the combustion of the captured LFG. Because the large carbon storage dominates this disposal option (landfilling), these emissions do not vary greatly. Again, the slightly lower values in Scenario 8 are due to the recycling of concrete as opposed to landfilling.

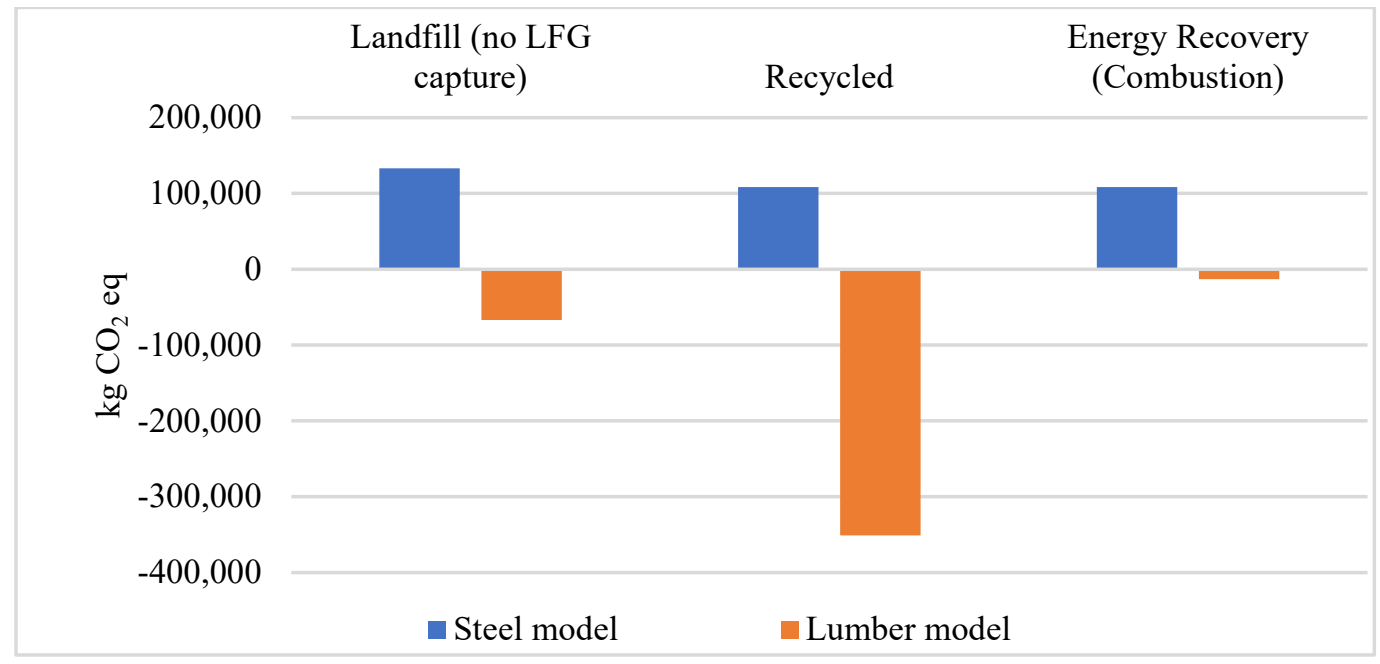

Figure 28. Comparison of GWP life cycle (pre-use, use, and EOL) impacts for three primary disposal options for steel and wood framed model.

Landfill denotes all of the concrete and wood waste being landfilled, steel remains recycled. Recycled denotes all concrete, steel, and wood waste is recycled. Energy recovery denotes all lumber is combusted for electricity, steel and concrete are fully recycled. The pre-use and use impacts are not affected by the waste scenario.

When the entire life cycle of each option was taken into consideration, the lumber model saw lower impacts that varied depending on the disposal scenario (see Figure 28). This is mostly due to lumber having a lower GWP than steel and concrete (see Table 6) which makes pre-use and use phase impacts significantly lower for lumber. Although recycling steel does result in a decrease 
in $24,000 \mathrm{~kg} \mathrm{CO}$ eq, the high pre-use and use phase impacts still result in large net EOL GWP for the steel framed model. Due to all the reasons previously discussed, lumber sees the largest negative impacts when the entire waste stream is recycled; the two other options also result in negative impacts, albeit much less. The landfilling option for the lumber frame is slightly positive as a result of the high concrete pre-use impacts offset by the carbon storage in the landfill. Similarly, the life cycle impacts are low for energy recovery because the offsets from this disposal option are slightly lower than that of landfill, resulting in concrete pre-use impacts becoming more significant, relatively.

Although previous studies found EOL impacts to account for a small percentage due to high use phases, the FEC still sees minor impacts from the EOL stage as a result of significant material and septic system impacts. If the steel and concrete that composes the steel model are both fully landfilled, which is unlikely due to steel's high recycled rate, these impacts would only account for $1 \%$ of the building's total GWP. Therefore, there should be a shift from a focus on the EOL negative impacts to rather the potential offsets a material can have. This is not to say that wood structural design is the full solution, but rather the waste streams of buildings should no longer be seen as waste but as valuable resources.

\subsubsection{Holistic LCA Impacts}

Renewable energy technologies are an interesting study because of their up-front investments of money, resources, and time. Another way renewable energy options should be assessed is by their environmental payback profiles, meaning how long it takes for the resources invested to be outweighed by offsetting fossil fuel impacts. This assessment was performed for the PV assembly at the FEC. 
Figure 29 shows the sum of annual energy offsets modeled off of the local grid mix and the material impacts that occur four times over the lifespan of the building, one installation and three replacements. The net total GWP of the PV was $-490,000 \mathrm{~kg} \mathrm{CO} 2 \mathrm{eq}$, which is equivalent to the annual electricity of 85 homes (USEPA, 2016b). Also, it should be noted that it only takes 10 years for the material impacts to be negated by the offset energy impacts; from then on, all net impacts are negative.

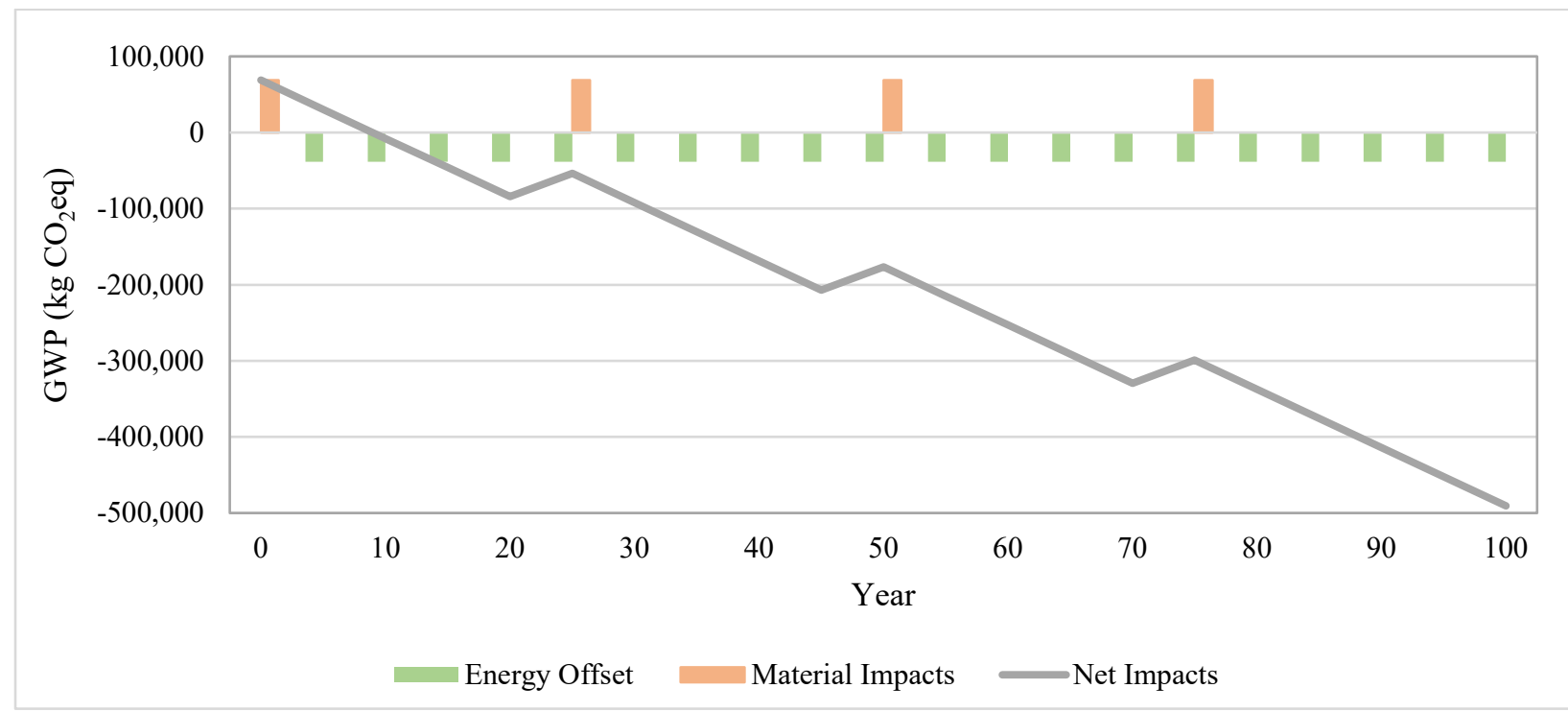

Figure 29. PV system GWP (kg CO $2 \mathrm{eq}$ ) over the lifespan of the building, summing energy offsets and material impacts.

Incorporating the material pre-use and use phases illustrates a different context. The specific replacements for each assembly were plotted over the 100-year lifespan of the structure, with continual contributions from architectural materials and with the constant negative from the offset electricity, seen in Figure 30. It can be seen that the embodied $\mathrm{CO}_{2} \mathrm{eq}$ in the materials outweighs any offsets seen via the PV panel electricity generation. If there were minimal septic emissions, the annual GWP would be negative via the electricity offsets unless there is a substantial material replacement; however, when the septic emissions are included the electricity can only 
offset these emissions, resulting in a positive net GWP each year. This brings up the ongoing discussion of how buildings truly achieve "net-zero" status from a life cycle perspective. Based on this assessment, the FEC is not a net-zero carbon building despite the significant number of sustainable features it implements. It also suggests a discussion on when energy offsets should be purchased over the lifespan of a building. Generally, they are one-time purchases near the beginning of a building's life. However, as impacts grow due to material replacements, it could be argued that recurring offsets should be purchased to allow a building to be truly "net-zero."

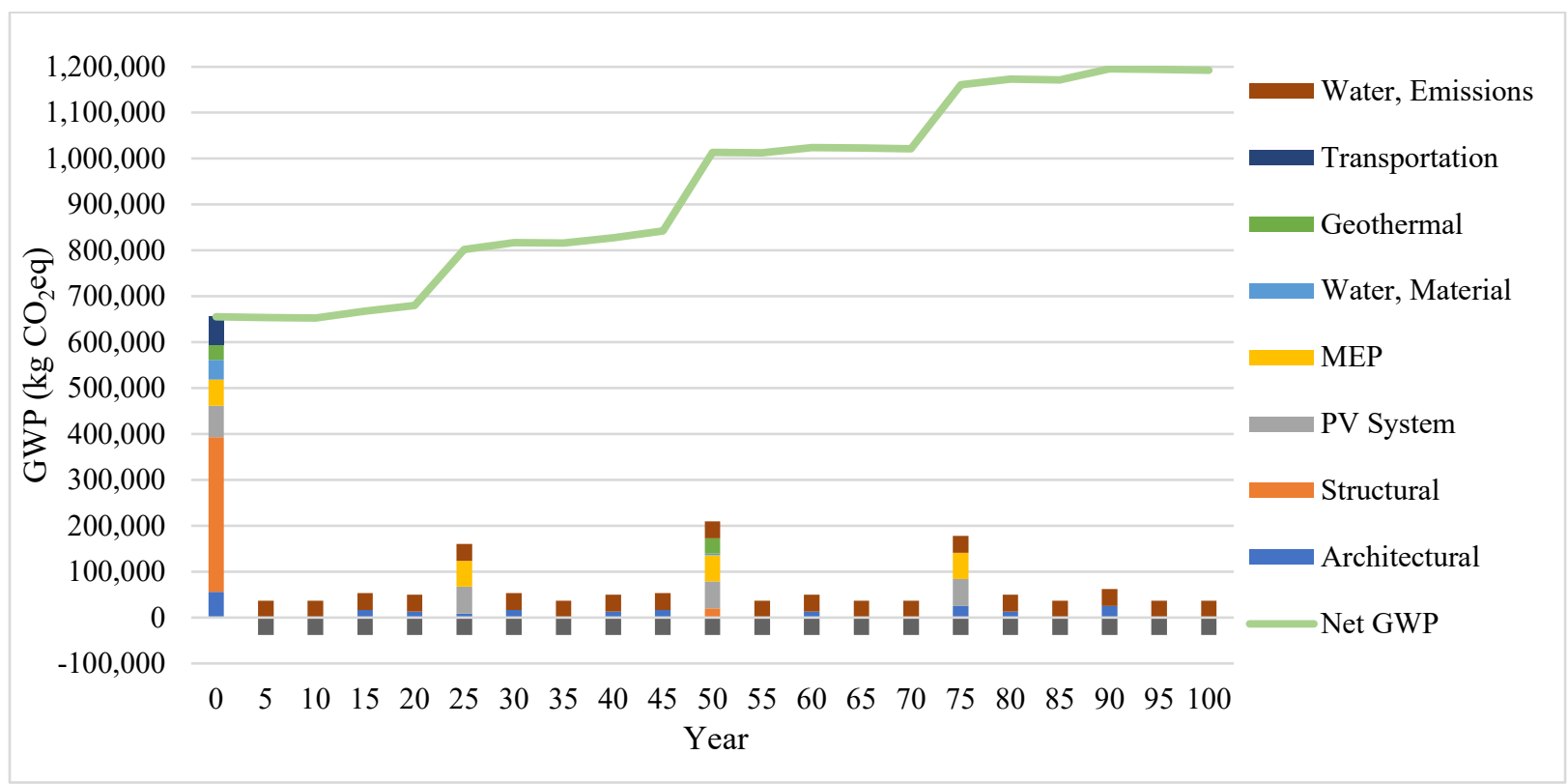

Figure 30. Cumulative GWP of material impacts (pre-use and use) and energy offsets over building lifespan with water system and transportation emissions.

The inclusion of the pre-use, transportation to site, and use phases of materials, along with the energy and emissions from the water system can be seen plotted in Figure 31 in the overall life cycle impacts. Despite their high embodied impacts, structural materials no longer dominate each life cycle impact assessment category; as discussed previously, MEP sees high replacement impacts and this assembly therefore dominates most categories. The carcinogen impacts (28\%) 
from the geothermal system are still prevalent even though this assembly sees minor replacements. Also, the transportation impacts from structural materials only see significant contributions to ozone depletion (16\%), which is attributed to the trucks' consumption of diesel fuel. The methane emissions from the water system can be seen in the GWP impacts, accounting for $41 \%$ of this category. Finally, the increases in architectural material impacts are a result of their multiple replacements over the lifespan of the structure.

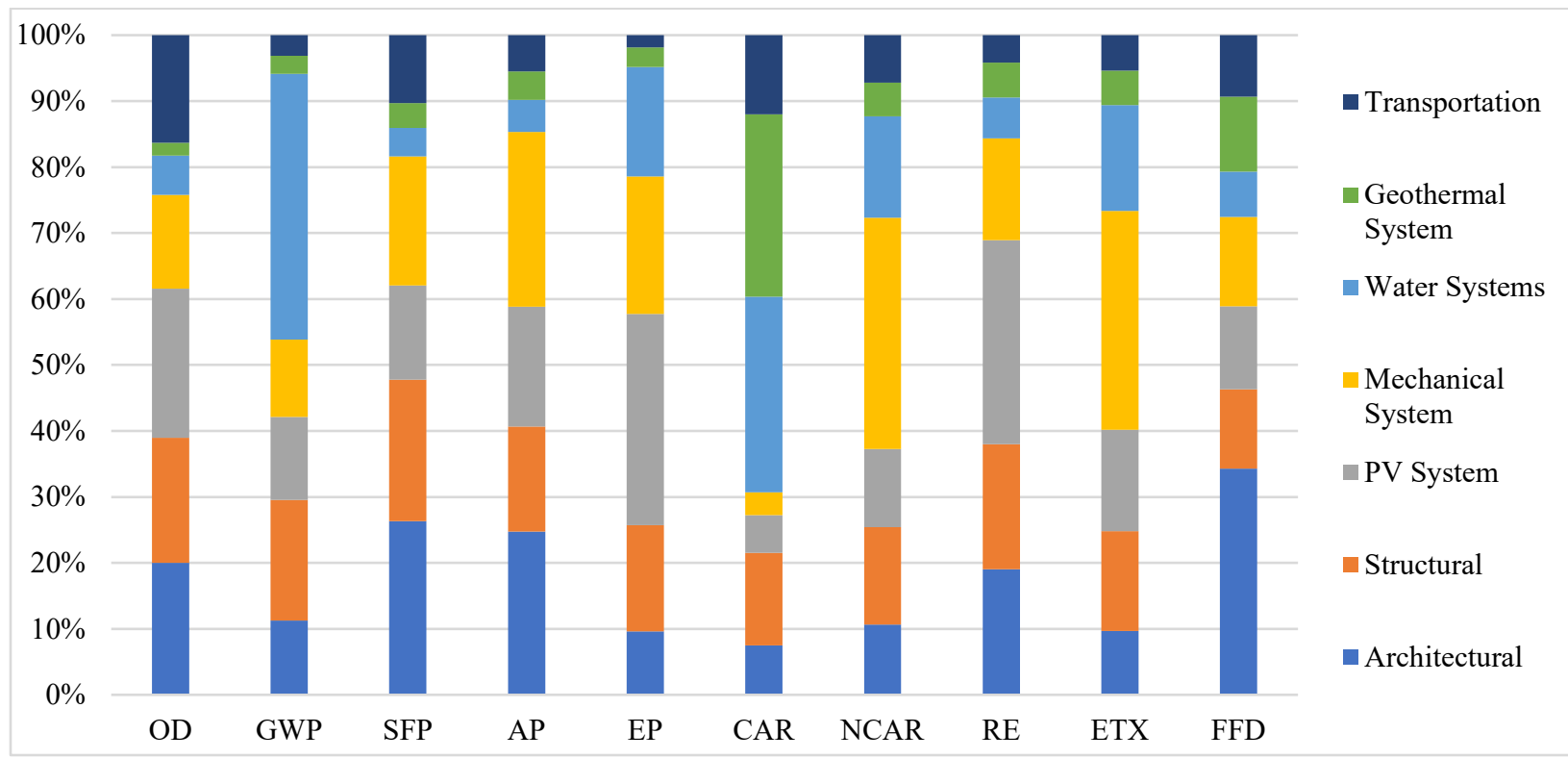

Figure 31. Percent per TRACI category for lifecycle impacts (pre-use, transportation, and use) per assembly.

Categories left to right are: Ozone Depletion (OD), Global Warming Potential (GWP), Smog Formation Potential (SFP), Acidification Potential (AP), Eutrophication Potential (EP), Carcinogens (Car), Non-Carcinogens (Ncar), Respiratory Effects (RE), Ecotoxicty (ETX), Fossil Fuel Depletion (FFD).

When the total global warming potential impacts are shown per assembly over the 100year lifespan of the building, it is clear that the FEC is not net zero carbon over its life, as seen in Figure 32. The electricity fed back into the grid only offsets $37 \%$ of the total GWP emissions of the building. If the emissions from the water system were minimized or eliminated, the PV electricity generated on-site could offset up to $57 \%$ of the buildings life cycle carbon. In order to 
achieve a net-zero carbon profile, the FEC would need to offset the equivalent of $11,500 \mathrm{~kg} \mathrm{CO}_{2} \mathrm{eq}$ per year, which using the local electricity profile would equate to sending $66,000 \mathrm{kWh}$ back into the grid; this is to say the FEC would need to increase its annual electricity production by $30 \%$. It is therefore recommended that the embodied GWP and septic emissions be mitigated before the electricity generated on-site is increased so substantially. Second to the water system emissions is the GWP of structural materials. As discussed in the EOL assessment, the selection of these materials is critical; many decisions made during the design and planning phase drastically affect the life cycle impacts and should be done after all options are evaluated.

The GWP impacts for each life cycle stage are plotted in Figure 33 to place each stage's impacts into perspective. Impacts from the use phase of materials (replacements) are nearly equal those of the pre-use (install) stage; this is reasonable because many assemblies see 2-5 replacements over the building's lifespan thus negating the absence of replacement impacts for structural materials, which have the highest pre-use impacts. Transportation emissions are minor on a life cycle scale, accounting for only $8 \%$ of overall GWP. The emissions from the water system are the largest on this scale and are almost entirely offset by 100 -year electricity offsets. The EOL impacts, however, are minimal accounting for only $0.1 \%$ of the building's life cycle GWP. This is attributed to the negative impacts from steel recycling $\left(-2,300 \mathrm{~kg} \mathrm{CO} \mathrm{CO}_{2}\right)$, combined with minor concrete impacts when the waste stream scenario is modeled at $50 \%$ recycled $\left(4,100 \mathrm{~kg} \mathrm{CO}_{2} \mathrm{eq}\right)$. Concrete landfilling only emits $0.01 \mathrm{~kg} \mathrm{CO} \mathrm{CO}_{2}$ eq per pound and recycling prevents $0.005 \mathrm{~kg} \mathrm{CO}_{2} \mathrm{eq}$ per pound, whereas production releases $0.07 \mathrm{~kg} \mathrm{CO}_{2}$ eq per pound; it follows that when half of the concrete is recycled the EOL impacts are significantly lower than those of the pre-use stage. 


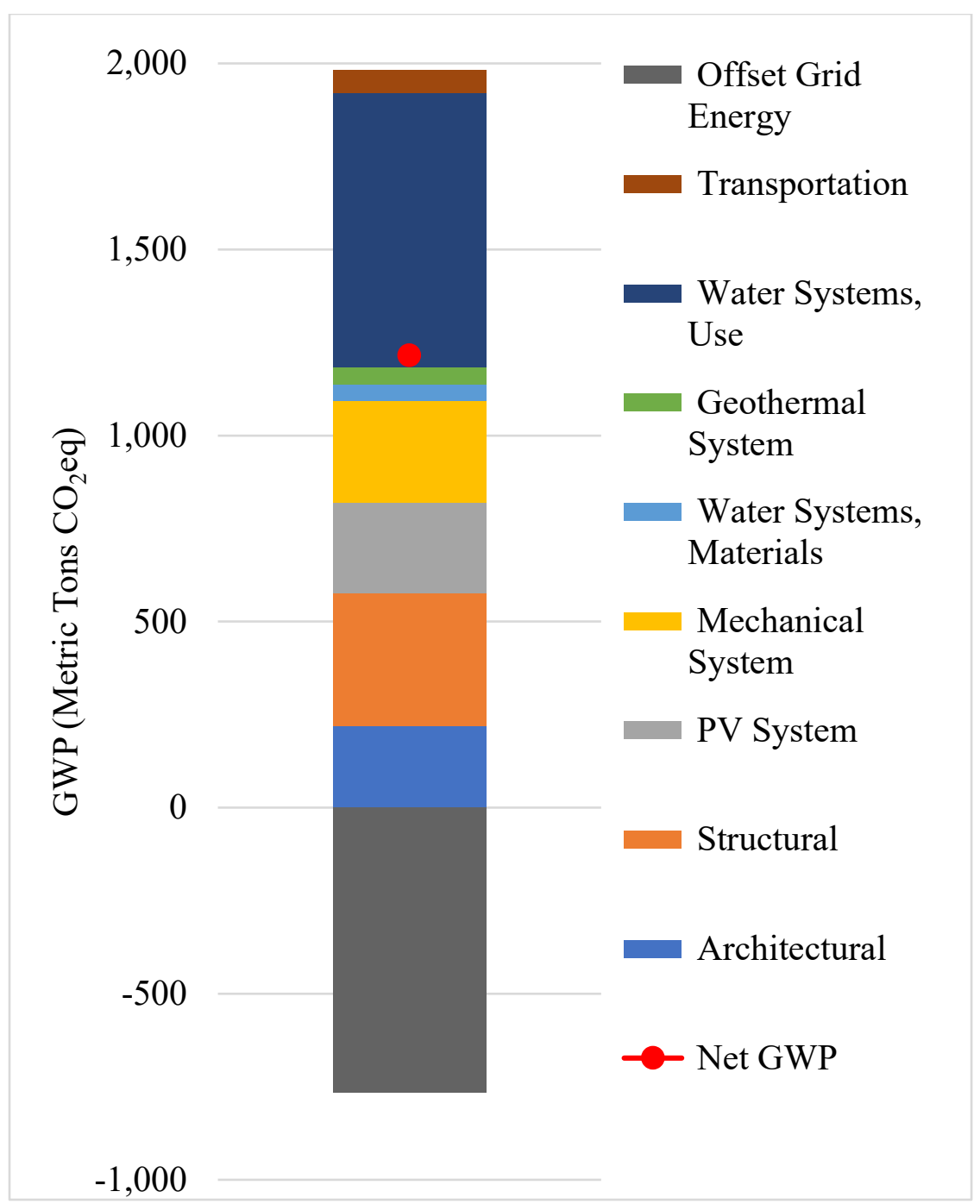

Figure 32. Total Global Warming Potential (MT CO $2 \mathrm{eq)} \mathrm{per} \mathrm{assembly} \mathrm{showing} \mathrm{net} \mathrm{GWP} \mathrm{after} \mathrm{energy} \mathrm{offsets}$ for the 100-year lifespan.

It should be noted that the material impacts of buildings are not increasing, but rather are seeing a rise in significance now that the use phase is negligible, or in the FEC's case offsetting. This will therefore be the focus of improving the sustainability of buildings now that the use phase (energy and water efficiency) have been effectively diminished. The consideration of embodied impacts will now be the target of reducing overall environmental impacts. 


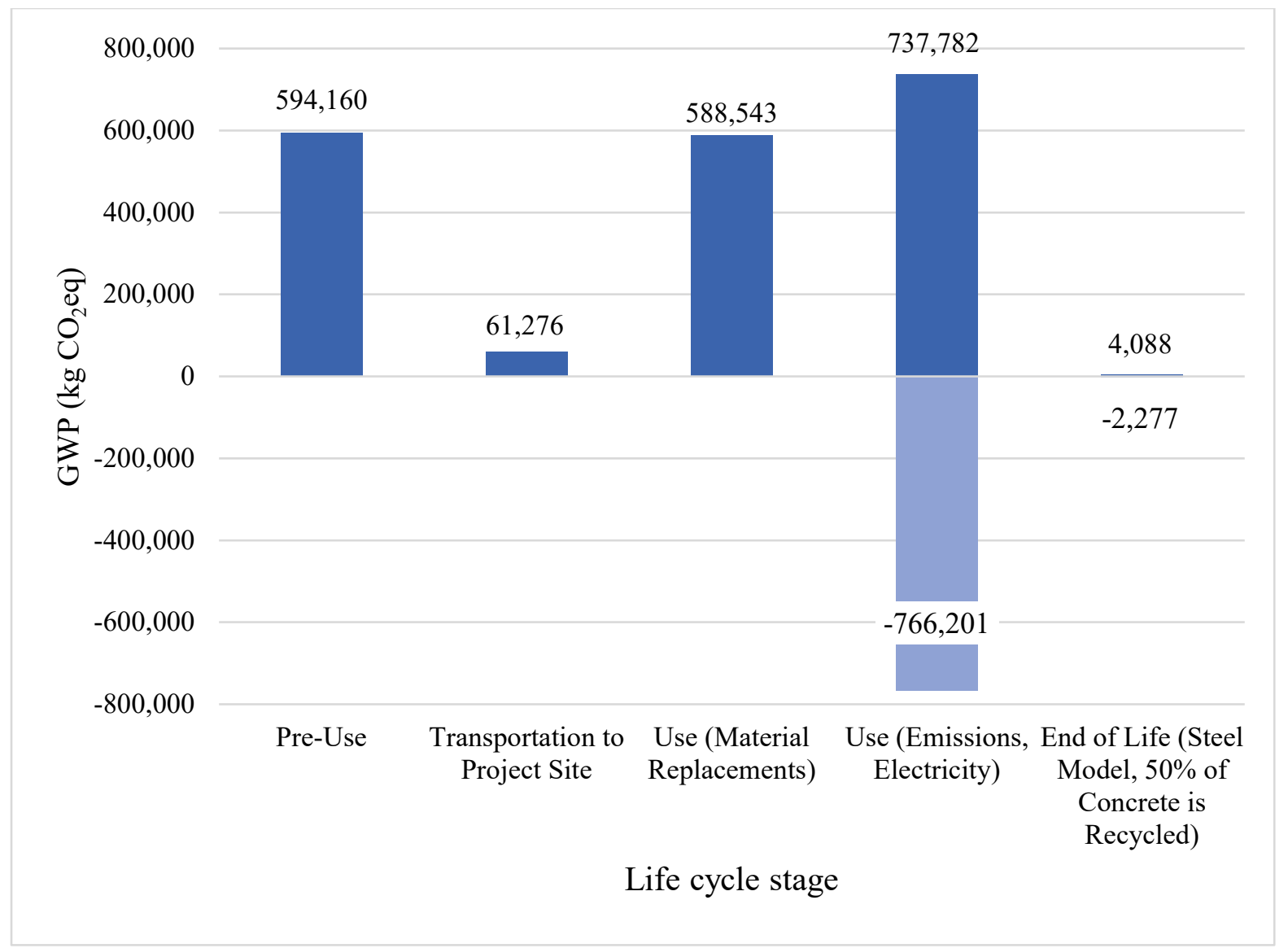

Figure 33. Total GWP impacts by life cycle stage for pre-use, transportation, use, and end of life.

Use includes material replacements, and water system emissions/electricity offsets. EOL scenario is steel frame, with disposal percentages are steel 100\% recycled and concrete 50\% recycled $/ 50 \%$ landfilled; Positive impacts from concrete landfilling, negative impacts from steel recycling).

\subsection{BUILDING COMPARISONS}

Many whole-building life cycle assessments have been performed over the last decades; results from these assessments are used to contextualize the results obtained for the Frick Environmental Center. Because LCAs have varying scopes and assess buildings with several different functions, often times it can be challenging to compare comprehensive results. Therefore, the material preuse GWP impacts have been extracted from three other studies and compared to those of the FEC, 
as seen in Figure 34. The case study building has the lowest material impacts per square foot and has comparable results to that of another living building in Pittsburgh, the Center for Sustainable Landscapes (Thiel et al., 2013). Although the FEC would expect to have lower overall life cycle impacts as well, results of whole-building LCAs are too varied to present comprehensive comparisons.

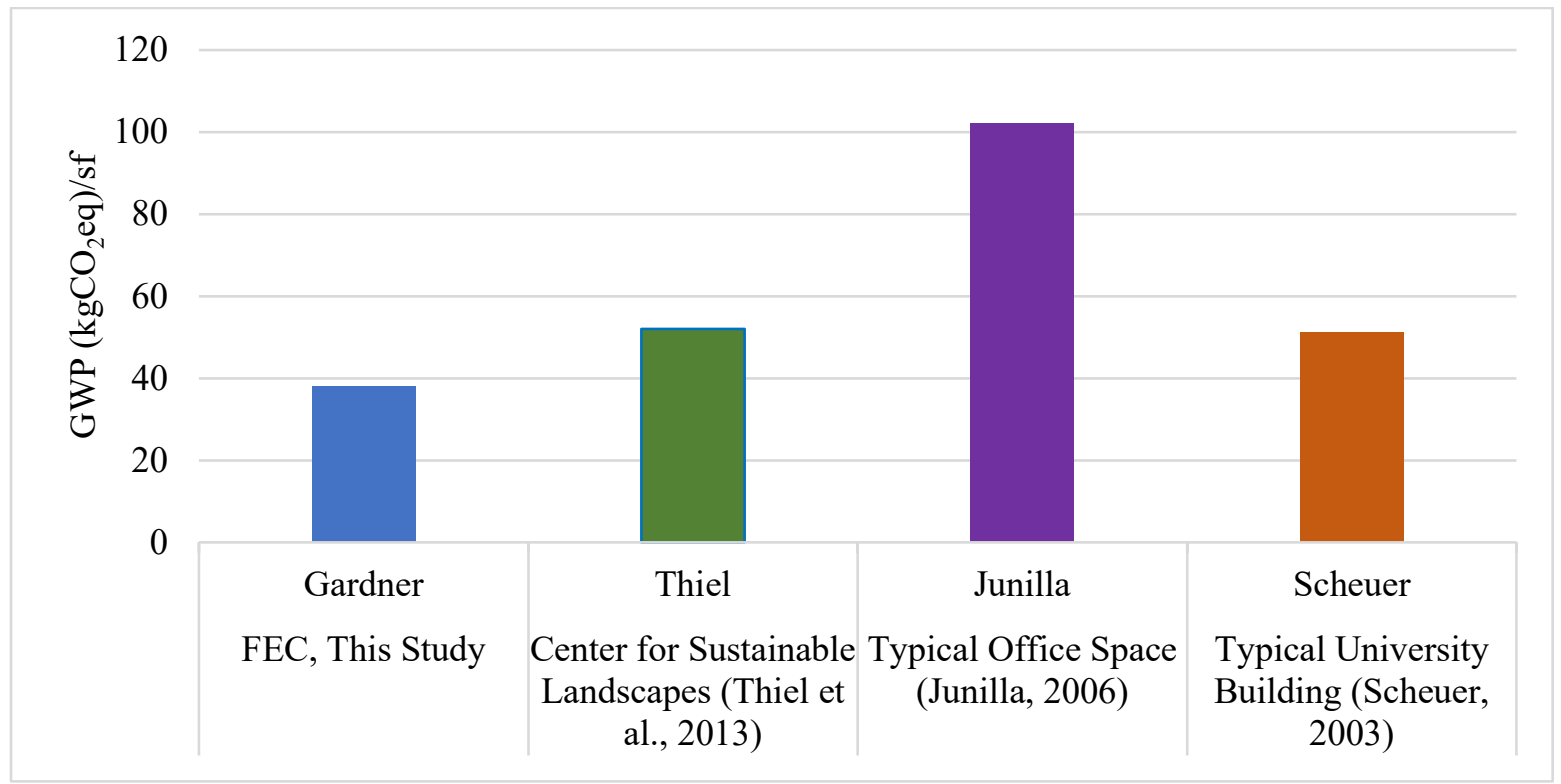

Figure 34. Comparison of material pre-use impacts (GWP, $\left.\mathrm{kg} \mathrm{CO}_{2} \mathrm{eq}\right)$ of three previous studies versus this case study. 


\subsection{RECOMMENDATIONS \& CONCLUSION}

\subsection{RECOMMENDATIONS}

\subsubsection{ILFI's Red List is Working, But More Can Be Done}

The removal of chemicals on the ILFI's Red List resulted in significant reductions in several TRACI impact categories, namely carcinogens and non-carcinogens. Because this was a holistic assessment with a building-scale scope, it was not within the scope of this work to develop a green material database. Therefore, it is recommended that material manufacturers, architects, and engineers work together on creating a comprehensive material database that includes significantly more information on green building materials than those that exist today. Many databases exist that have product information that was added to this LCI, such as recycled content or whether or not it is a Declare product ("HBN Pharos Project," ; Origin; SustainableMinds); however, there is a lack of integration of this information into databases that can be used for LCA. As the building industry shifts from proprietary information to a more transparent model, these databases will quickly become less of an idealistic proposition and more of an integral industry tool.

In the meantime, as ideally this central database is created by professionals and experts, this could be a project for computer scientist. Since this information is available on many websites (Declare Labels, EPDs, etc.), programming can be used to extract what is needed. This could help dramatically during the inventory phase while the green material database is being created. 


\subsubsection{Septic Systems of Green Buildings Must Be Aerated}

Based on the significant emissions from the septic system in the form of methane, it is recommended that the FEC invest in an aerator for their system. This would increase the energy demand for the building and therefore reduce the amount of energy they are offsetting and sending back into the grid; however, the methane emissions are so potent that this would be a wise investment economically and environmentally. According to the comparison made to the CSL, aerating this water system could reduce the emissions by up to $90 \%$ and would therefore change the GWP emissions profile of the entire lifespan of the structure. Although more electricity would be needed, the drastic decrease in methane would offset any additional electricity needed for the system. Therefore, if a septic system is used in a living or low-energy building, it is critical to aerate the system in order to prevent significant methane emissions and subsequently reduce an otherwise large GWP profile.

\subsubsection{FEC is Net-Zero Energy and Water, but Not Net-Zero Carbon}

As seen in the discussion of the comprehensive life cycle impacts of the FEC, this building is not net-zero carbon. Building designers and operators worked hard to ensure the energy profile of the building was net-zero, which they achieved by a large margin. However, once all the material replacement impacts, not to mention the emissions from the water system, were added it became clear that the total embodied carbon was much higher than the amount offset by electricity fed back into the grid. This brings up an emerging conversation about embodied impacts of highperformance buildings. Because the use phases are so low, or in the FEC's case negative, the embodied carbon in the materials quickly dominate the life cycle impacts. This illustrates a shift 
from reducing the energy loads to figuring out next steps to further reduce the embodied impacts of buildings. These impacts are significantly affected by material selection, sourcing, and product lifespans; this supports the need for an improved material database in order to accurately assess their impacts to get a true picture of a green building's embodied impacts. It is therefore critical that building designers take all of these factors in when creating a new structure since these impacts carry more weight in living buildings.

This also introduces the potential for a conversation about regular energy offsets. Similar to that of modeling the energy and water profiles on an annual basis, perhaps embodied carbon should be modeled on a 5- or 10-year timescale to account for regular material replacements. This way, embodied impacts could be tracked in order to calculate what quantity of offsets should be purchased, allowing the building to truly achieve net-zero carbon over its lifetime. Alternatively, adjusting the required amount of electricity generated on-site could be a way to achieve net-zero carbon as well; if the electricity of the building is modeled as being artificially higher than it is in order to account for embodied material impacts, the required electricity generated will automatically offset the impacts from material pre-use and use. The Living Building Challenge requires these offsets are tracked for the building pre-use (construction) but has no requirements for continuous offsets. The main objective now is to account for life cycle embodied impacts so the best option can be evaluated a case-by-case basis whether that is purchasing offsets, increasing the electricity generated on-site, or any other effective offsetting option.

\subsubsection{End of Life Impacts: It Depends}

Although the EOL assessment resulted in interesting findings, the total EOL impacts are too dependent on a number of variables to provide a one-sized fits all recommendation. Therefore, 
EOL impacts must be evaluated based on the project in question and the waste stream of specific products used. For example, the lumber used in this product is FSC certified and locally sourced; therefore, if this lumber were to replace the steel structural elements and recycled at its end of life, the deforestation impacts would not be a primary concern and the net offsets would be very large. However, that is not to say that all projects should use lumber for their structural elements because it might not be the most sustainable option for that region. Because EOL impacts have the potential to have such significant offsets, it is recommended that each project consider EOL impacts during the design stage, using project-specific attributes to model the ideal waste scenario. A question to be considered during the design stage should not be what the end-of-life impacts are, but rather how large can the end-of-life offsets be. This will shift the focus in order to help guide building designers and construction managers to the most sustainable option for the project at hand.

\subsubsection{Quantitative LCA Cannot Capture Critical Qualitative Aspects}

Because LCA is a highly quantitative form of assessing the sustainability of a building, it often misses unquantifiable although critical attributes. Specifically, for the FEC, there are many biophilic design attributed integrated into this structure. Biophilia, defined as the innate connection humans have with nature, has been proven to have positive impacts on occupant productivity and health, among other things (Stephen R. Kellert, 2008). Many of these design elements are incorporated in the FEC, including but not limited to: natural light, biomimicry, use of natural materials, views and vistas, and historic connection to place. These result in positive impacts on occupants and visitors that are not incorporated into a whole-building LCA, which focuses on material, energy, and emission impacts. When evaluating living buildings, it is suggested that building assessors include a discussion regarding qualitative benefits of various building features. 


\subsection{CONCLUSION}

The results of this research could have significant impacts on the future design of living buildings. The hotspots identified in this life cycle assessment are likely present in many other green buildings and from now on can be mitigated. It is recommended that more emphasis is placed on material selection during the design phase of living buildings due both to their high global warming potential impacts throughout the lifespan of the building combined with their high potential for offsetting impacts during material end-of-life. Additionally, any water systems used on-site should be vigilantly monitored to ensure there are no fugitive GHG emissions from those systems. Embodied impacts from material selection as well as all emissions seen on-site should be considered in calculating a living building's "net-zero" footprint. It is imperative to consider the building from a life-cycle perspective in order to minimize holistic impacts. Green building rating systems should use these recommendations to update their standards, thus preventing similar projects from facing these challenges while reducing the impacts of all future living buildings. 


\subsection{FUTURE WORK \& LIMITATIONS}

Future work of this research includes continuing the development of a database containing green building material information. Additionally, a limitation with the use of the ecoinvent database for this LCA is there is a lack of US-specific data, which may lead to uncertainties in the assessment.

An additional analysis would include construction phase impacts. Although there was a lack of data for this case study building, assumptions could be made based on previous studies to model expected impacts. Additionally, transportation distances could be assessed in greater detail. Because LBC and LEED require material tracking, these distances could be compared to other benefits (i.e. higher recycled content but greater sourcing distance) to assess the tradeoffs of these GBRS requirements.

With regards to the water system, the volume of water that flows through the on-site system could be refined should the FEC increase submetering throughout the site. This updated data would allow for more precise septic system emissions.

Because the end-of-life assessment of materials is so complex, a few components could be assessed in greater detail to allow for a more robust analysis. First, the performance of a structural analysis of wood model could be assessed. Also, a comparison could be made of waste scenario factors from EPA's WARM to other studies and databases. Lastly, consideration of deforestation, land use, and timber quality degradation with increased demand of lumber products could be integrated into the assessment.

Future work also included incorporating indoor air quality impacts into a building's life

cycle impacts. This involves applying characterization factors for various impact categories to measured quantities of common air pollutants (e.g. particulate matter, carbon monoxide, ozone) 
present in the building. These impacts can ultimately be modeled annually and totaled for the building's life, creating a more comprehensive assessment of the building over its lifespan. Incorporating these impacts would allow for better understanding of particularly impacts on the health of building occupants.

Another consideration when moving forward with green buildings is establishing a new way to compare their performance. Energy use intensity (EUI) is currently used for baseline assessments, which measure the energy used in a space per square foot. This may become an insufficient way to compare living buildings to other living buildings because the performance of these green buildings is no longer the main focus; comparing embodied energy per square foot for a specific function (office, university, etc.) may be a potential way; alternative comparison options should be explored.

Performing these additional analyses would result in more precise results, allowing building designers and other decision makers to construct the least impactful buildings possible. 


\section{RED LIST CHEMICALS}

Table 11. Red List Chemicals.

\begin{tabular}{|c|}
\hline Red List Item \\
Alkylphenols \\
Asbestos \\
\hline Bisphenol A (BPA) \\
\hline Cadmium \\
\hline Chlorinated Polyethylene and Chlorosulfonated Polyethlene \\
\hline Chlorobenzenes \\
\hline Chlorofluorocarbons (CFCs) and Hydrochlorofluorocarbons (HCFCs) \\
\hline Chloroprene (Neoprene) \\
\hline Chromium VI \\
\hline Chlorinated Polyvinyl Chloride (CPVC) \\
\hline Formaldehyde (added) \\
\hline Halogenated Flame Retardants (HFRs) \\
\hline Lead (added) \\
\hline Mercury \\
\hline Polychlorinated Biphenyls (PCBs) \\
\hline Perfluorinated Compounds (PFCs) \\
\hline Phthalates \\
\hline Polyvinyl Chloride (PVC) \\
\hline Polyvinylidene Chloride (PVDC) \\
\hline Short Chain Chlorinated Paraffins \\
\hline holtps://living-future.org/declare/declare-about/red-list/ \\
\hline Organic Compounds (VOCs) in wet applied products \\
\hline treatments containing Creosote, Arsenic or Pentachlorophenol \\
\hline Folile \\
\hline
\end{tabular}




\section{LIFE CYCLE INVENTORY - UNIT PROCESSES}

\section{Structural}

Table 12. Structural Unit Processes and Additional Data.

\begin{tabular}{|c|c|c|c|c|c|c|}
\hline Assembly & Material & Database & Unit Process & $\begin{array}{l}\text { WB } \\
(\%)\end{array}$ & $\begin{array}{l}\mathrm{RC} \\
(\%)\end{array}$ & PL \\
\hline \multirow{3}{*}{ CMU Blocks } & $\begin{array}{l}\text { Portland } \\
\text { Cement } \\
\text { (NO fly ash) }\end{array}$ & ecoinvent 3.4 & $\begin{array}{l}\text { Cement, Portland }\{U S\} \text {, } \\
\text { market for, Alloc Def, } U\end{array}$ & 20 & & 100 \\
\hline & River Sand & ecoinvent 3.4 & $\begin{array}{l}\text { Sand }\{\mathrm{GLO}\} \text { market for } \\
\text { Alloc Def, } U\end{array}$ & 40 & & 100 \\
\hline & River Gravel & ecoinvent 3.4 & $\begin{array}{l}\text { Gravel, crushed, }\{\mathrm{ROW}\} \text {, } \\
\text { market for, Alloc Def, U }\end{array}$ & 40 & & 100 \\
\hline \multirow{3}{*}{ Concrete } & $\begin{array}{l}\text { Portland } \\
\text { Cement } \\
\text { (incl fly ash) }\end{array}$ & ecoinvent 3.4 & $\begin{array}{l}\text { Cement, pozzolana and fly } \\
\text { ash } 15-40 \% \text {, US only, } \\
\text { market for, Alloc Def, U }\end{array}$ & 10 & & 100 \\
\hline & Gravel & ecoinvent 3.4 & $\begin{array}{l}\text { Gravel, crushed, }\{\mathrm{ROW}\} \text {, } \\
\text { market for, Alloc Def, U }\end{array}$ & 30 & & 100 \\
\hline & Natural Sand & ecoinvent 3.4 & $\begin{array}{l}\text { Sand }\{\mathrm{GLO}\} \text { market for } \\
\text { Alloc Def, U }\end{array}$ & 60 & & 100 \\
\hline Steel Beams & Steel & ecoinvent 3.4 & $\begin{array}{l}\text { Steel, low alloyed }\{\mathrm{GLO}\} \text {, } \\
\text { market for, Alloc Def, U }\end{array}$ & -- & $83 \%$ & 100 \\
\hline Steel Plates & Steel & ecoinvent 3.4 & $\begin{array}{l}\text { Steel, low alloyed }\{\mathrm{GLO}\} \text {, } \\
\text { market for, Alloc Def, U }\end{array}$ & -- & $78 \%$ & 100 \\
\hline \multirow{2}{*}{$\begin{array}{l}\text { Reinforcing } \\
\text { Steel }\end{array}$} & Steel & ecoinvent 3.4 & $\begin{array}{l}\text { Reinforcing Steel, market } \\
\text { for, Alloc Rec, U }\end{array}$ & 90 & $99 \%$ & 100 \\
\hline & Steel Alloys & ecoinvent 3.4 & $\begin{array}{l}\text { Steel, low alloyed }\{\mathrm{GLO}\} \text {, } \\
\text { market for, Alloc Def, U }\end{array}$ & 10 & & 100 \\
\hline Steel Trellis & Steel & ecoinvent 3.4 & $\begin{array}{l}\text { Steel, low alloyed }\{\mathrm{GLO}\} \\
\text { market for, Alloc Def, } \mathrm{U}\end{array}$ & -- & $82 \%$ & 75 \\
\hline
\end{tabular}

Note: $\mathrm{WB}=$ =weight breakdown; $\mathrm{RC}=$ Recycled Content, Life $=$ Product Lifespan (years) 
2. Mechanical, Electrical, Plumbing

Table 13. MEP Unit Processes and Additional Data.

\begin{tabular}{|c|c|c|c|c|c|c|}
\hline Assembly & Material & Database & Unit Process & $\begin{array}{l}\text { WB } \\
(\%) \\
\end{array}$ & $\begin{array}{l}\mathrm{RC} \\
(\%)\end{array}$ & PL \\
\hline \multirow{2}{*}{$\begin{array}{l}\text { Air Terminal } \\
\text { Units (VAVs) }\end{array}$} & Steel & ecoinvent 3.4 & $\begin{array}{l}\text { Galvanized steel sheet, at } \\
\text { plant/RNA }\end{array}$ & 95 & & 25 \\
\hline & $\begin{array}{l}\text { Fiberglass } \\
\text { insulation }\end{array}$ & ecoinvent 3.4 & $\begin{array}{l}\text { Glass fibre }\{\mathrm{GLO}\} \text {, market } \\
\text { for, Alloc Def, } U\end{array}$ & 5 & & 25 \\
\hline \multirow{3}{*}{ Air Vent } & Cast Iron & ecoinvent 3.4 & $\begin{array}{l}\text { Cast iron }\{\mathrm{GLO}\}, \text { market } \\
\text { for, Alloc Def, U }\end{array}$ & 80 & & 25 \\
\hline & Brass & ecoinvent 3.4 & $\begin{array}{l}\text { Brass }\{\mathrm{GLO}\}, \text { market for, } \\
\text { Alloc Def, } U\end{array}$ & 10 & & 25 \\
\hline & Steel & ecoinvent 3.4 & $\begin{array}{l}\text { Steel, low-alloyed }\{\mathrm{GLO}\} \text {, } \\
\text { market for, Alloc Def, U }\end{array}$ & 10 & & 25 \\
\hline \multirow{3}{*}{ Diffusers } & Steel & ecoinvent 3.4 & $\begin{array}{l}\text { Steel, stainless } 304 \\
\{\text { GLO }\} \text { scrap/lb }\end{array}$ & 40 & & 25 \\
\hline & $\begin{array}{l}\text { Iron } \\
\text { (Pig Iron) }\end{array}$ & ecoinvent 3.4 & $\begin{array}{l}\text { Pig Iron }\{\mathrm{GLO}\}, \text { Market } \\
\text { for, Alloc Def, } U\end{array}$ & 40 & & 25 \\
\hline & Bronze & ecoinvent 3.4 & $\begin{array}{l}\text { Bronze }\{\mathrm{GLO}\}, \text { Market } \\
\text { for, Alloc Def, } U\end{array}$ & 20 & & 25 \\
\hline \multirow[t]{2}{*}{ Fan } & Aluminum & ecoinvent 3.4 & $\begin{array}{l}\text { Aluminum removed by } \\
\text { drilling, conventional } \\
\{G L O\} \text {, market for, Alloc } \\
\text { Def, } U\end{array}$ & & $60 \%$ & 25 \\
\hline & Steel & ecoinvent 3.4 & $\begin{array}{l}\text { Steel, low-alloyed }\{\mathrm{GLO}\} \text {, } \\
\text { market for, Alloc Def, U }\end{array}$ & & $90 \%$ & 25 \\
\hline \multirow{3}{*}{ Fan Coil Units } & Steel & ecoinvent 3.4 & $\begin{array}{l}\text { Steel, low-alloyed }\{\mathrm{GLO}\} \text {, } \\
\text { market for, Alloc Def, } U\end{array}$ & 40 & & 25 \\
\hline & Copper & ecoinvent 3.4 & $\begin{array}{l}\text { Cooper }\{\mathrm{GLO}\}, \text { market } \\
\text { for, Alloc Def, } U\end{array}$ & 20 & & 25 \\
\hline & $\begin{array}{l}\text { Galvanized } \\
\text { Steel }\end{array}$ & ecoinvent 3.4 & $\begin{array}{l}\text { Galvanized steel sheet, at } \\
\text { plant/RNA }\end{array}$ & 40 & & 25 \\
\hline \multirow[b]{2}{*}{ Ducts } & $\begin{array}{l}\text { Stainless } \\
\text { Steel }\end{array}$ & ecoinvent 3.4 & $\begin{array}{l}\text { Galvanized steel sheet, at } \\
\text { plant/RNA }\end{array}$ & 95 & & 25 \\
\hline & $\begin{array}{l}\text { Biosoluble } \\
\text { glass mineral } \\
\text { wool }\end{array}$ & US LCI & $\begin{array}{l}\text { Glass wool mat }\{\mathrm{GLO}\} \text {, } \\
\text { market for, Alloc Def, } U\end{array}$ & 5 & & 25 \\
\hline
\end{tabular}

Note: $\mathrm{WB}=$ weight breakdown; $\mathrm{RC}=$ Recycled Content, Life =Product Lifespan (years) 
3. PV System

Table 14. PV Unit Processes and Additional Data.

\begin{tabular}{|c|c|c|c|c|c|c|}
\hline Assembly & Material & Database & Unit Process & $\begin{array}{l}\text { WB } \\
(\%)\end{array}$ & $\begin{array}{l}\mathrm{RC} \\
(\%)\end{array}$ & PL \\
\hline $\begin{array}{l}\text { Aluminum } \\
\text { Gutter }\end{array}$ & Aluminum & ecoinvent 3.4 & $\begin{array}{l}\text { Aluminum alloy, } \mathrm{AlMg}_{3} \\
\{\mathrm{GLO}\} \text {, market for, Alloc } \\
\text { Def, U }\end{array}$ & & $60 \%$ & 75 \\
\hline Panels & Monocrystal & ecoinvent 3.4 & $\begin{array}{l}\text { Silicon, single crystal, } \\
\text { Czochralski process, } \\
\text { electronics }\{\text { GLO }\} \text {, market } \\
\text { for, Alloc Def, U }\end{array}$ & -- & & 25 \\
\hline Inverter & $\begin{array}{l}\text { Inverter } \\
(600 \mathrm{~W})\end{array}$ & ecoinvent 3.4 & $\begin{array}{l}\text { Inverter, } 0.5 \mathrm{~kW}\{\mathrm{ROW}\} \text {, } \\
\text { production, Alloc Def, } \mathrm{U}\end{array}$ & -- & & 15 \\
\hline \multirow{3}{*}{$\begin{array}{l}\text { Structure - } \\
\text { Concrete }\end{array}$} & $\begin{array}{l}\text { Portland } \\
\text { Cement } \\
\text { (incl fly ash) }\end{array}$ & ecoinvent 3.4 & $\begin{array}{l}\text { Cement, pozzolana and fly } \\
\text { ash } 15-40 \% \text {, US only, } \\
\text { market for, Alloc Def, U }\end{array}$ & 20 & & 75 \\
\hline & Gravel & ecoinvent 3.4 & $\begin{array}{l}\text { Gravel, crushed, }\{\mathrm{ROW}\} \text {, } \\
\text { market for, Alloc Def, } U\end{array}$ & 20 & & 75 \\
\hline & Natural Sand & ecoinvent 3.4 & $\begin{array}{l}\text { Sand }\{\text { GLO }\} \text { market for } \\
\text { Alloc Def, } U\end{array}$ & 60 & & 75 \\
\hline $\begin{array}{l}\text { Structure - } \\
\text { Steel }\end{array}$ & Steel & ecoinvent 3.4 & $\begin{array}{l}\text { Reinforcing steel }\{\mathrm{GLO}\} \\
\text { market for, Alloc Def, } U\end{array}$ & & $96 \%$ & 75 \\
\hline
\end{tabular}

4. Geothermal System

Table 15. Geothermal Unit Processes and Additional Data.

\begin{tabular}{|c|c|c|c|c|c|c|}
\hline Assembly & Material & Database & Unit Process & $\begin{array}{l}\text { WB } \\
(\%)\end{array}$ & $\begin{array}{l}\mathrm{RC} \\
(\%)\end{array}$ & PL \\
\hline $\begin{array}{l}\text { Piping } \\
\text { Network }\end{array}$ & HDPE & ecoinvent 3.4 & $\begin{array}{l}\text { Polyethylene pipe, DN } 200, \text { SDR } \\
41\{\text { GLO } \mid \text { market for earth tube } \\
\text { heat exchanger, polyethylene, DN } \\
200 \mid \text { Alloc Def, U }\end{array}$ & -- & & 50 \\
\hline \multirow{3}{*}{ Grout } & $\begin{array}{l}\text { Cement } \\
\text { Mortar }\end{array}$ & ecoinvent 3.4 & $\begin{array}{l}\text { Cement mortar }\{\mathrm{GLO}\} \text { market for, } \\
\text { Alloc Rec, U }\end{array}$ & 90 & & 75 \\
\hline & Silica sand & ecoinvent 3.4 & $\begin{array}{l}\text { Silica sand }\{\mathrm{GLO}\}, \text { market for, } \\
\text { Alloc Rec, } U\end{array}$ & 5 & & \\
\hline & $\begin{array}{l}\text { Activated } \\
\text { bentonite }\end{array}$ & ecoinvent 3.4 & $\begin{array}{l}\text { Activated bentonite }\{\mathrm{GLO}\} \text {, } \\
\text { market for, Rec, } \mathrm{U}\end{array}$ & 5 & & 75 \\
\hline $\begin{array}{l}\text { HVAC } \\
\text { Piping }\end{array}$ & Steel & ecoinvent 3.4 & $\begin{array}{l}\text { Chromium Steel pipe }\{\mathrm{GLO}\} \\
\text { market for, Alloc Def, } \mathrm{U}\end{array}$ & -- & & 25 \\
\hline
\end{tabular}


5. Architectural

Table 16. Architecture Unit Processes and Additional Data.

\begin{tabular}{|c|c|c|c|c|c|c|}
\hline Assembly & Material & Database & Unit Process & $\begin{array}{l}\text { WB } \\
(\%)\end{array}$ & $\begin{array}{l}\mathrm{RC} \\
(\%)\end{array}$ & PL \\
\hline \multirow{3}{*}{$\begin{array}{l}\text { Ceiling - } \\
\text { ACT }\end{array}$} & ACT Tiles & ecoinvent 3.4 & $\begin{array}{l}\text { Glass fibre }\{\mathrm{GLO}\} \text {, market for, } \\
\text { Alloc Def, } U\end{array}$ & 80 & & 25 \\
\hline & $\begin{array}{l}\text { Steel } \\
\text { Suspension }\end{array}$ & ecoinvent 3.4 & $\begin{array}{l}\text { Steel hot dip galvanized, } \\
\text { including recycling, blast furnace } \\
\text { route, production mix, at plant, } \\
11 \mathrm{~b},\{\mathrm{GLO}\} \mathrm{S}\end{array}$ & 15 & & 25 \\
\hline & $\begin{array}{l}\text { Aluminum } \\
3005 \text { Alloy } \\
\text { Suspension }\end{array}$ & ecoinvent 3.4 & $\begin{array}{l}\text { Aluminum alloy, AlMg3 } \\
\{\mathrm{GLO}\}, \text { market for, Alloc Def, } \mathrm{U}\end{array}$ & 5 & $60 \%$ & 25 \\
\hline $\begin{array}{l}\text { Ceiling - } \\
\text { Gypsum } \\
\text { Wallboard }\end{array}$ & Sheathing & ecoinvent 3.4 & $\begin{array}{l}\text { Gypsum wallboard product, } \\
\text { regular, } 0.5 \mathrm{inch} / \mathrm{m} 2 / \text { RNA }\end{array}$ & -- & $30 \%$ & 50 \\
\hline \multirow[t]{2}{*}{$\begin{array}{l}\text { Ceiling - } \\
\text { Metal } \\
\text { Decking }\end{array}$} & Steel & ecoinvent 3.4 & $\begin{array}{l}\text { Steel hot dip galvanized, } \\
\text { including recycling, blast furnace } \\
\text { route, production mix, at plant, } \\
11 \mathrm{~b},\{\mathrm{GLO}\}\end{array}$ & 80 & & 100 \\
\hline & $\begin{array}{l}\text { Fibrous } \\
\text { Glass }\end{array}$ & ecoinvent 3.4 & $\begin{array}{l}\text { Glass fibre }\{\mathrm{GLO}\} \text { market for, } \\
\text { Alloc Def, } \mathrm{U}\end{array}$ & 20 & & 100 \\
\hline $\begin{array}{l}\text { Door - } \\
\text { Aluminum }\end{array}$ & Aluminum & ecoinvent 3.4 & $\begin{array}{l}\text { Aluminum alloy, AlMg3 } \\
\{\text { GLO }\} \text {, market for, Alloc Def, U }\end{array}$ & -- & $60 \%$ & 100 \\
\hline \multirow{2}{*}{$\begin{array}{l}\text { Door - } \\
\text { HM }\end{array}$} & Steel & ecoinvent 3.4 & $\begin{array}{l}\text { Steel, low alloyed }\{\mathrm{GLO}\} \\
\text { market for, Alloc Def, } \mathrm{U}\end{array}$ & $2.51 b$ & & 100 \\
\hline & $\begin{array}{l}\text { Polystyrene } \\
\text { Core }\end{array}$ & ecoinvent 3.4 & $\begin{array}{l}\text { Polystyrene, general purpose } \\
\{\text { GLO }\} \text {, market for, Alloc Def, U }\end{array}$ & $5 \mathrm{lb}$ & & 100 \\
\hline $\begin{array}{l}\text { Door C- } \\
\text { Wood }\end{array}$ & $\begin{array}{l}\text { Wood } \\
\text { (maple) }\end{array}$ & US LCI & $\begin{array}{l}\text { Lumber, softwood, borate } \\
\text { treated, SE/m3/RNA }\end{array}$ & $3.0651 \mathrm{~b}$ & & 100 \\
\hline \multirow{2}{*}{$\begin{array}{l}\text { Door E - } \\
\text { Wood \& } \\
\text { Glass }\end{array}$} & Wood & ecoinvent 3.4 & $\begin{array}{l}\text { Lumber, softwood, borate } \\
\text { treated, SE/m3/RNA }\end{array}$ & $21 b$ & & 100 \\
\hline & Glass & ecoinvent 3.4 & $\begin{array}{l}\text { Flat glass, uncoated }\{\mathrm{GLO}\}, \\
\text { market for, Alloc Def, U }\end{array}$ & $201 \mathrm{~b}$ & & 100 \\
\hline \multirow{2}{*}{$\begin{array}{l}\text { Door F - } \\
\text { Glass \& } \\
\text { Aluminum }\end{array}$} & Aluminum & ecoinvent 3.4 & $\begin{array}{l}\text { Aluminum alloy, AlMg3 } \\
\{\mathrm{GLO}\} \text {, market for, Alloc Def, U }\end{array}$ & $44 \mathrm{lb}$ & & 100 \\
\hline & Glass & ecoinvent 3.4 & $\begin{array}{l}\text { Flat glass, coated }\{\mathrm{GLO}\} \text {, market } \\
\text { for, Alloc Def, } \mathrm{U}\end{array}$ & $32.51 \mathrm{~b}$ & & 100 \\
\hline
\end{tabular}

Note: $\mathrm{WB}=$ =weight breakdown; $\mathrm{RC}=$ Recycled Content, Life =Product Lifespan (years) 
Table 17. Architecture Unit Processes and Additional Data, cont'd.

\begin{tabular}{|c|c|c|c|c|c|}
\hline Assembly & Material & Database & Unit Process & $\begin{array}{l}\text { WB } \\
(\%)\end{array}$ & Life \\
\hline $\begin{array}{l}\text { Door G - } \\
\text { Glass \& } \\
\text { Aluminum }\end{array}$ & $\begin{array}{l}\text { Aluminum } \\
\text { Glass }\end{array}$ & $\begin{array}{l}\text { ecoinvent } 3.4 \\
\text { ecoinvent } 3.4\end{array}$ & $\begin{array}{l}\text { Aluminum alloy, AlMg3 }\{\mathrm{GLO}\} \text {, } \\
\text { market for, Alloc Def, U } \\
\text { Flat glass, coated }\{\mathrm{GLO}\} \text {, market } \\
\text { for, Alloc Def, } \mathrm{U}\end{array}$ & $\begin{array}{l}32 \mathrm{lb} \\
17.5 \mathrm{lb}\end{array}$ & $\begin{array}{l}100 \\
100\end{array}$ \\
\hline \multirow{3}{*}{$\begin{array}{l}\text { Door H - } \\
\text { Alum, Glass, } \\
\text { Wood }\end{array}$} & Wood & ecoinvent 3.4 & $\begin{array}{l}\text { Lumber, softwood, borate treated, } \\
\text { SE/m3/RNA }\end{array}$ & $31 b$ & 100 \\
\hline & Aluminum & ecoinvent 3.4 & $\begin{array}{l}\text { Aluminum alloy, AlMg3 }\{\mathrm{GLO}\} \text {, } \\
\text { market for, Alloc Def, U }\end{array}$ & $441 \mathrm{~b}$ & 100 \\
\hline & Glass & ecoinvent 3.4 & $\begin{array}{l}\text { Flat glass, coated }\{\mathrm{GLO}\} \text {, market } \\
\text { for, Alloc Def, } \mathrm{U}\end{array}$ & $32.51 \mathrm{~b}$ & 100 \\
\hline $\begin{array}{l}\text { Flooring - } \\
\text { Carpet }\end{array}$ & $\begin{array}{l}\text { Nylon Squares } \\
\text { (Type 6) } \\
\text { Polypropylene } \\
\text { Base } \\
\end{array}$ & $\begin{array}{l}\text { ecoinvent } 3.4 \\
\text { ecoinvent } 3.4 \\
\end{array}$ & $\begin{array}{l}\text { Nylon } 6\{\mathrm{GLO}\} \text { market for, } \\
\text { Alloc Def, } \mathrm{U} \\
\text { Polypropylene, granulate }\{\mathrm{GLO}\} \text {, } \\
\text { market for, Alloc Def, U }\end{array}$ & $\begin{array}{l}20 \\
80 \\
\end{array}$ & 15 \\
\hline \multirow{3}{*}{$\begin{array}{l}\text { Flooring - } \\
\text { Resilient }\end{array}$} & Rubber Base & ecoinvent 3.4 & $\begin{array}{l}\text { Synthetic rubber }\{\text { GLO }\} \text { market } \\
\text { for, Alloc Def, } U\end{array}$ & 80 & 15 \\
\hline & Limestone & ecoinvent 3.4 & $\begin{array}{l}\text { Limestone, crushed, washed } \\
\{\text { GLO }\}, \text { market for, Alloc Def, U }\end{array}$ & 10 & 15 \\
\hline & $\begin{array}{l}\text { Limestone } \\
\text { (recycled) }\end{array}$ & ecoinvent 3.4 & $\begin{array}{l}\text { Limestone, crushed, washed } \\
\{\text { GLO }\}, \text { market for, Alloc Rec, U }\end{array}$ & 10 & 15 \\
\hline $\begin{array}{l}\text { Flooring - } \\
\text { Tile }\end{array}$ & Tile & ecoinvent 3.4 & $\begin{array}{l}\text { Ceramic tile }\{\mathrm{GLO}\} \text {, market for, } \\
\text { Alloc Def, U }\end{array}$ & -- & 100 \\
\hline \multirow{2}{*}{$\begin{array}{l}\text { Furnishings - } \\
\text { Cabinetry }\end{array}$} & $\begin{array}{l}\text { Veneer } \\
\text { Exterior }\end{array}$ & ecoinvent 3.4 & $\begin{array}{l}\text { Veneer, hardwood, dry, at veneer } \\
\text { mill, E/lb/RNA }\end{array}$ & 50 & 25 \\
\hline & Plywood walls & ecoinvent 3.4 & $\begin{array}{l}\text { Plywood, for indoor use }\{\text { RER }\} \\
\text { market for, Alloc Def, } U\end{array}$ & 50 & 25 \\
\hline Guard Rail & Steel & Ecoinvent. 3.4 & $\begin{array}{l}\text { Steel, un-alloyed }\{\mathrm{GLO}\} \text {, market } \\
\text { for, Alloc Def, U }\end{array}$ & 0.9 & 75 \\
\hline \multirow[b]{2}{*}{ Roofing } & Thermoplastic & ecoinvent 3.4 & $\begin{array}{l}\text { Polypropylene, granulated } \\
\{\mathrm{GLO}\} \text {, market for, Alloc Def, } \mathrm{U}\end{array}$ & 0.5 & 20 \\
\hline & Thermoplastic & ecoinvent 3.4 & $\begin{array}{l}\text { Polyethylene, low density, } \\
\text { granulated }\{\text { GLO\}, market for, } \\
\text { Alloc Def, } U\end{array}$ & 0.5 & 20 \\
\hline
\end{tabular}

Note: $\mathrm{WB}=$ =weight breakdown; $\mathrm{RC}=$ Recycled Content, Life =Product Lifespan (years) 
Table 18. Architecture Unit Processes and Additional Data, cont'd.

\begin{tabular}{|c|c|c|c|c|c|c|}
\hline Assembly & Material & Database & Unit Process & $\begin{array}{l}\text { WB } \\
(\%)\end{array}$ & $\begin{array}{l}\mathrm{RC} \\
(\%)\end{array}$ & Life \\
\hline Steel Grate & $\begin{array}{l}\text { Galvanized } \\
\text { Steel }\end{array}$ & ecoinvent 3.4 & $\begin{array}{l}\text { Galvanized steel sheet, } \\
\text { at plant/RNA }\end{array}$ & & $96 \%$ & 75 \\
\hline $\begin{array}{l}\text { Wall - Aluminum } \\
\text { Frame }\end{array}$ & Aluminum & ecoinvent 3.4 & $\begin{array}{l}\text { Aluminum alloy, AlMg3 } \\
\{\text { GLO }\}, \text { market for, } \\
\text { Alloc Def, U }\end{array}$ & & $60 \%$ & 15 \\
\hline \multirow[b]{2}{*}{$\begin{array}{l}\text { Wall - Gypsum } \\
\text { Wall Board }\end{array}$} & Glass fibre & ecoinvent 3.4 & $\begin{array}{l}\text { Glass fibre }\{\mathrm{GLO}\} \\
\text { market for, Alloc Def, } U\end{array}$ & 20 & & 20 \\
\hline & $\begin{array}{l}\text { Gypsum } \\
\text { Board (5/8") }\end{array}$ & ecoinvent 3.4 & $\begin{array}{l}\text { Gypsum wallboard } \\
\text { product, regular, } \\
0.675 \mathrm{inch} / \mathrm{m} 2 / \mathrm{RNA}\end{array}$ & 80 & $30 \%$ & 20 \\
\hline $\begin{array}{l}\text { Wall - } \\
\text { Polycarbonate }\end{array}$ & Polycarbonate & ecoinvent 3.4 & $\begin{array}{l}\text { Polycarbonate }\{\mathrm{GLO}\}, \\
\text { market for, Alloc Def, } \mathrm{U}\end{array}$ & -- & & 50 \\
\hline $\begin{array}{l}\text { Wall - Exterior } \\
\text { Lumber }\end{array}$ & Lumber & US LCI & $\begin{array}{l}\text { Lumber, softwood, } \\
\text { borate treated, } \\
\text { SE/m3/RNA }\end{array}$ & -- & & 25 \\
\hline $\begin{array}{l}\text { Window Frame - } \\
\text { Wood }\end{array}$ & Lumber & US LCI & $\begin{array}{l}\text { Lumber, softwood, } \\
\text { borate treated, } \\
\text { SE/m3/RNA }\end{array}$ & -- & & 25 \\
\hline $\begin{array}{l}\text { Window Frame - } \\
\text { Aluminum }\end{array}$ & Aluminum & ecoinvent 3.4 & $\begin{array}{l}\text { Aluminum alloy, } \\
\text { AlMg3 }\{\text { GLO }\} \text {, market } \\
\text { for, Alloc Def, } U\end{array}$ & -- & $60 \%$ & 15 \\
\hline $\begin{array}{l}\text { Window - } \\
\text { Tempered/Spandrel }\end{array}$ & Coated Glass & ecoinvent 3.4 & $\begin{array}{l}\text { Flat glass, coated } \\
\{\text { GLO }\}, \text { market for, } \\
\text { Alloc Def, } U\end{array}$ & -- & & 20 \\
\hline Window - Standard & Glass & ecoinvent 3.4 & $\begin{array}{l}\text { Flat glass, uncoated } \\
\{\text { GLO\}, market for, } \\
\text { Alloc Def, U }\end{array}$ & -- & & 20 \\
\hline \multirow{5}{*}{$\begin{array}{l}\text { Wood - Black } \\
\text { Locust Envelope }\end{array}$} & $\begin{array}{l}\text { Black Locust } \\
\text { Lumber }\end{array}$ & US LCI & $\begin{array}{l}\text { Lumber, softwood, } \\
\text { borate treated, } \\
\text { SE/m3/RNA }\end{array}$ & 70 & & 25 \\
\hline & \multirow{2}{*}{$\begin{array}{l}\text { Sheathing } \\
(1 ")\end{array}$} & ecoinvent 3.4 & $\begin{array}{l}\text { Gypsum, mineral } \\
\{\text { GLO }\} \text {, market for, } \\
\text { Alloc Def, U }\end{array}$ & 5 & & 25 \\
\hline & & ecoinvent 3.4 & $\begin{array}{l}\text { Glass fibre }\{\mathrm{GLO}\} \\
\text { market for, Alloc Def, } \mathrm{U}\end{array}$ & 5 & & 25 \\
\hline & $\begin{array}{l}\text { Gypsum } \\
\text { Board (5/8") }\end{array}$ & ecoinvent 3.4 & $\begin{array}{l}\text { Gypsum wallboard } \\
\text { product, type } x, \\
0.625 \mathrm{in} / \mathrm{m} 2 / \mathrm{RNA}\end{array}$ & 10 & $30 \%$ & 25 \\
\hline & $\begin{array}{l}\text { Mineral Wool } \\
\text { Insulation } \\
(5 ")\end{array}$ & ecoinvent 3.4 & $\begin{array}{l}\text { Glass wool mat }\{\mathrm{GLO}\} \text {, } \\
\text { market for, Alloc Def, } U\end{array}$ & 10 & & 25 \\
\hline
\end{tabular}

Note: WB =weight breakdown; RC =Recycled Content, Life =Product Lifespan (years) 
6. Use Phase

Table 19. Use Phase Unit Processes and Additional Data.

\begin{tabular}{|l|l|l|l|l|}
\hline Assembly & Unit & Database & Unit Process & $\%$ \\
\hline \multirow{3}{*}{$\begin{array}{l}\text { Grid } \\
\text { Electricity }\end{array}$} & $\mathrm{kWh}$ & ecoinvent 3.4 & $\begin{array}{l}\text { Electricity, high voltage \{RoW\}| electricity } \\
\text { production, hard coal } \mid \text { Alloc Def, U }\end{array}$ & 35 \\
\cline { 2 - 5 } & $\mathrm{kWh}$ & ecoinvent 3.4 & $\begin{array}{l}\text { Electricity, medium voltage \{RoW\}| market for } \\
\text { Alloc Def, U }\end{array}$ & 29 \\
\cline { 2 - 5 } & $\mathrm{kWh}$ & ecoinvent 3.4 & Electricity, nuclear, at power plant/US & 26 \\
\hline
\end{tabular}

Note: $\mathrm{WB}=$ weight breakdown; RC =Recycled Content, Life =Product Lifespan (years) 


\section{BIBLIOGRAPHY}

Architecture 2030. (2018). 2030 Challenge. Retrieved from https://architecture2030.org.

Al-Ghamdi, S., G., \& Bilec, M., M. (2017). "Green Building Rating Systems and WholeBuilding Life Cycle Assessment: Comparative Study of the Existing Assessment Tools." Journal of Architectural Engineering, 23(1), 04016015.

Arpke, A., \& Hutzler, N. (2005). "Operational Life-Cycle Assessment and Life-Cycle Cost Analysis for Water Use in Multioccupant Buildings." Journal of Architectural Engineering, 11(3), 99-109.

ASTM International. (2016). E2921-16a: Standard Practice for Minimum Criteria for Comparing Whole Building Life Cycle Assessments for Use with Building Codes, Standards, and Rating Systems. West Conshohocken, PA

Bare, J. (2012). Tool for the Reduction and Assessment of Chemical and Other Environmental Impacts (TRACI) User's Manual, v2.1. Washington, D.C., USA: US Environmental Protection Agency.

Berggren, B., Hall, M., \& Wall, M. (2013). "LCE analysis of buildings - Taking the step towards Net Zero Energy Buildings.” Energy and Buildings, 62, 381-391.

Blengini, G. A. (2009). "Life cycle of buildings, demolition and recycling potential: A case study in Turin, Italy." Building and Environment, 44(2), 319-330.

Blengini, G. A., \& Di Carlo, T. (2010). "The changing role of life cycle phases, subsystems and materials in the LCA of low energy buildings." Energy and Buildings, 42(6), 869-880.

BRE Group. (2018). BREEAM New Construction 2018 (UK). Retrieved from https://www.bregroup.com/.

Bribián, I. Z., Capilla, A. V., \& Usón, A. A. (2011). "Life cycle assessment of building materials: Comparative analysis of energy and environmental impacts and evaluation of the eco-efficiency improvement potential." Building and Environment, 46(5), 1133-1140.

Cellura, M., Guarino, F., Longo, S., \& Mistretta, M. (2014). "Energy life-cycle approach in Net zero energy buildings balance: Operation and embodied energy of an Italian case study." Energy and Buildings, 72, 371-381.

De Sousa, M. R. C., Montalto, F. A., \& Spatari, S. (2012). "Using Life Cycle Assessment to Evaluate Green and Grey Combined Sewer Overflow Control Strategies." Journal of Industrial Ecology, 16(6), 901-913. 
ecoinvent. (2018). ecoinvent database. Retrieved from https://www.ecoinvent.org/database/database.html.

Fouquet, M., Levasseur, A., Margni, M., Lebert, A., Lasvaux, S., Souyri, B., et al. (2015). "Methodological challenges and developments in LCA of low energy buildings: Application to biogenic carbon and global warming assessment." Building and Environment, 90, 51-59.

Frischknecht, R., Jungbluth, N., Althaus, H.-J., Doka, G., Dones, R., Heck, T., et al. (2005). “The ecoinvent Database: Overview and Methodological Framework (7 pp)." The International Journal of Life Cycle Assessment, 10(1), 3-9.

Google. Google Maps. Retrieved from www.google.com/maps.

Hasik, V., Anderson, N. E., Collinge, W. O., Thiel, C. L., Khanna, V., Wirick, J., et al. (2017). "Evaluating the Life Cycle Environmental Benefits and Trade-Offs of Water Reuse Systems for Net-Zero Buildings.” Environmental Science \& Technology, 51(3), 11101119.

Healthy Building Network. HBN Pharos Project. Retrieved from https://www.pharosproject.net/.

Hendrickson, T. P., Nguyen, M. T., Sukardi, M., Miot, A., Horvath, A., \& Nelson, K. L. (2015). "Life-Cycle Energy Use and Greenhouse Gas Emissions of a Building-Scale Wastewater Treatment and Nonpotable Reuse System.” Environmental Science \& Technology, 49(17), 10303-10311.

International Code Council. (2015). ICC Plumbing Code 2015 of Pennsylvania. Chapter 13 Nonpotable Water Systems. Retrieved from https://www.iccsafe.org/.

International Code Council. (2018). International Green Construction Codes: Chapte 9 Materials and Resources. Washington, D.C.

International Living Future Institute. (2017). Living Building Challenge 3.1: A Visionary Path to a Regenerative Future. Seattle, WA

International Living Future Institute. (2018). Declare Label. Retrieved from https://livingfuture.org/declare/.

International Organization for Standardization. (2006). Environmental management - Life cycle assessment - Requirements and guidelines. Geneva, Switzerland

International Organization for Standardization. (2010). Sustainability in building construction Framework for methods of assessment of the environmental performance of construction works. Geneva, Switzerland 
International Well Building Institute. (2018). WELL v2 pilot.

Institute for Building Environment and Energy Conservation, Japan Sustainable Building Consortium. (2014). CASBEE for Buildings (New Construction). Retrieved from http://www.ibec.or.jp/CASBEE/.

Junnila, S., \& Horvath, A. (2003). "Life-Cycle Environmental Effects of an Office Building." Journal of Infrastructure Systems, 9(4), 157-166.

Levasseur, A., Lesage, P., Margni, M., \& Samson, R. (2013). "Biogenic Carbon and Temporary Storage Addressed with Dynamic Life Cycle Assessment." Journal of Industrial Ecology, 17(1), 117-128.

Leverenz, H. L. T., G.; Darby, J. (2010). Evaluation of Greenhouse Gas Emissionos from Septic Systems (pp. 134). Alexandria, VA: Water Environment Research Foundation.

National Renewable Energy Laboratory. (2012a). Life Cycle Greenhouse Gas Emissions from Solar Photovoltaics. Golden, CO

National Renewable Energy Laboratory. (2012b). US Life Cycle Inventory Database. Retrieved from https://www.lcacommons.gov/nrel/search.

O'Sullivan, A. D., Wicke, D., Hengen, T. J., Sieverding, H. L., \& Stone, J. J. (2015). "Life Cycle Assessment modelling of stormwater treatment systems." Journal of Environmental Management, 149(Supplement C), 236-244.

Origin. Mindful Materials Library. Retrieved from http://www.mindfulmaterials.com/.

OST. (2018). OST 3.95 - Welcome to On-Screen Takeoff 3.95. Houston, TX: On Center Software.

Pittsburgh Parks Conservancy. Frick Environmental Center. Retrieved from https://www.pittsburghparks.org/frick-environmental-center.

PRé. (2017). SimaPro v8.5.2: PRé Sustainability.

Ramesh, T., Prakash, R., \& Shukla, K. K. (2010). "Life cycle energy analysis of buildings: An overview." Energy and Buildings, 42(10), 1592-1600.

Rashid, A. F., A.; Yusoff, S. (2015). "A review of life cycle assessment method for building industry." Renewable and Sustainable Energy Reviews, 45, 244-248.

Sartori, I., \& Hestnes, A. G. (2007). "Energy use in the life cycle of conventional and low-energy buildings: A review article." Energy and Buildings, 39(3), 249-257. 
Scheuer, C., Keoleian, G. A., \& Reppe, P. (2003). "Life cycle energy and environmental performance of a new university building: modeling challenges and design implications." Energy and Buildings, 35(10), 1049-1064.

Sierra Club. (2018). Open Letter: Climate-Smart Cross-Laminated Timber: Mass Timber Buildings and Forest Stewardship.

Steel Recycling Institute. (2017). Steel Recycling. Retrieved from https://www.steelsustainability.org/recycling.

Stephen R. Kellert, J. H., Martin Mador. (2008). Biophilic Design: the theory, science, and practice of bringing buildings to life. Hoboken, New Jersey: Wiley.

Sustainable Minds. Transparency Catalog. Retrieved from https://www.transparencycatalog.com/.

Thiel, C. L., Campion, N., Landis, A. E., Jones, A. K., Schaefer, L. A., \& Bilec, M. M. (2013). “A Materials Life Cycle Assessment of a Net-Zero Energy Building." Energies, 6(2), 16.

Thormark, C. (2002). "A low energy building in a life cycle—its embodied energy, energy need for operation and recycling potential." Building and Environment, 37(4), 429-435.

US Department of Health and Human Services. (2001). Toxicological Profile for Asbestos.

US Department of Energy (2012). Building Energy Data Book.

US Energy Information Administration. (2011). Guide to Geothermal Heat Pumps. Washington, D.C.

US Energy Information Administration. (2017). 2012 CBECS: Water Consumption in Large Buildings Survey.

US Energy Information Administration. (2018). Annual Energy Review. Washington, D.C.

US Environmental Protection Agency. (2014). Emissions Factors for Greenhouse Gas Inventories.

US Environmental Protection Agency, Office of Resource Conservation and Recovery. (2016a). Documentation for Greenhouse Gas Emissions and Energy Factors Used in the Waste Reduction Model (WARM).

US Environmental Protection Agency. (2016b). Greenhouse Gas Equivalencies Calculator. Retrieved from https://www.epa.gov/energy/greenhouse-gas-equivalencies-calculator.

US Environmental Protection Agency. (2018). Advancing Sustainable Materials Management: 2015 Fact Sheet. 
US Green Building Council. (2018). LEED v4 for Building Design and Construction. Washington, D.C.

Wang, R. E., Matthew; Zimmerman, Julie. (2013). "Consequential Environmental and Economic Life Cycle Assessment of Green and Gray Stormwater Infrastructures for Combined Sewer Systems.” Environmental Science \& Technology, 47(19), 11189-11198. 